\title{
Wax formation in linear and branched alkanes with dissipative particle dynamics
}

\author{
David J. Bray, Richard L. Anderson, Patrick B. Warren and \\ Kenneth Lewtas
}

\section{Published version information}

Citation: DJ Bray et al. 'Wax formation in linear and branched alkanes with dissipative particle dynamics.' Journal of Chemical Theory and Computation, vol. 16, no. 11 (2020): 7109-7122.

DOI: $10.1021 /$ acs.jctc.0c00605

This document is the unedited author's version of a Submitted Work that was subsequently accepted for publication in Journal of Chemical Theory and Computation, copyright (C2020 American Chemical Society after peer review. To access the final edited and published work see DOI above.

Please cite only the published version using the reference above. This is the citation assigned by the publisher at the time of issuing the AAM. Please check the publisher's website for any updates. 


\title{
Wax formation in linear and branched alkanes
}

\section{with dissipative particle dynamics}

\author{
David J. Bray, ${ }^{*}{ }^{\dagger}$ Richard L. Anderson, ${ }^{\dagger}$ Patrick B. Warren, ${ }^{\dagger}{ }^{\ddagger}$ and Kenneth \\ Lewtas $^{\mathbb{I I}, \S}$
}

$\dagger$ The Hartree Centre, STFC Daresbury Laboratory, Warrington, WA4 4AD, United Kingdom \$Unilever R\&D Port Sunlight, Quarry Road East, Bebington, Wirral, CH63 3JW, United Kingdom.

ILLewtas Science \& Technologies Ltd., 246 Banbury Road, Oxford, OX2 7DY, United Kingdom $\S$ School of Chemistry, The University of Edinburgh, Joseph Black Building, David Brewster Road, Edinburgh, EH9 3FJ, United Kingdom.

E-mail: david.bray@stfc.ac.uk

\begin{abstract}
We present a dissipative particle dynamics (DPD) model for wax formation (i.e. the freezing transition) in linear and branched alkanes at room temperature $(298 \mathrm{~K})$ and atmospheric pressure. We parametrise the model using pure liquid phase densities, and the onset of wax formation as a function of alkyl chain length. Significant emphasis is placed on building an accurate representation of the underlying molecular architecture by careful consideration of bond lengths and angles, aided by distributions obtained from molecular dynamics simulation. Using the derived model we observe wax formation in n-alkanes when the alkyl chain length is greater than 18 (n-octadecane), in excellent agreement with experimental observations. Further, we reproduce the behaviour of branched alkanes, and mixtures including solubility of heavy alkanes in light alkane solvents.
\end{abstract}




\section{Introduction}

Understanding and predicting the phase behavior of alkanes is important for a variety of applications and industries. In solid form alkanes are collectively known as waxes $^{1,2}$ and they are divided into four main types: natural waxes (e.g. carnauba, candelilla), synthetic waxes (e.g. polyethylene, polypropylene, Fischer-Tropsch waxes, including oxidised waxes), petroleum waxes (e.g. paraffin wax, slack wax, microcrystalline wax, petrolatum) and others (e.g. lignite waxes such as montan wax). At room temperature $\left(298 \mathrm{~K} / 25^{\circ} \mathrm{C}\right)$ and atmospheric pressure $(1 \mathrm{~atm})$ the lightest alkanes (n-butane and smaller) are vapors, intermediate length alkanes (n-pentane to n-heptadecane) are liquids which are fully miscible with each other and have many useful properties; ${ }^{3}$ but the fact that linear alkanes (n-alkanes) with alkyl chain length 18 and above freeze to form waxes presents a challenge for many very important processes. ${ }^{2}$ For example, crude oil transportation through pipelines poses a major problem when waxes crystallize and deposit on the walls of the pipes. ${ }^{4}$ In another example, significant issues arise for diesel engines when higher molecular weight alkanes are used as a fuel source (we note that lower molecular weight alkanes also form waxes at temperatures below $\left.25^{\circ} \mathrm{C}\right) .{ }^{5,6}$ These examples have to be treated with special wax modifiers and it is no exaggeration to say that the modern world would not have developed without them. Such waxes and the modifiers have been the subject of many simulation studies over the years. ${ }^{7-9} \mathrm{Be}-$ yond their use as a fuel, alkanes are the constituent of many chemical products. As waxes, they are used in candles, adhesives, rubber additives, wood-polymer composites, paints, coatings, etc. They are also derivatised to produce useful chemical products such as oil additives $(e . g$. sulfonates and alkylbenzyl sulfonates), lubricants and oils (e.g. triglycerides), surfactants (e.g. alkyl sulfates), plastics (e.g. polyethylene), adhesives, and in biochemical lipids. The wax industry has changed considerably in the recent past because of the changes that have occurred in the de-waxing of lubricating oil basestocks. This has removed a significant amount of wax from the marketplace and thus research is more important than ever. In particular the characterisation and prediction of wax formation is of key importance, particularly in alkane blends and mixtures. 


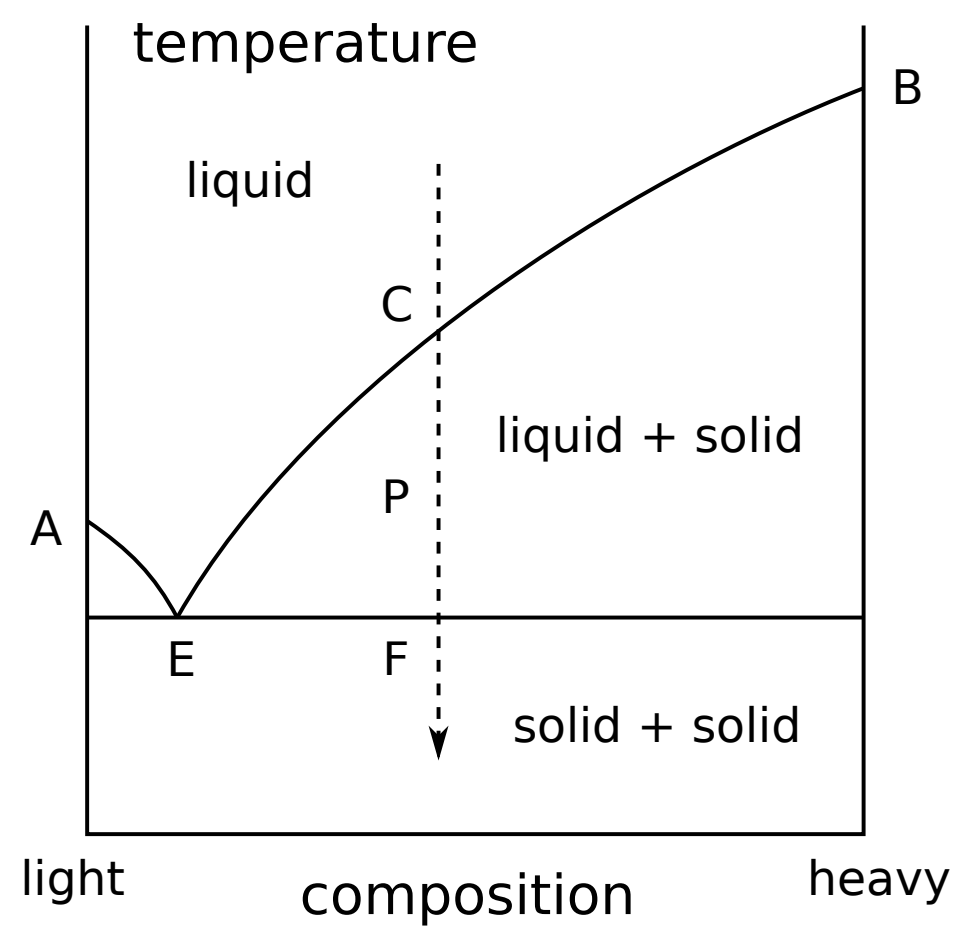

Figure 1 Schematic phase diagram for a binary mixture of 'light' and 'heavy' alkanes, redrawn from Dirand $e t$ al. ${ }^{13} \mathrm{~A}$ and $\mathrm{B}$ are the freezing points of the pure alkanes; $\mathrm{E}$ is the eutectic point. A mixture cooled from high temperature (dashed line) meets the liquidus at $\mathrm{C}$, which corresponds to the cloud point, and passes the eutectic temperature at $\mathrm{F}$, which corresponds to the freezing point for the mixture as a whole. The solid content increases from $\mathrm{C}$ to $\mathrm{F}$, and somewhere between the two is the pour point $\mathrm{P}$ where the mixture no longer easily flows. Ordering transitions in the solid phases have been omitted for simplicity.

Wax formation has been extensively studied ${ }^{10}$ and is characterised by three distinct temperatures, corresponding to the fact that 'heavy' long chain n-alkanes are only partially soluble in 'light' low molecular weight alkanes, and tend to precipitate out of solution even at modest concentrations of the former as shown in the schematic binary composition-temperature phase diagram in Fig. 1. ${ }^{11-13}$ The cloud point is the temperature at which solid materials are first seen to precipitate and corresponds to crossing the liquidus in Fig. 1. The pour point refers to the temperature at which the solid content has built up to the extent that the liquid will no longer easily flow (e.g. when tilted to a horizontal position in a bottle). Finally the freezing point corresponds to the eutectic temperature where the mixture solidifies completely.

When the temperature of an alkane system is reduced below the cloud point, formation of a 
solid precipitate takes place by a nucleation and growth mechanism. ${ }^{14}$ Waxes grow as large stable crystals with a plate-like habit. ${ }^{13}$ The morphology number, sizes and aspect ratios of these crystals obviously have a significant impact on the pour point, for example, as little as $2 \%$ solids crystallising from a diesel fuel can gel the whole volume. The development of crystal habit modifiers is an interesting avenue to explore to control this. Additionally, nucleation can be inhibited by additives which typically disrupt the crystal packing. ${ }^{6,15}$ Modelling waxes and additives has been progressing for decades ${ }^{16}$ and it is anticipated that the computational model developed here could provide mechanistic insights into these effects.

Branched alkanes (isoalkanes) generally have lower melting points than the n-alkanes as they are unable to pack as well in the ordered state. Nevertheless, some high molecular weight branched alkanes have been experimentally observed to form ordered solids, for example mono methyl alkanes between $\mathrm{C}_{23}$ and $\mathrm{C}_{32}$ freeze into two types of crystal structure depending on the methyl location. ${ }^{17}$ It has been demonstrated that it is even possible to accommodate a single butyl, hexyl or phenyl side-chain off the main chain in the crystal structure. ${ }^{18}$

Experimentally, wax formation can be explored by techniques which characterise changes in the physical properties of the system. Methods commonly employed include viscosity measurements, ${ }^{19-21}$ Fourier transform infrared spectroscopy, ${ }^{22-25}$ differential scanning calorimetry, ${ }^{26-28}$ in addition to visual observation (e.g. American Society for Testing and Materials Standard ASTM D2500). ${ }^{29}$

Thermodynamic modelling of waxes has been extensively studied and different models proposed. ${ }^{30-33}$ This study starts from the molecular level and from a computational simulation stand point, all-atom force fields such as OPLS, ${ }^{6,34,35}$ COMPASS $^{36}$ and ReaxFF ${ }^{37}$ successfully reproduce the behaviour and thermodynamic properties of alkanes. United-atom and coarse-grained molecular dynamics (CG-MD) approaches such as TraPPE are also available, ${ }^{38-41}$ as are liquid state theories like SAFT. ${ }^{42,43}$

Dissipative particle dynamics (DPD) is a coarse-graining approach which has seen significant developments in recent years and is competitive with the above molecular dynamics methods. ${ }^{44}$ 
In the DPD approach, complex molecules are built up from beads which represent one or more chemical groups, giving a coarse-grained representation of the molecular architecture. ${ }^{45-47}$ These DPD beads interact by soft repulsions, the parameters for which become the key target to represent chemical specificity. Additionally (but not essentially) a pairwise, momentum-conserving thermostat ensures the NVT ensemble. ${ }^{48}$ The combination of these enables DPD to access much longer length and time-scales than MD or CG-MD type approaches (whilst trading off some level of accuracy in the representation of a molecular system). In theory, these features of DPD make it well-suited to studying alkane waxing phenomena. Whilst the DPD method has been used study surfactant behaviour (extensively) and interfacial phenomena, ${ }^{49-59}$ friction reduction,${ }^{60}$ and aggregation behaviour in heavy oils and asphaltenes, ${ }^{61-64}$ to the best of our knowledge, DPD has not yet been exploited as a technique for the study of alkane waxes despite the benefits in accessible system sizes and time-scales. However, the liquid-based properties of alkanes have been explored as part of bottom-up approaches to DPD parametrization. ${ }^{65,66}$ Rather than repeat the details of what is a standard simulation method, we point the reader to chapter 17 of the textbook by Frenkel and Smit, ${ }^{67}$ and the original DPD literature. ${ }^{45-48}$ An up-to-date perspective on the DPD methodology can be found in Español and Warren. ${ }^{44}$

In this work we report on a DPD model for linear and branched alkanes capable of reproducing much of the phenomenology involved in alkane wax formation. We have limited ourselves to the behaviour at room temperature $\left(298 \mathrm{~K} / 25^{\circ} \mathrm{C}\right)$ and atmospheric pressure $(1 \mathrm{~atm})$, aiming to reproduce, for example, wax formation in linear alkanes as a function of chain length. The extension to other temperatures will be discussed briefly at the end. A key step in the development of the model was to pay careful attention to the bond lengths and angles, using a combination of (i) matching to realistic distributions using atomistic simulations for guidance (bottom-up parametrisation) and (ii) the onset of wax formation (top-down parametrisation) at the correct alkane chain length. The model interaction parameters are optimised using pure liquid densities of many different alkane molecules at room temperature and atmospheric pressure. The application of DPD to describe a freezing transition in a molecular liquid is novel, to our knowledge. Our approach differs from 
Table 1 Chemical models for selected alkanes.

\begin{tabular}{|c|c|c|c|c|c|c|}
\hline \multirow{2}{*}{$\begin{array}{l}\text { Arrangement: } \\
\text { Formula: }\end{array}$} & \multicolumn{2}{|c|}{ n-alkane } & \multicolumn{2}{|c|}{ isobutyl-type } & \multicolumn{2}{|c|}{ neopentyl-type } \\
\hline & $\mathrm{C}_{2 \mathrm{n}} \mathrm{H}_{4 \mathrm{n}+2}$ & $\mathrm{C}_{2 \mathrm{n}+1} \mathrm{H}_{4 \mathrm{n}+4}$ & $\mathrm{R}_{1} \mathrm{C}_{4} \mathrm{H}_{9}$ & $\mathrm{R}_{1} \mathrm{C}_{4} \mathrm{H}_{8} \mathrm{R}_{2}$ & $\mathrm{R}_{1} \mathrm{C}_{5} \mathrm{H}_{11}$ & $\mathrm{R}_{1} \mathrm{C}_{5} \mathrm{H}_{10} \mathrm{R}_{2}$ \\
\hline Beading: & $\begin{array}{l}\mathrm{CH}_{3} \\
\backslash \\
\stackrel{\left.\mathrm{CH}_{2} \mathrm{CH}_{2}\right\}_{\mathrm{n}-1}}{\backslash} \\
\quad \mathrm{CH}_{3}\end{array}$ & $\begin{array}{c}\mathrm{CH}_{3} \\
\left.\backslash \mathrm{CH}_{2} \mathrm{CH}_{2}\right\}_{\mathrm{n}-1} \\
\backslash \\
\mathrm{CH}_{2} \\
\mathrm{CH}_{3}\end{array}$ & $\begin{array}{l}\mathrm{R}_{1} \\
\mid \\
\mathrm{CH}_{2} \\
\mid \\
\mathrm{CH}\end{array}$ & $\stackrel{\mathrm{R}_{1}}{\stackrel{\mathrm{CH}}{\mid}}$ & 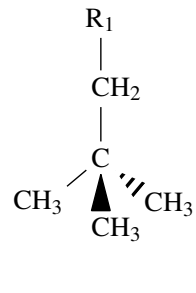 & 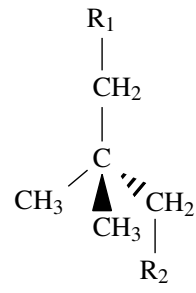 \\
\hline
\end{tabular}

previous DPD models (used to study surfactants, for example) since we use much stiffer bonding potentials to enforce the match to the underlying molecular architectures. When combined with the tendency of soft sphere fluids to exhibit a re-entrant melting transition, ${ }^{68,69}$ and for soft rods to show an isotropic-nematic transition, this promotes the formation of ordered structures. ${ }^{70}$ Then, with suitable parametrisation, the model can reproduce the basic freezing transition in linear and branched alkanes in good agreement with experiment. Of course, the model is still coarse-grained and as such is unable to reproduce the plethora of subtle ordering transitions that are exhibited in real alkanes below the freezing point. ${ }^{13}$

The remainder of the article is arranged as follows: In Section 2 we outline the adopted coarsegrained model including details on the coarse graining strategy, molecular architecture and the crucial DPD interaction parameters used. In Section 3 we describe the parametrisation strategy adopted to obtain the interaction parameters. Section 4 summarises how alkane waxes are identified from our simulations and Section 5 gives details of the simulation setup. Section 6 presents the performance of the model in reproducing liquid densities and key behaviours associated with alkane waxes (such as liquid-solid transitions and crystallisation in branched alkanes). Our conclusions are provided following the Results Section. 


\section{Model development}

\subsection{Fragmentation strategy (atom to bead mapping)}

In our model, linear and branched alkanes are given coarse-grained representations in terms of bonded DPD beads, each of which represents a chemical subgroup (e.g. $\mathrm{CH}_{2} \mathrm{CH}_{2}$ is a particular type of DPD bead from the model). Linear alkane molecules are represented by linear chains of DPD beads containing the groups $\mathrm{CH}_{3}, \mathrm{CH}_{2}$, and $\mathrm{CH}_{2} \mathrm{CH}_{2}$. The $\mathrm{CH}_{2} \mathrm{CH}_{2}$ bead is interchangeable with two $\mathrm{CH}_{2}$ beads and, when either choice is equally valid, we choose the larger bead type to reduce computation cost. Thus alkyl chains contain at most a single $\mathrm{CH}_{2}$ and its placement is pragmatically beside the terminating bead such as $\mathrm{CH}_{3}$ in preference to another location. These three alkane bead types allow us to generate all the non-branched alkanes without limitation. Branch points in alkyl chains are always represented in the isobutyl-type or neopentyl-type form (Table 1) using sets of four or five beads. Each form contains a single carbon atom at their centre with either $\mathrm{CH}$ or $\mathrm{C}$ functionality which is connected to several $\mathrm{CH}_{3}$ or $\mathrm{CH}_{2}$ beads. This arrangement allows for a great degree of freedom and flexibility in the molecule without preferencing particular branch arms. Table 1 shows representative schematics of the bead and bond configurations used for the various molecules in the present study.

All beads have a reduced mass of one and are charge neutral. It is convenient to set the DPD unit of length $r_{c}=5.65 \AA$ as in our previous work. ${ }^{55,57}$ Although water does not feature in the present study, this corresponds to treating water $\left(\mathrm{H}_{2} \mathrm{O}\right)$ supramolecularly with a mapping number $N_{m}=2$ (see Section A of Supporting Information). We thermostat the model with the standard DPD pairwise random and dissipative forces, ${ }^{44,67}$ with damping coefficient $\gamma=4.5$, and range $1.1 r_{c}$ just above the maximum $R_{i j}$ used for the conservative forces (see next section). Additionally, we barostat the model using a Langevin piston, with the pressure chosen to match the density of liquid water under the above mapping number rule. 
Table 2 Bond $\left(i\right.$ and $j$ ) and angle $\left(i, j\right.$ and $k$ ) properties adopted in the model. Here $\mathrm{CH}_{m}$ are single carbon beads representing $\mathrm{C}, \mathrm{CH}, \mathrm{CH}_{2}$ and $\mathrm{CH}_{3}$, for $m=0,1,2,3$ respectively.

\begin{tabular}{crrrc}
\hline bead $i$ & bead $j$ & & $K_{B}^{i j}$ & $r_{0}^{i j}$ \\
\hline $\mathrm{CH}_{m}-\mathrm{CH}_{m}$ & & 5000 & 0.30 \\
$\mathrm{CH}_{2,3}-\mathrm{CH}_{2} \mathrm{CH}_{2}$ & & 5000 & 0.35 \\
$\mathrm{CH}_{2} \mathrm{CH}_{2}-\mathrm{CH}_{2} \mathrm{CH}_{2}$ & & 5000 & 0.44 \\
\hline bead $i$ & bead $j$ & bead $k$ & $K_{A}^{i j k}$ & $\theta_{0}^{i j k}$ \\
\hline $\mathrm{CH}_{2,3}-\mathrm{CH}_{2} \mathrm{CH}_{2}-\mathrm{CH}_{2,3}$ & 70 & $180^{\circ}$ \\
$\mathrm{CH}_{2,3}-\mathrm{CH}_{2} \mathrm{CH}_{2}-\mathrm{CH}_{2} \mathrm{CH}_{2}$ & 150 & $166^{\circ}$ \\
$\mathrm{CH}_{m}-\mathrm{CH}_{m}-\mathrm{CH}_{m}$ & 150 & $100^{\circ}$ \\
$\mathrm{CH}_{m}-\mathrm{CH}_{2}-\mathrm{CH}_{2} \mathrm{CH}_{2}$ & 150 & $125^{\circ}$ \\
$\mathrm{CH}_{2} \mathrm{CH}_{2}-\mathrm{CH}_{2} \mathrm{CH}_{2}-\mathrm{CH}_{2} \mathrm{CH}_{2}$ & 70 & $180^{\circ}$ \\
$\mathrm{CH}_{2} \mathrm{CH}_{2}-\mathrm{CH}_{2}-\mathrm{CH}_{2} \mathrm{CH}_{2}$ & 150 & $146^{\circ}$ \\
\hline
\end{tabular}

\subsection{Non-bonded interactions}

The non-bonded interactions (conservative forces) in the model are the standard DPD short-range, soft, pairwise repulsions given by the pair potentials $\beta U_{i j}^{C}=\frac{1}{2} A_{i j}\left(1-r_{i j} / R_{i j}\right)^{2}$ (for $r_{i j} \leq R_{i j}$ ), where $\beta=1 / k_{\mathrm{B}} T, r_{i j}=\left|\mathbf{r}_{j}-\mathbf{r}_{i}\right|$ the separation between beads $i$ and $j$ located at $\mathbf{r}_{i}$ and $\mathbf{r}_{j}$ respectively, $A_{i j}$ is the repulsion amplitude, and $R_{i j}$ the cut-off distance. The methodology to fix the repulsion amplitudes $A_{i j}$ will be described below. To fix the cut-off distances $R_{i j}$, we note that different bead types contribute unequally to the molar volume of the molecules concerned, therefore we follow the methodology we have previously successfully used for surfactant models. ${ }^{55,57}$ We first assign $R_{i i}^{3}$ for different beads in proportion to the fragment (bead) molar volume using the Durchschlag and Zipper rules, ${ }^{71}$ taking the molar volume of a water bead $\left(2 \times \mathrm{H}_{2} \mathrm{O}\right)$ as a reference. This fixes the cut-off distance $R_{i i}$ between DPD beads of the same type. Thereafter we use a simple arithmetic mixing rule $R_{i j}=\frac{1}{2}\left(R_{i i}+R_{j j}\right)$ to define the cut-off between dissimilar bead types.

\subsection{Bonded interactions}

In DPD, molecules are built up from the molecular fragments described above by connecting together the corresponding DPD beads. We use pairwise bonds, augmented by three-body angular 

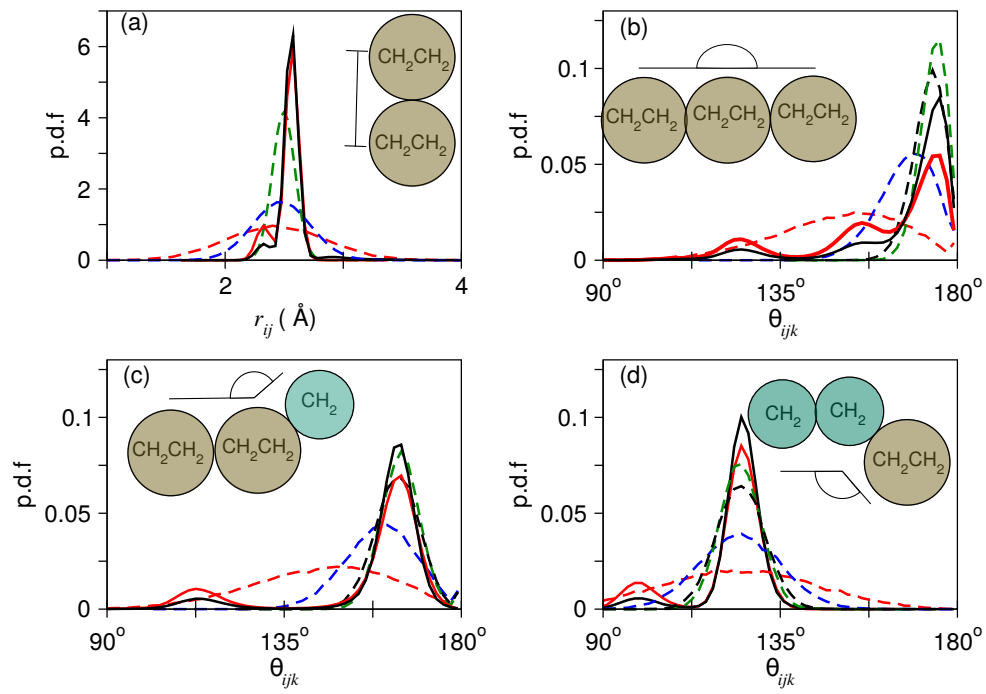

Figure 2 Comparison of (a) bond distribution and (b,c,d) angle distribution between OPLS and DPD models. Solid-line gives reference distribution obtained from OPLS for pure alkanes n-decane (red) and n-hexadecane (black). Dashed-lines give distributions for DPD models with $K_{B}^{i j}$ set to 150 (red), 500 (blue) or 5000 (green) in panel (a) and $K_{A}^{i j k}$ set to 5 (red), 30 (blue), 100 (black) or 150 (green) in panels (b-d).

potentials to confer additional rigidity to the structures. For the pairwise bonds we use a harmonic spring potential $\beta U_{i j}^{B}(t)=\frac{1}{2} K_{B}^{i j}\left(r_{i j}-r_{0}^{i j}\right)^{2}$ where $K_{B}^{i j}$ is the bond (spring) constant, $r_{i j}$ is the distance between bonded beads $i$ and $j$, and $r_{0}^{i j}$ is a bare bond length. We note that typically $\left\langle r_{i j}\right\rangle$ is not equal to $r_{0}^{i j}$ because of the non-bonded repulsions. Our strategy to set $r_{0}^{i j}$ for bead pairs based on molecular representations of alkanes is described in Sections B and C of Supporting Information.

Atomistic simulations were used to guide our choice of the spring constant $K_{B}^{i j}$, and we settled upon a single value $K_{B}^{i j}=5000$ (DPD units) for all bond pairs (See Section E of Supporting Information). This is different than our recent published works for which we use a smaller value of $K_{B}^{i j}=150 .{ }^{55,57}$ Adopting a higher value for $K_{B}^{i j}$ results in a much narrower bond length distribution which is in better agreement with those found in atomistic simulations. This is illustrated in Fig. 2a. We note that a still closer match between the bond length distributions from DPD and atomistic simulations could be achieved by using even stiffer bonds, but then the associated vibrational frequencies would require the DPD time-step to be reduced. We view this as an undesirable 
Table 3 Repulsion amplitudes $\left(A_{i j}\right)$ and cut-off distances $\left(R_{i j}\right)$ between all bead pairs in the model.

\begin{tabular}{llll}
\hline bead $i$ & bead $j$ & $A_{i j}$ & \multicolumn{2}{c}{$R_{i j}$} \\
\hline & \multicolumn{3}{c}{ n-alkane } \\
$\mathrm{CH}_{2} \mathrm{CH}_{2}$ & $\mathrm{CH}_{2} \mathrm{CH}_{2}$ & 19.5 & 1.0740 \\
$\mathrm{CH}_{2} \mathrm{CH}_{2}$ & $\mathrm{CH}_{3}$ & 25.9 & $1.0155^{*}$ \\
$\mathrm{CH}_{2} \mathrm{CH}_{2}$ & $\mathrm{CH}_{2}$ & 12.8 & $0.9995^{*}$ \\
$\mathrm{CH}_{3}$ & $\mathrm{CH}_{3}$ & 33.0 & 0.9570 \\
$\mathrm{CH}_{3}$ & $\mathrm{CH}_{2}$ & 19.2 & $0.9410^{*}$ \\
$\mathrm{CH}_{2}$ & $\mathrm{CH}_{2}$ & 5.0 & 0.9250 \\
\hline & & \multicolumn{2}{c}{ isobutyl } \\
$\mathrm{CH}_{2} \mathrm{CH}_{2}$ & $\mathrm{CH}$ & 5.0 & $0.9820^{*}$ \\
$\mathrm{CH}_{3}$ & $\mathrm{CH}$ & 19.2 & $0.9235^{*}$ \\
$\mathrm{CH}_{2}$ & $\mathrm{CH}$ & 5.0 & $0.9075^{*}$ \\
$\mathrm{CH}$ & $\mathrm{CH}$ & 5.0 & 0.8900 \\
& \multicolumn{3}{c}{ neopentyl } \\
$\mathrm{CH}_{2} \mathrm{CH}_{2}$ & $\mathrm{C}$ & 5.0 & $0.9630^{*}$ \\
$\mathrm{CH}_{3}$ & $\mathrm{C}$ & 5.0 & $0.9045^{*}$ \\
$\mathrm{CH}$ & $\mathrm{C}$ & 5.0 & $0.8885^{*}$ \\
$\mathrm{CH}$ & $\mathrm{C}$ & 5.0 & $0.8710^{*}$ \\
$\mathrm{C}$ & $\mathrm{C}$ & 5.0 & 0.8520 \\
\hline \multirow{2}{*}{$\mathrm{U}$} & & \multicolumn{2}{c}{50}
\end{tabular}

* Using arithmetic mixing rule.

constraint and the value $K_{B}^{i j}$ used in the present work is a compromise in this sense.

Further molecular rigidity is introduced by the inclusion of an angular three-body potential between pairs of bonds. We adopt the same harmonic angular potential used by Smit and collaborators, ${ }^{72,73} \beta U_{i j k}^{A}=\frac{1}{2} K_{A}^{i j k}\left(\theta_{i j k}-\theta_{0}^{i j k}\right)^{2}$ where $\theta_{i j k}$ (in rads) is the angle between adjoining bonds and $\theta_{0}^{i j k}$ is a bare equilibrium angle based on the chemical identities of $i, j$, and $k$. In the present work we set $\theta_{0}^{i j k}$ based on molecular representations of alkanes (see Section B \& D of Supporting Information). The angular spring constant $K_{A}^{i j k}$ (in units $\mathrm{rad}^{-2}$ ) is optimised for different pairs of bonds such that the melting temperature of alkanes is appropriately captured (Section 3) to match experiment. Figs. $2 \mathrm{~b}-\mathrm{d}$ show the effect of varying $K_{A}^{i j k}$ on the angle distributions of model alkanes compared to those calculated from atomistic simulations (as described in Section E of Supporting Information). Adopting $K_{A}^{i j k}=5$ results in very broad distributions compared to the sharper distri- 
butions obtained for $K_{A}^{i j k}>30$. Table 2 lists the bond and angles properties of the model used in this work.

\section{Parametrization scheme}

With the model defined, it is now appropriate to turn to the important task of determining an appropriate set of model parameters.

In the first step, the conservative interaction parameters, $A_{i j}$, are specified (See Appendix for extended details). These are fitted such that the experimental densities of pure alkane systems at room temperature $\left(298 \mathrm{~K} / 25^{\circ} \mathrm{C}\right)$ and atmospheric pressure $(1 \mathrm{~atm})$ are reproduced by DPD simulations. Tables in Sections F1-F3 of the Supporting Information list the experimental densities and melting temperatures of all linear and branched alkanes considered in this work.

In the second parametrization step the spring constant in the three-body angular potentials was optimized. Melting points of the n-alkanes molecules were tuned to be consistent with experiment by optimizing $K_{A}^{i j k}$ to obtain the correct freezing transition for n-octadecane $\left(\mathrm{n}-\mathrm{C}_{18}\right)$ at room temperature as defined by criteria given in Section 4 (e.g. see Fig. $3 \mathrm{~b}$ for $\left.\mathrm{n}-\mathrm{C}_{18}\right)$. We found the alkane densities to be largely unaffected by changes to $K_{A}^{i j k}$ with calculated values changing by $<0.4 \%$ (based on $n-\mathrm{C}_{18}$ for $10<K_{A}^{i j k}<150$ ). We set the default value of $K_{A}^{i j k}=150$ as this produces an angle distribution which broadly agrees with the atomistic simulations, see Fig. 2 (in fact values of $K_{A}^{i j k}>60$ all produce distributions that largely fit the dominate peak of the distribution). We do not explicitly fit $K_{A}^{i j k}$ to atomistically derived distributions presented in Fig. 2 to avoid developing a model based upon another model and passing along the inaccuracies associated with the original atomistic force field. Rather we use the atomistic data to verify our distribution is sensible. Only $K_{A}^{i j k}$ for $\left(\mathrm{CH}_{2} \mathrm{CH}_{2}\right)-\left(\mathrm{CH}_{2} \mathrm{CH}_{2}\right)-\left(\mathrm{CH}_{2} \mathrm{CH}_{2}\right)$ is refined further since it is the rigidity of the backbone that largely determines the melting point (increasing $K_{A}^{i j k}$ increases the alkane persistence length). We found that $\mathrm{n}$-heptadecane $\left(\mathrm{n}-\mathrm{C}_{17}\right)$ melts for $85<K_{A}^{i j k}<90$ whereas $\mathrm{n}-\mathrm{C}_{18}$ melts for $40<K_{A}^{i j k}<50$. Since $\mathrm{n}-\mathrm{C}_{17}$ is liquid and $\mathrm{n}-\mathrm{C}_{18}$ solid at room temperature, we use $K_{A}^{i j k}=70$ (in 
fact any value in the range $50<K_{A}^{i j k}<85$ can be used and further refinement is not possible at fixed temperature due to the discrete nature of melting transition as a function of the alkane chain length). $K_{A}^{i j k}$ for $\left(\mathrm{CH}_{2,3}\right)-\left(\mathrm{CH}_{2} \mathrm{CH}_{2}\right)-\left(\mathrm{CH}_{2,3}\right)$ is then chosen to match.

Table 3 presents the optimised set of $A_{i j}$ and $R_{i j}$ values for the model. Table 2 lists the optimised angle constants, $K_{A}^{i j k}$. In combination with the bond parameters also in Table 2, this fully specifies the DPD model.

\section{Identifying alkane waxes}

Experimentally a crystal exhibits long range order, and the molecules lack significant mobility. For alkanes this equates microscopically to an alignment in position and direction of each molecule, and the absence of significant molecular self-diffusion. To aid in the identification of alkane waxes we therefore calculate three metrics, or order parameters, from the simulations: (i) the static structure factor; (ii) a nematic order parameter; and (iii) molecular mean squared displacement (MSD). The structure factor is a standard technique for identifying crystalline structures since well defined sharp peaks indicate the presence of long-range positional order. Nematic order parameters describe the degree of molecular alignment in the system. MSDs indicates the ability of a molecule to diffuse. Collectively, these metrics characterise the local configuration and molecular mobility, and help us characterise a system as a liquid or wax.

In this work, the bead-bead static structure factor is calculated using

$$
S(q)=\frac{1}{N}\left\langle\sum_{j=1}^{N} \sum_{k=1}^{N} \exp \left(i \mathbf{q} \cdot \mathbf{r}_{k j}\right)\right\rangle
$$

where the sums are over all beads and $S(q)$ is radially-averaged $(q=|\mathbf{q}|)$.

To measure the degree of nematic order, a unit vector $\mathbf{n}_{i}$ is defined for each molecule as the normalised vector separation between the beads at the ends of the molecule; this unit vector is oriented for definiteness and without loss of generality such that $\mathbf{n}_{i} \cdot \mathbf{e}_{z} \geq 0$ where $\mathbf{e}_{z}$ is the unit vector directed along the $z$-axis. A local director (vector) $\mathbf{D}_{i}$ is then defined for each molecule 
by averaging the orientation vectors $\mathbf{n}_{i}$ for molecules with mid-points lying within a sphere of radius 5 DPD units $(\approx 28 \AA)$ of the mid-point of the target molecule. Finally for each molecule $\cos \phi_{i}=\mathbf{n}_{i} \cdot \mathbf{D}_{i} /\left|\mathbf{D}_{i}\right|$ is computed, and in terms of this an orientational order parameter based on the usual Legendre polynomial is extracted, $S=\left\langle P_{2}(\cos \phi)\right\rangle=\left\langle\left(3 \cos ^{2} \phi-1\right) / 2\right\rangle$. The order parameter obeys $0 \leq S \leq 1$, with $S \approx 0$ in an isotropic liquid and $S \rightarrow 1$ as the molecules become perfectly aligned; the material is said to exhibit nematic order when $S \gtrsim 0.5 .{ }^{74}$ Note that in constructing $\mathbf{D}_{i}$ as a simple average, the (arbitrary) choice $\mathbf{n}_{i} \cdot \mathbf{e}_{z} \geq 0$ resolves the orientational ambiguity arising from the molecular centre of symmetry present in $\mathrm{n}$-alkanes.

We use the mean square displacement (MSD) to assess molecular mobility. This is calculated from the bead coordinates as $\left\langle\left|\mathbf{r}_{i}(t+\Delta t)-\mathbf{r}_{i}(t)\right|^{2}\right\rangle$, where $\mathbf{r}_{i}(t)$ is the position of the $i$-th bead at time $t$. For concreteness, we report the MSD at $\Delta t=500$ DPD time units (hereafter MSD @ 500). The effective diameter of a DPD bead is approximately 2 DPD units (based on $2 R_{i j}$ ) thus a MSD @500 value of less than 4 means that on average the bead has not moved more than two bead diameters in the box during that period. Conversely, in a liquid we expect the self-diffusion coefficient to be of order unity in DPD units, and therefore MSD@500 to be of the order 500 for freely-diffusing molecules (see Fig. 3). We therefore set the criteria for the material to be an ordered crystal when MSD@500<4 and $S>0.9$. Fig. 3 illustrates the typical $S$ values and the MSD as a function of $\Delta t$.

\section{Simulations}

\subsection{General conditions}

DPD simulations were performed using the DL_MESO simulation package. ${ }^{75}$ Periodic boundary conditions were assumed. The thermal scale was set at $k_{\mathrm{B}} T=1$. Constant pressure simulations were performed using the Langevin piston implementation of Jakobsen. ${ }^{76}$ The pressure was set to that of water in the model, corresponding to a pure DPD fluid of beads at reduced density $\rho=3$ and repulsion amplitude $A_{i i}=25$. This reference pressure was determined in separate constant- 
(a)

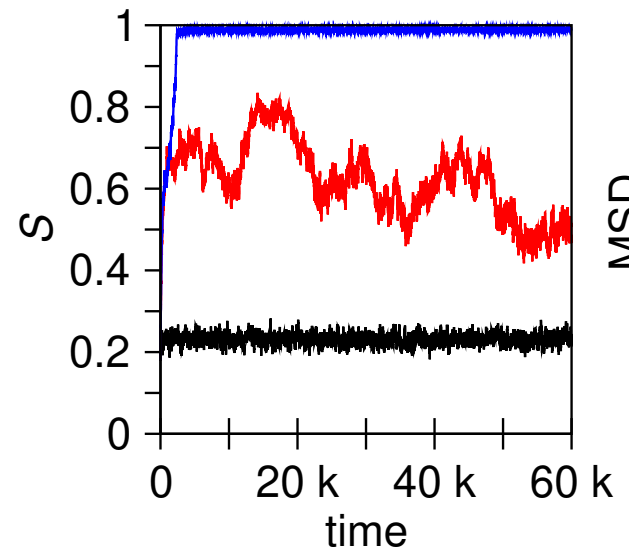

(b)

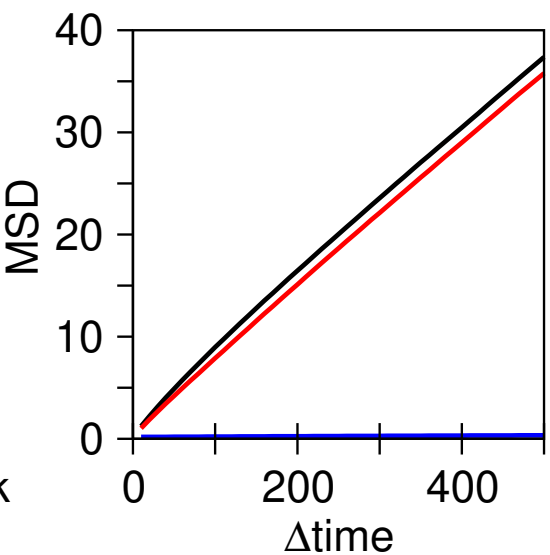

Figure 3 Properties of (a) nematic order parameter $S$ and (b) MSD for model of pure n-octadecane when varying angular spring constant $K_{A}^{i j k}=10$ (black) 30 (red) 50 (blue); the first two values represent liquid behaviour while the last would meet our criteria to be classified as an ordered crystal phase.

volume simulations to be $P=23.7 \pm 0.1$ (in DPD units). A time-step of $\Delta t=0.01$ was adopted for all simulations and data was collected every 10 DPD time units (1000 time steps) following equilibration. The analysis code UMMAP was used to analyse simulation trajectory files. ${ }^{77}$

\subsection{Pure n-alkanes and liquid-liquid mixtures}

Molecules were initially configured in random orientations on a cubic lattice which spans the box dimensions. To optimise $A_{i j}$ and $K_{A}^{i j k}$, and to study liquid-liquid mixtures, simulations were run for a total of $2 \times 10^{3} \mathrm{DPD}$ time units and data collected after the initial $10^{3} \mathrm{DPD}$ time units. The same procedure was applied for studies of crystallisation in branched alkanes except the simulation duration was extended to at least $5 \times 10^{4}$ DPD time units and data collected throughout. See Supporting Information Section F for further details on system sizes and sampling times used.

\subsection{Mixtures of heavy and light n-alkanes}

For mixtures of molecules we explored two kinds of initial conditions: randomly mixed (notionally equivalent to a high-temperature quench), and fully segregated. For the randomly mixed case, a total of 4000 molecules were placed at random in a box of side-length 20 DPD units (results for 
additional larger system sizes are reported in Supporting Information Section F5). For the fully segregated case, a box of size $60 \times 20 \times 20$ DPD units was divided into two sub-volumes (along the long axis) with the relative volumes fixed by the desired mole fraction, and each of these sub-volumes was filled by randomly placed molecules of the desired type. For these simulations we used an initial bead density of 3 to avoid large volume changes during the simulation. This latter procedure is the same as that done by Anderson et al. to initialise simulations for partition coefficients. ${ }^{55}$ Simulations studying alkane solubility were run for 6000 DPD time units and data collected after the initial 5000 DPD time units.

\section{Results}

\subsection{Liquid phase densities of pure alkanes}

Fig. 4 (and Sections F1-F3 of the Supporting Information) compares the calculated alkane densities to the corresponding experimental values for the linear and branched alkanes used to parametrize the self-interaction parameters $\left(A_{i i}\right)$ in the DPD model. The calculated values are in excellent agreement with literature values. The deviations for the linear alkanes are typically within $1 \%$ of the reported experimental values with the exception of n-pentane, which is the alkane with the lowest boiling point $\left(36^{\circ} \mathrm{C}\right)$ of the ones we have considered. Calculated model and experimental densities for isoalkanes which have a single branch (i.e. molecules with three methyl groups) or double branch (i.e. molecules with four methyl groups) are within $1 \%$ and $5 \%$, respectively. Alkanes with higher degrees of branching show mixed results, e.g., 2, 6, 10, 14-tetramethyl pentadecane (with six methyl groups) was within $<1 \%$, while $2,2,4,4,6,8,8$-heptamethyl nonane, (with nine methyl groups) was much worse being within $<7 \%$ agreement. Comparing the experimental and calculated values of the liquid phase densities for the linear and branched alkanes (Figs. 4b, $d$ respectively) results in a root mean square deviation (RMSD) of 0.00542 and a correlation coefficient $R^{2}=0.988$ for linear alkanes; a RMSD of 0.00413 and $R^{2}=0.983$ for single branched alkanes, and a RMSD of 0.01950 and $R^{2}=0.481$ for alkanes with two branch points. 
(a)

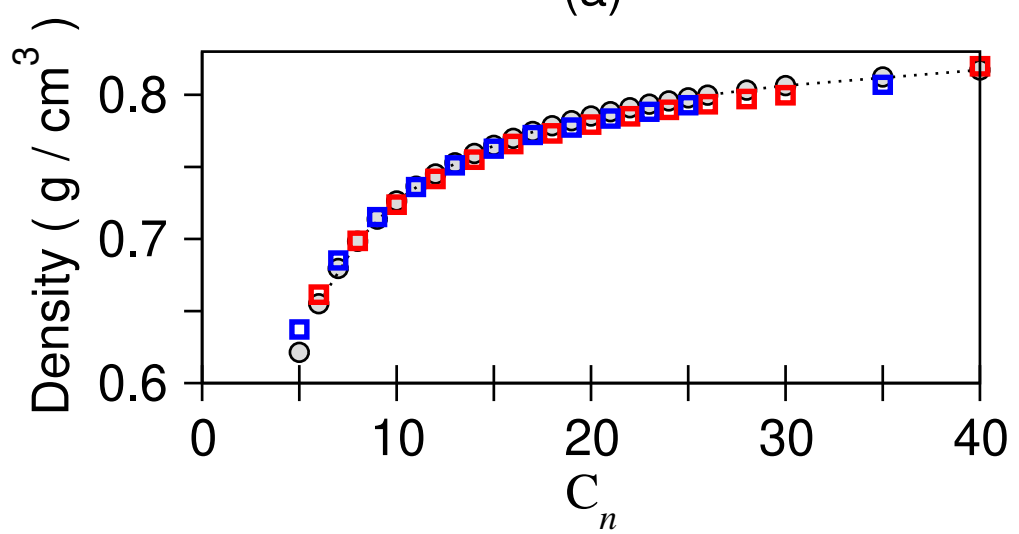

(c)

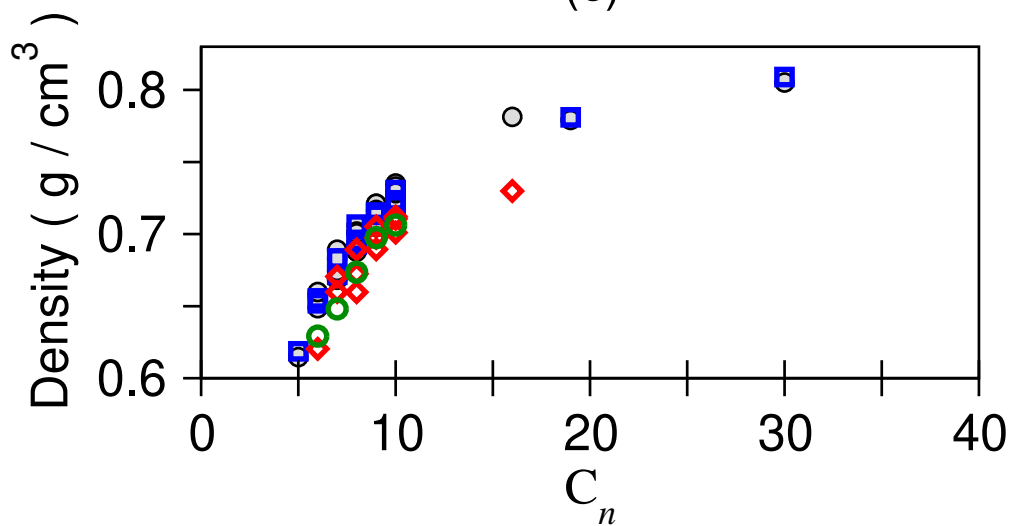

(b)

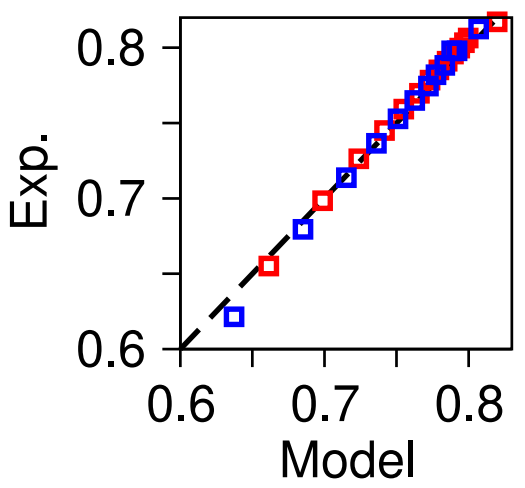

(d)

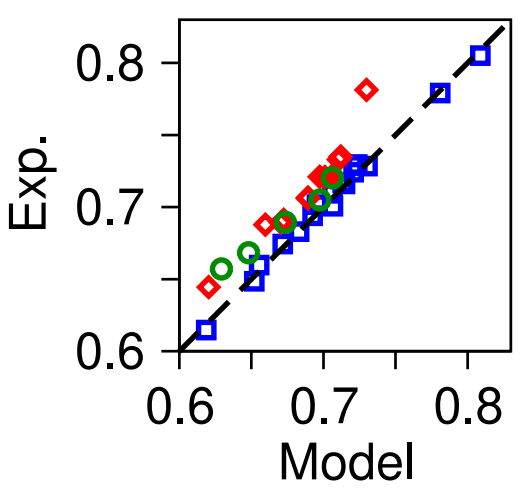

Figure 4 Density of n-alkane (a,b) and branched-alkanes (c,d) families. (a,c) shows a comparison of density with alkyl chain length. Experimental measurement ${ }^{2,3,78}$ are the filled $\bigcirc$ while model values are shown in (a) as red $\square$ and blue $\square$ for even and odd carbon length, respectively, and in (b) as blue $\square$ for methylalkanes, green $\bigcirc$ for $1, n$ - dimethylalkanes, red $\diamond$ for $n, n$-dimethylalkanes. (b,d) shows experimental density versus model density (dashed line represents perfect fit).

Whilst the calculated densities for the double branched alkane molecules are lower than the literature values, in Fig. 4c we observe a strong correlation between our model and experimental densities (red $\diamond$ and green $\bigcirc$ points). Improvements to the agreement between models and experiment is possible by either adjusting the methyl-methyl interaction to be softer (i.e. smaller $A_{i j}$ value) or shortening the bond length, suggesting that that the local bonded environment (i.e. the local arrangement that the methyl group is bonded within the molecule) may be important for specifying this bead. In DPD the overlap between beads can be significant and so contributions to non-bonded interactions can come from the nearest, next-nearest, etc, bonded neighbours, and this effect is more prominent with highly repulsive beads such as the methyl group. Therefore, 
(a)

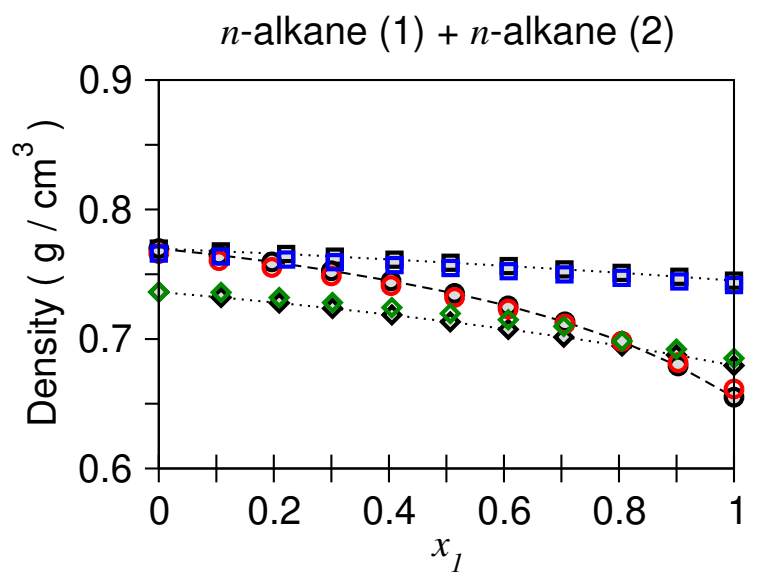

(b)

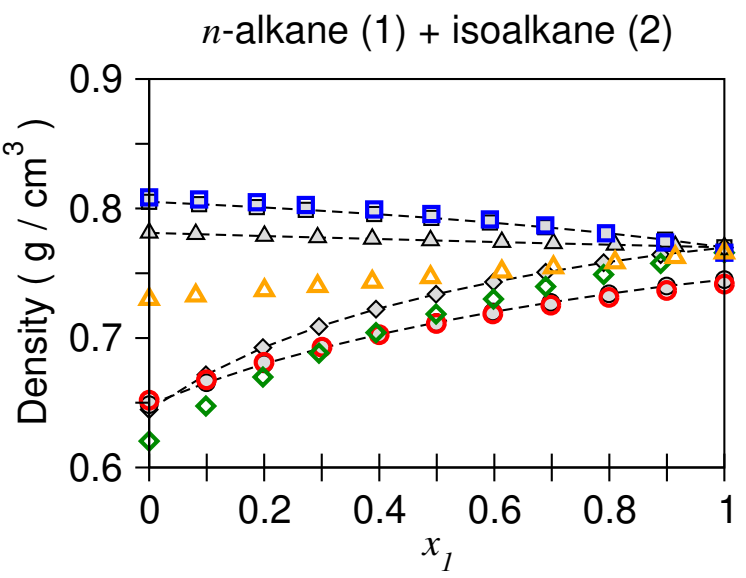

Figure 5 Changes in density with mole fraction $\left(x_{1}\right)$ for liquid mixtures: (a) n-alkane + n-alkane mixtures of $\bigcirc$ n-hexane (1) + n-hexadecane (2), $\square$ n-dodecane (1) + n-hexadecane (2) or $\diamond$ n-heptane (1) + n-undecane (2); (b) n-alkane + isoalkane mixtures of $\bigcirc$ n-dodecane (1) + 2-methyl pentane (2), n-hexadecane (1) $+2,6,10,15,19,23$-hexamethyl tetracosane (2), $\diamond$ n-hexadecane $(1)+2,2$-dimethyl pentane (2) or $\triangle \mathrm{n}$-hexadecane (1) + 2, 2, 4, 4, 6, 8, 8-heptamethyl nonane (2). The dashed lines with filled points are for experimental values $3,78,80$ and coloured points are for DPD model mixtures.

further improved accuracy may require a special bead type for methyls in a di-methyl or tri-methyl arrangement. This should not come as a surprise as such unique beads are common place in atomistic and united atom molecular dynamics, such as in united atom OPLS where the methyl bead parameters depend on whether it is in n-alkane, isobutyl-type or neopentyl-type arrangement. ${ }^{79}$ In addition, potential improvement to the n-pentane model density could result from higher values for the methyl-methyl interactions which would be counterbalanced by lowering the methyl- $\mathrm{CH}_{2} \mathrm{CH}_{2}$ bead repulsion to avoid overpredicting the densities at medium n-alkane lengths around $\mathrm{C}_{10}$. To introduce a special bead would require fitting six new interaction pairings and so in this work we do not develop these ideas further.

\subsection{Liquid phase densities of mixtures of alkanes}

Fig. 5a shows the density of three liquid binary n-alkane mixtures at various mole fractions of the lighter (i.e. lower molecular weight) alkane component. The mixtures are combinations of light (n-hexane $\left(\mathrm{n}-\mathrm{C}_{6}\right)$, n-heptane $\left(\mathrm{n}-\mathrm{C}_{7}\right)$ ) and medium weight (n-undecane $\left(\mathrm{n}-\mathrm{C}_{11}\right), \mathrm{n}$-dodecane $\left(\mathrm{n}-\mathrm{C}_{12}\right)$, n-hexadecane $\left(n-C_{16}\right)$ ) alkanes. The calculated densities of these binary mixtures (which are all 
single-phase liquids) fall within $1 \%$ of the corresponding experimental value with the following agreement across the sampled range: $\mathrm{n}^{-} \mathrm{C}_{7}+\mathrm{n}-\mathrm{C}_{11}$ has RMSD of 0.00276 and $R^{2}=0.985 ; \mathrm{n}^{-} \mathrm{C}_{6}$ $+\mathrm{n}^{-\mathrm{C}_{16}}$ has RMSD of 0.00364 and $R^{2}=0.992$; and $\mathrm{n}-\mathrm{C}_{12}+\mathrm{n}-\mathrm{C}_{16}$ has RMSD of 0.00393 and $R^{2}=0.763$. In the latter case the $R^{2}$ value is lower than the other mixtures as the densities are consistently larger than experiment which relates to the fact that the corresponding alkanes $\left(\mathrm{n}-\mathrm{C}_{12}\right.$,

$\mathrm{n}-\mathrm{C}_{16}$ ) have model densities slightly larger than experimental values. Thus $R^{2}$ may have limited value for assessing model performance for mixtures and the RMSD gives a better indication of model performance.

Fig. $5 \mathrm{~b}$ shows the densities of four liquid binary mixtures containing one $\mathrm{n}$-alkane and one branched alkane at various mole fractions of the n-alkane component. We achieve the following agreement across the sampled range: $\mathrm{n}^{-\mathrm{C}_{12}}+2$-methyl pentane has RMSD of 0.00226 and $R^{2}=0.994 ; \mathrm{n}^{-} \mathrm{C}_{16}+2,6,10,15,19,23$-hexamethyl tetracosane has RMSD of 0.00307 and $R^{2}=$ $0.92235 ; \mathrm{n}^{-\mathrm{C}_{16}}+2,2$-dimethyl butane has RMSD of 0.01679 and $R^{2}=0.810$; and finally $\mathrm{n}^{-\mathrm{C}_{16}}$ $+2,2,4,4,6,8,8$-heptamethyl nonane has RMSD of 0.0318 and $R^{2}=-77.026$. As seen with pure branch alkanes (Section 6.1) the agreement visibly worsens when studying a model with neopentyl-type group rather than isobutyl-type group (groups defined in Table 1). In fact the negative correlation $\left(R^{2}<0\right)$ observed for the 2, 2, 4, 4, 6, 8, 8-heptamethyl nonane mixture is worse than assuming a constant value for density, and gives us clear evidence that the model constraints put on the neopentyl-type group are far from ideal (this molecule contains three neopentyl-type groups). Overall we observe good performance for mixed alkanes systems provided the underlying models for the pure components are precise.

The tabulated experimental data for the considered mixtures can be found in Section F4 of the Supporting Information.

\subsection{Freezing transition for pure alkanes}

Fig. 6a shows simulation outputs for four selected alkanes to highlight the observed freezing transitions in the model. Fig. $6 \mathrm{~b}$ shows the chain length at which we find a freezing transition in 
(a)

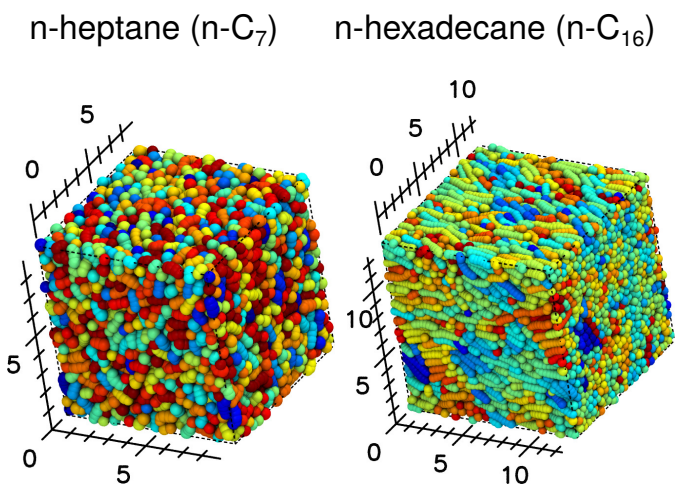

(b)

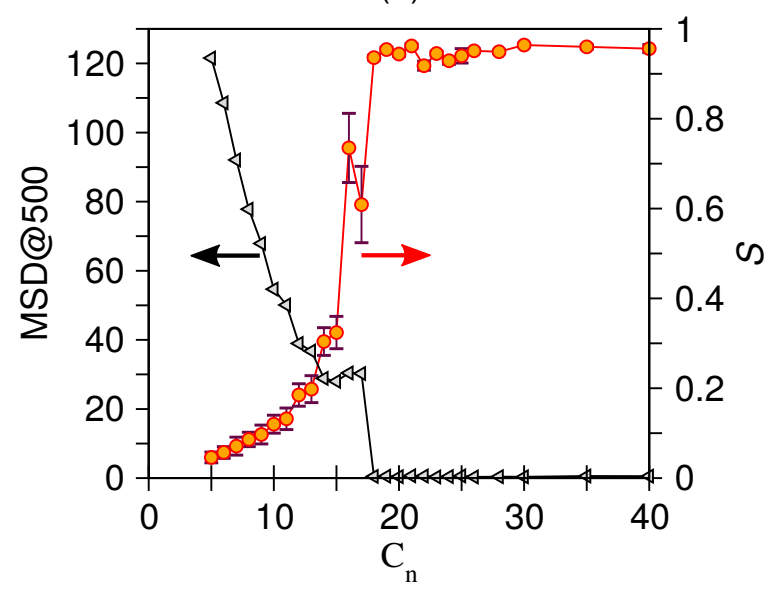

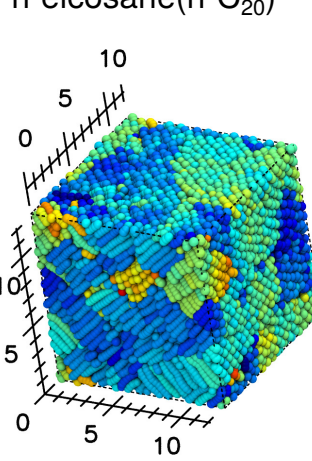

10

n-pentatriacontane $\left(\mathrm{n}-\mathrm{C}_{35}\right)$

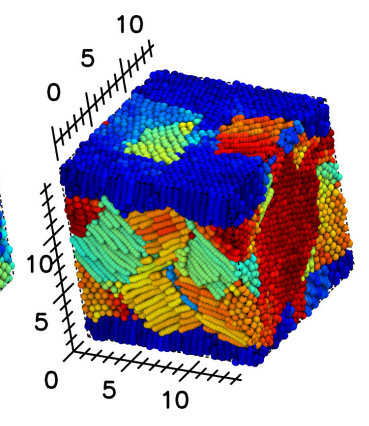

(c)

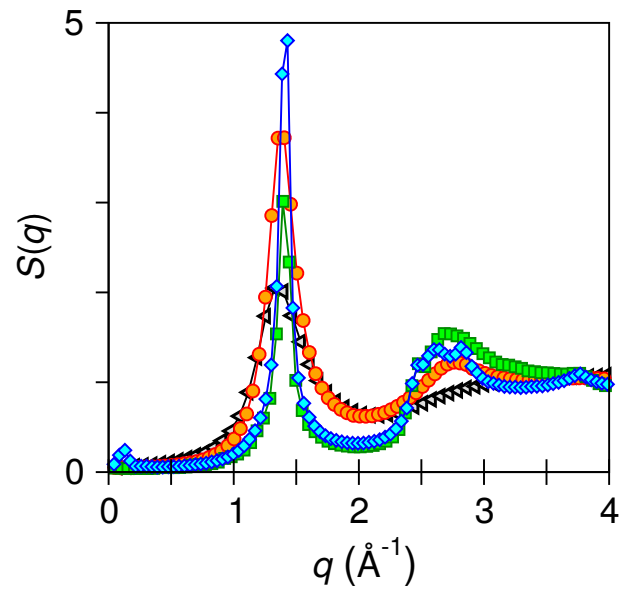

Figure 6 The onset of freezing with increasing carbon chain length for n-alkanes: (a) each sub-figure shows a snapshot of the final state (distance units given in nm); (b) mean square displacement (MSD@ 500) and $S$ order parameter given by $\bigcirc$ and $\triangleleft$ points, respectively; (c) static structure factor $S(q)$ for $\triangleleft$ n-heptane, $\bigcirc$ n-hexadecane, $\square$ n-eicosane, $\diamond$ n-pentatriacontane. The error bars in (b) are $\pm 2 \sigma$ for $S$.

the model for the studied n-alkanes according to the calculated MSD@500 and $S$ values, as defined in Section 4. For both metrics, there is a sharp transition in the region of $n-C_{15}$ to $n-C_{18}$. For the lighter alkanes MSD@500 decreases with increasing chain length from around 120 to a plateau value of around 30 (spanning $n-C_{14}$ to $n-C_{17}$ ), corresponding to the decline in molecular self-diffusion coefficient as the molecular weight increases. Then MSD@500 undergoes a precipitous drop between $n-C_{17}$ and $n-C_{18} n$-alkanes to small value of approximately 1 DPD length unit. Similarly, the nematic order parameter $S$ increases with chain length from 0 (indicating random molecule orientation) to a plateau value close to 1 (indicating molecules locally orientated in the same direction) starting from chain length $\mathrm{n}-\mathrm{C}_{18}$. According to our definitions in Section 4 , this places the liquid-solid freezing transition to be at $\mathrm{n}-\mathrm{C}_{18}$. This is in precise agreement with 
literature reported observations as intended following our parametrisation strategy. Fig. 6c shows the static structure factor for four n-alkane molecules with chain lengths spanning $n-C_{7}$ to $n-C_{35}$. At $n-C_{7}$ the structure factor is smooth with finite non-zero values as expected for a liquid, and the microstructure is visually disordered and isotropic (see $n-C_{7}$ snapshot in Fig. 6a). For n- $C_{16}$ there are more pronounced peaks in $S(q)$ but it maintains the smooth profile, and the visual appearance suggests nematic order but positional disorder (see $n-C_{16}$ snapshot Fig. 6a). Both n-eicosane $\left(\mathrm{n}-\mathrm{C}_{20}\right)$, n-pentatriacontane $\left(\mathrm{n}-\mathrm{C}_{35}\right)$ show similar behaviour with a sharp peak in $S(q)$ at around

$q \approx 1.5$, equivalent to the separation distance between contacting DPD beads, and a depleted region $(S(q) \approx 0)$ just after the peak which is indicative of the formation of lattice like order as expected for nucleate of a crystal. Both these systems have high positional and orientational order (see n- $\mathrm{C}_{20}$ and $\mathrm{n}-\mathrm{C}_{35}$ snapshots Fig. 6a).

To test for finite size effects we simulated several larger system sizes and found no notable effects on the result. Further we also confirmed that the simulations had reached final steady state within the time scale of simulation. These results are reported in Supporting Information Section F1. Only $n-C_{16}$ and $n-C_{17}$ models show variability in final structure (but not temporal behaviour) which is accounted for by them having liquid crystal properties.

\subsection{Freezing transitions in mixed alkane systems}

In Figs. 7 and 8 we show the behaviour of n-tricosane $\left(n-C_{23}\right)$ and n-octacosane $\left(n-C_{28}\right)$ in a nheptane solvent. We measured the MSD and $S$ of the heavy alkane (i.e. ignoring the solvent) and plot the results as a function of the mole fraction of this component, $x_{2}$. Section F5 of the Supporting Information give the raw tabulated values for these mixtures. As described in Section 5.3, two approaches were adopted for initial starting state of the system : (a) a randomly mixed initial configuration or (b) a fully segregated initial configuration where the two alkanes are initially placed into separate sub-volumes. Perhaps unsurprisingly, the two different initial conditions result in different behaviours with respect to $x_{2}$, such that the mole fraction at which the heavy alkane drops out of solution is higher for the random case than for the initially segregated state. 

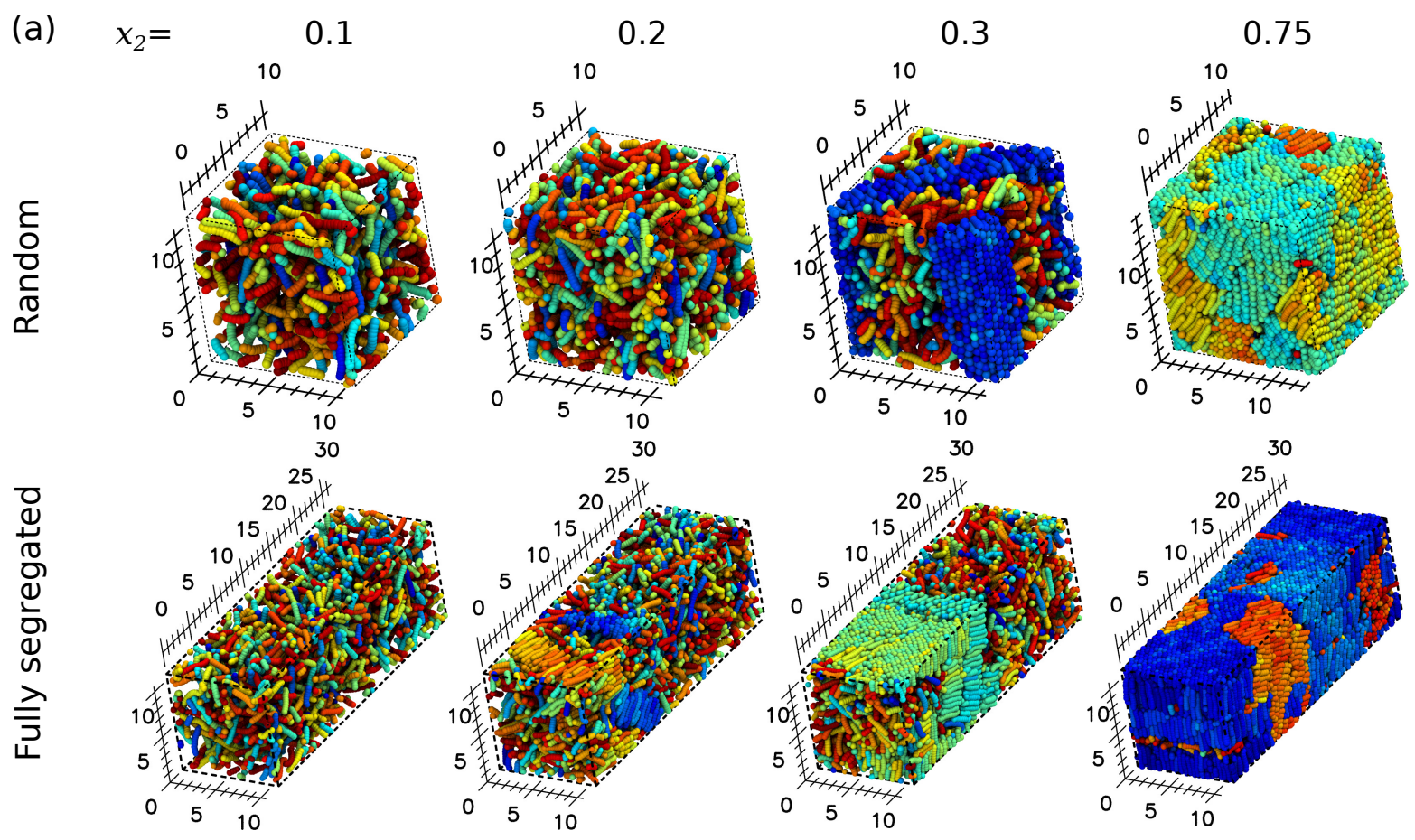

(b)
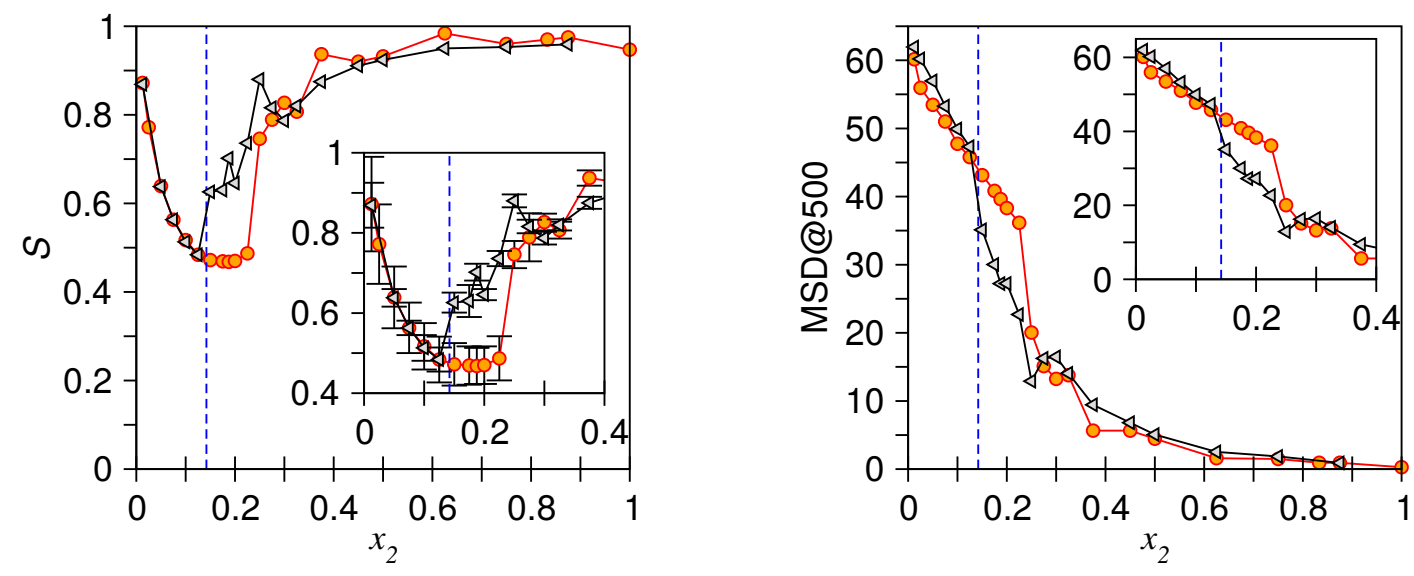

Figure 7 Behaviour with mole fraction $x_{2}$ of the heavy alkanes for the mixture (1) n-heptane $+(2)$ n-tricosane: (a) each subfigure shows a snapshot of the final state (distance units given in $\mathrm{nm}$ and with only the heavy alkane visible) obtained when started in random (top row) or segregated initial condition (bottom row); (b) plots of MSD and $S$ statistics for n-tricosane as function of mole fraction $x_{2}$. $\bigcirc$ and $\triangleleft$ points are for the simulations started from random or segregated initial conditions, respectively. The insets focus on the region of hysteresis and error bars where shown are $\pm 2 \sigma$ for $S$. The blue dashed vertical line is the experimental solubility limit given in Provost et al. ${ }^{11}$

For the initially random configuration, a transition in behaviour can be observed in both the MSD and $S$ at $x_{2} \approx 0.21\left(\mathrm{n}-\mathrm{C}_{23}\right)$ and $x_{2} \approx 0.1\left(\mathrm{n}-\mathrm{C}_{28}\right)$ where the heavy alkanes start to show long-range order (i.e. rapid increase in $S$ towards 1) and the mobility of molecules reduces (i.e. MSD@500 goes towards zero). Finite size affects were tested for and ruled out by running simula- 

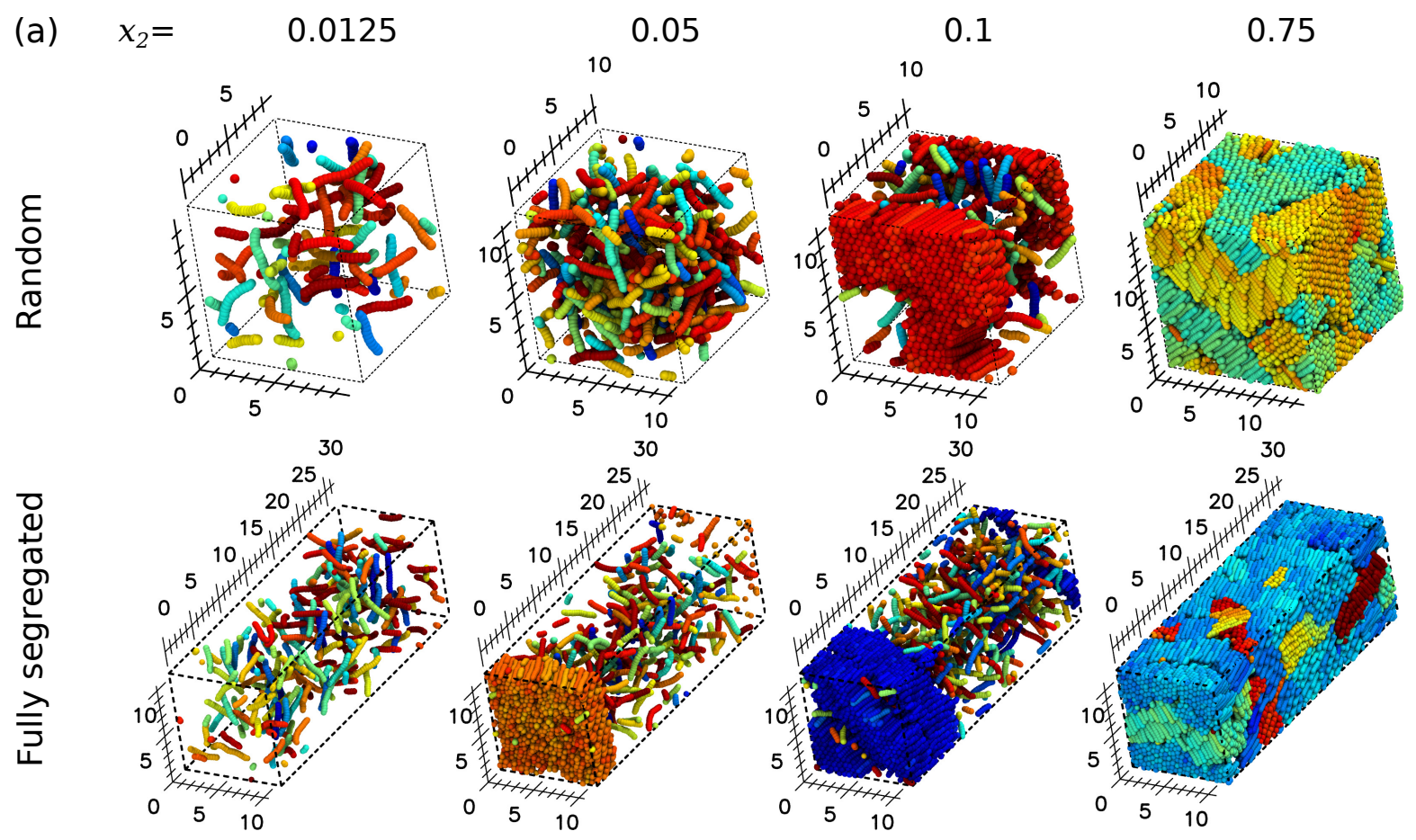

(b)
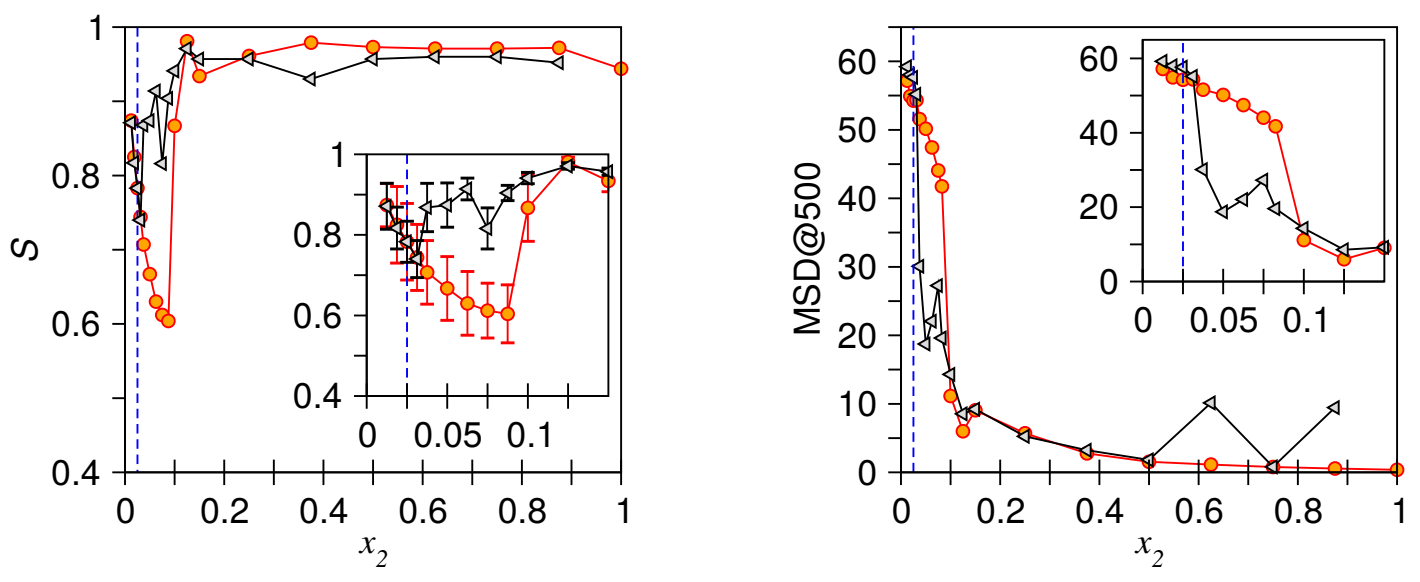

Figure 8 Behaviour with mole fraction $x_{2}$ of the heavy alkanes for the mixture (1) n-heptane $+(2)$ n-octacosane: (a) each subfigure shows a snapshot of the final state (distance units given in $\mathrm{nm}$ and with only the heavy alkane visible) obtained when started in random (top row) or segregated initial condition (bottom row); (b) plots of MSD and $S$ statistics for n-tricosane as function of mole fraction $x_{2} . \bigcirc$ and $\triangleleft$ points are for the simulations started in the random or segregated initial condition, respectively. The insets focus on the region of hysteresis and error bars where shown are $\pm 2 \sigma$ for $S$. The blue dashed vertical line is the experimental solubility limit given in Provost et al. ${ }^{11}$

tions with $2 \times$ and $3 \times$ larger mass; this only acted to sharpen the transition (See Supporting Information Section F5). Examining the microstructures we find that below the transition point the systems appear disordered, isotropic and liquid-like (e. g. see top row $x_{2}=0.2$ in Fig. 7a and $x_{2}=0.05$ in Fig. 8a). Above the transition the system show signs of phase separating into solvent-rich do- 
mains that remain liquid-like and heavy-alkane-rich domains that organise into tightly packed and highly ordered platelets (e.g. see top row $x_{2}=0.3$ in Fig. 7a and $x_{2}=0.1$ in Fig. 8a). These platelet-like domains are found to be a single alkane in thickness and extend in two dimensions until higher mole fractions at which point the system heavy alkanes freeze fully and MSD@500 drops to nearly zero (e. $g$. see top row $x_{2}=0.75$ Figs. 7 and 8 ).

For the fully segregated initial condition, a transition in behaviour can be observed in both MSD@500 and $S$ at $x_{2} \approx 0.15\left(\mathrm{n}-\mathrm{C}_{23}\right)$ and $x_{2} \approx 0.0375\left(\mathrm{n}-\mathrm{C}_{28}\right)$ where the some of the heavy alkanes forms a stable ordered layer (see lower row of Figs. 7a and 8a). Again, with increasing mole fraction the number of ordered layers increases until they span the system.

According to the literature, ${ }^{11}$ the cloud point (also known as limit of solubility) occurs at $x_{2} \approx 0.1295\left(\mathrm{n}-\mathrm{C}_{23}\right)$ and $x_{2} \approx 0.025\left(\mathrm{n}-\mathrm{C}_{28}\right)$ and these are marked on Figs. $7 \mathrm{~b}, \mathrm{c}$ and $8 \mathrm{~b}, \mathrm{c}$ for reference. In our diagrams (Figs. 7b 8b) we can see that there is a region of hysteresis (between $0.15>x_{2}>0.21\left(n-C_{23}\right)$ and $\left.0.0375>x_{2}>0.1\left(n-C_{28}\right)\right)$ just above the experimental cloud point where the precipitation of solid material from the liquid mixture is dependent on the initial starting configuration; in particular it appears that the initially random configuration must be super-cooled before precipitation occurs, corresponding to homogeneous nucleation. Conversely, for the fully segregated starting condition, the formation of solid domains of the heavy alkane is much easier. However, at high mole fraction of the heavy alkane the behaviour of the systems is the same, indicating that the starting configuration does not matter.

\subsection{Freezing of branched alkanes}

As a final test of our model we investigated whether we could capture the freezing transition for selected singly-methylated branched alkanes $\left(\mathrm{Me}-\mathrm{C}_{n}\right)$ by modelling examples derived from eicosane $\left(\mathrm{C}_{20}\right)$ and pentatriacontane $\left(\mathrm{C}_{35}\right)$. We add a methyl $(\mathrm{Me})$ group to the linear chains at various locations. Unlike the n-alkanes, which we found to rapidly form ordered crystalline states (within $10^{5}$ DPD time units), these singly-methylated branched alkanes take significant longer to freeze into ordered structures if indeed they do at all. Again, we measured $S$ and MSD@500 as a 
(a)
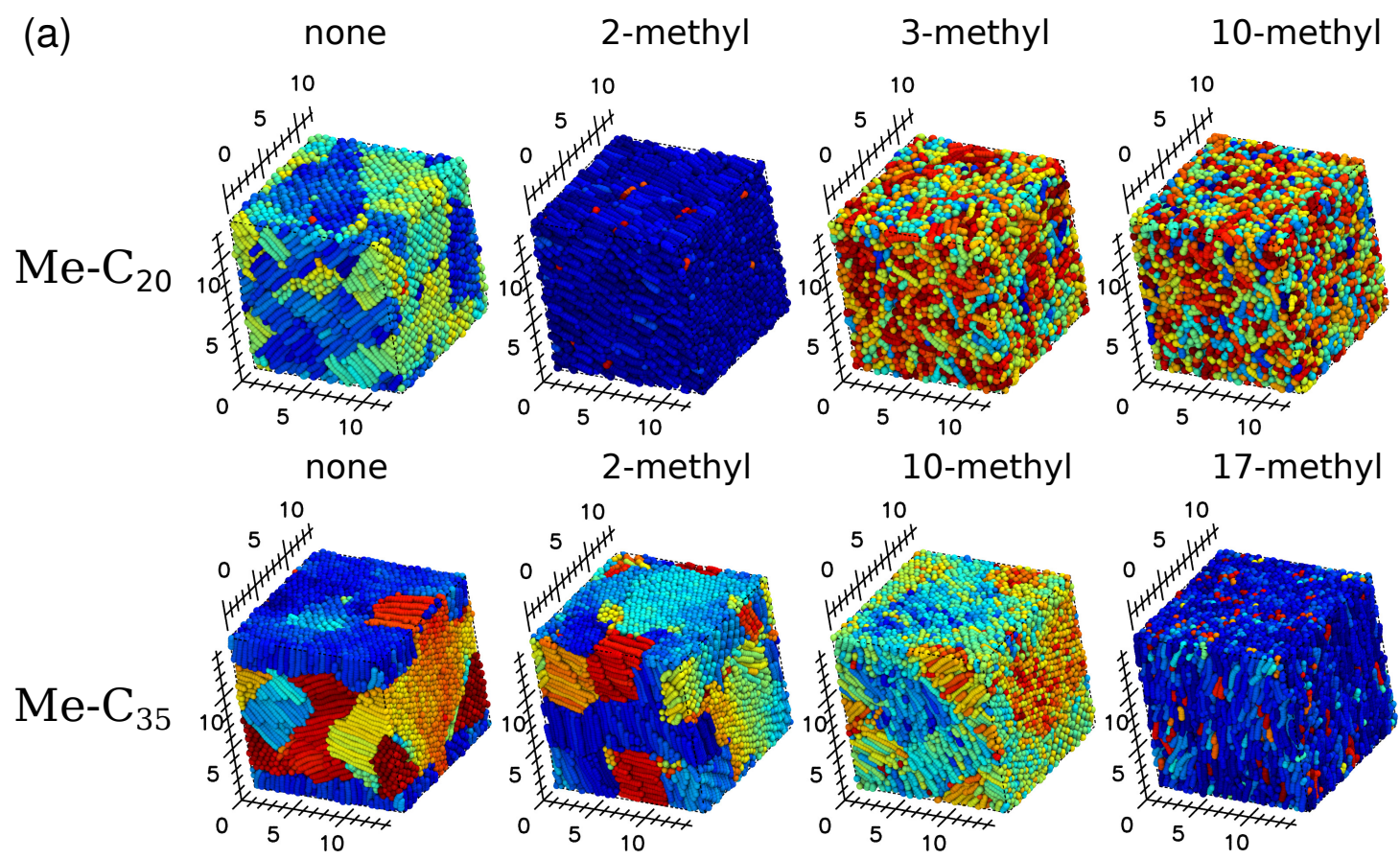

(b)
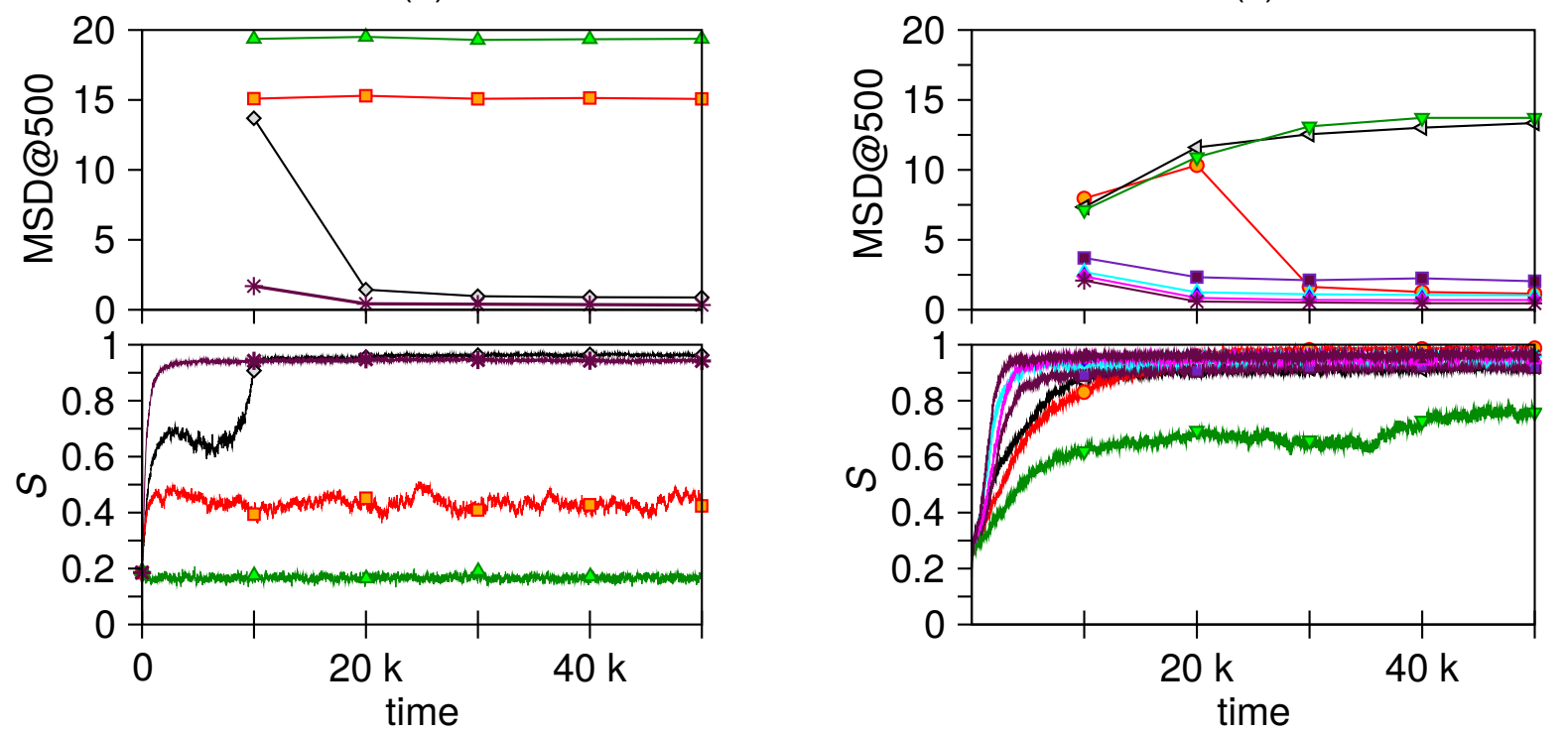

Figure 9 Linear and branched alkane behaviour: (a) each subfigure shows a snapshot of the final state (distance units given in $\mathrm{nm}$ ); (b,c) changes in order parameter $S$ and MSD as the system evolves in time for (b) n-eicosane ( $*$ no methyl, $\diamond 2$-methyl, $\square$ 3-methyl or $\triangle 10$-methyl) and (c) n-pentatriacontane ( $*$ no methyl, $\triangle$ 2-methyl, $\diamond$ 4-methyl, $\square$ 10-methyl, $\bigcirc 14$-methyl, $\nabla$ 16-methyl or $\triangleleft 17$-methyl ).

function of time (see Fig. 9).

For the $\mathrm{n}-\mathrm{C}_{20}$ derived branched alkanes (snapshots of final structures are shown in the upper row in Fig. 9a) we found that freezing only occurred when the methyl group was placed in the '2' position, as indicated in Fig. 9 b by a drop in MSD@500 towards 0 and a high order value for $S$. 
In all other cases the molecules continued to exhibit considerable mobility (MSD@500 > 10) and the liquid remained disordered (moderate to low value of $S<0.5$ ).

The $\mathrm{n}-\mathrm{C}_{35}$ derived branched alkanes proved more interesting. Here freezing was observed for most methyl positions (see the middle representative structure in the lower row in Fig. 9a). Only the 17-methyl $\mathrm{C}_{35}$ remained elusive (see the right representative structure in the lower row in Fig. 9a) even after very long simulations $\left(5 \times 10^{5}\right.$ time units). A longer time version of Fig. 9c is provided in the Supporting Information Section F6. In this case $S$ and MSD continued to increase to a plateau and apparently the final state is beyond the accessible simulation time. Thus, we found that the freezing kinetics (liquid to solid) took longer as the methyl group was moved away from the terminal end and towards the middle of the molecule (e.g. 16 -methyl $\mathrm{C}_{35}$ took $10 \times$ longer to crystallized than 14-methyl $\mathrm{C}_{35}$ ).

This is also supported by the behaviour of the MSD as the system evolves from a random start (Fig. 9c). In all cases the MSD metric shows either liquid-like behaviour (MSD@500 $\approx 10-20$ ) as illustrated by 3-methyl $\mathrm{C}_{20}$, 16-methyl $\mathrm{C}_{35}$, or solid-like behaviour (MSD@500 $\lesssim$ ) as illustrated by $n-C_{20}$ and $n-C_{30}$. As the system evolves this metric can switch from liquid-like to solid-like, as illustrated by 2 -methyl $\mathrm{C}_{20}$ and 14 -methyl $\mathrm{C}_{35}$. In contrast the nematic order parameter $S$ does not provide a sharp indicator of this transition as both the dense liquid and solid state can have high degree of orientational order.

These results lead us to the conclusion that these branched alkanes will freeze if the largest linear branch is long enough to form a molecular crystal in its own right, e.g. the largest branch is at least $\mathrm{C}_{18}$ at room temperature. Thus 2-methyl-eicosane freezes whereas 3-methyl-eicosane does not, and singly-methylated $\mathrm{C}_{35}$ is sufficiently long to satisfy this ad hoc criterion for most methyl positions. In the resulting molecular crystals, the shorter branches could be accommodated in liquid-like sub-regions or pockets. 


\section{Conclusions}

In this work we have demonstrated that the DPD method is capable of simulating alkane waxes, provided the model accurately represents the underlying molecular structure. Specifically, the bond lengths and bond angles should be accurately reproduced. We have parametrised our DPD model using real molecular bond lengths and angles, pure liquid phase densities and melting transitions of a large number of alkanes, including both branched and linear variants.

A major finding in this work is that the angular stiffness necessary to see wax formation is significantly higher than that typically used in previous DPD studies, including our own work. ${ }^{55}$ When lower values are adopted, it is not possible to observe this behaviour and crystalline structures cannot form. We note that refining the angular stiffness to precise values is difficult when simulating at room temperature alone due to the fairly large, discrete, changes in melting points for alkanes as a function of chain lengths. Thus, parametrising at a single fixed temperature (here, room temperature $25^{\circ} \mathrm{C}$ ) constrains the angular stiffnesses only to a range of values. Further refinement is obviously potentially possible by modelling freezing as a function of temperature (see Supporting Information Section G for demonstration of why this is necessary). We note that the temperature-dependence is non-trivial, and the behaviour of real molecular liquids cannot simply be captured by proportionally adjusting the DPD thermostat. One possible approach is to repeat the entire parametrisation exercise at a different temperature (for example, $40{ }^{\circ} \mathrm{C}$ ), and test the assumption that the DPD model parameters can be linearly interpolated. This is a substantial program for which the present study lays the groundwork, and is an area we are actively pursuing.

With our model we have been able to achieve excellent agreement between experimentally observed alkane densities and the chain-length-induced melting transition, at both short and long carbon lengths illustrating the benefits of fitting across the whole spectrum of alkane lengths. We used these models to explore the solidification and formation of alkane waxes. This has shown that DPD can be used to accurately model across a whole range of liquid / solid formulations. In particular it can be used to determine the solubilities of heavy alkanes in light solvents, something that 
is not generally reported in the experimental literature. Having an accurate model for alkane (particularly branched alkanes) is the basis for studying a range of problems where the microstructure is important, for example, in developing potential wax inhibitors for automotive fuels.

Our DPD model reproduces liquid phase densities within 3\%. This compares favourably against atomistic simulations where densities can be as much as 15\% different from experiment (e. g. for OPLS-AA the deviation was found to be $14 \%$ for hexadecane) ${ }^{81}$ How accurate do these models need to be though? To put this in context, experimentally a $1.4 \%$ change in density is equivalent to increasing the carbon chain length by one (based on $n-C_{10}$ to $n-C_{11}$ ) or decreasing the temperature by about $15^{\circ} \mathrm{C}\left(\right.$ e.g. the densities of decane at $20^{\circ} \mathrm{C}$ and $30^{\circ} \mathrm{C}$ are $0.730 \mathrm{~g} \mathrm{~cm}^{-3}$ and $0.722 \mathrm{~g} \mathrm{~cm}^{-3}$ respectively). ${ }^{2}$ In contrast, the typical measurement error is around $0.03 \%$ (based on $\left.\mathrm{n}-\mathrm{C}_{16}\right) \cdot{ }^{2,3,78}$ The development of high-accuracy atomistic or coarse-grained molecular models therefore should aim for a predictive error of between $0.03-1 \%$ of the experimental value. Our hand-tuned model comes close to this, but we anticipate that the accuracy could be further improved using automated methods (such as machine learning or classical parameter optimisation), ${ }^{82}$ fitting holistically to liquid phase density data across the family of alkanes and mixtures thereof.

Our model struggles with some types of branched alkanes, specifically highly methylated structures such as the neopentyl-type arrangement shown in Table 1. We believe this indicates the need for special consideration of these highly-branched motifs, due to the high level of bead overlap in this kind of coarse-grained model. Hence a choice is forced upon us: we either accept a reduction in accuracy for some chemistries in return for a having a relatively small number of bead types and/or bond lengths, or we accept a reduction in transferability by adding special beads and bonds to represent certain chemical arrangements. The former may be less intensive to parameterise, but the latter would lead to a higher accuracy model. An alternative approach could be to adopt many-body DPD to allow the pairwise interactions to reflect the local environment. ${ }^{44}$ However this also introduces a proliferation of parameters, and is not obviously advantageous compared to adding bead types. The challenge here also highlights the importance of determining an appropriate molecular fragmentation (or 'beading') strategy to represent specific chemistries before 
undertaking parameter optimisation.

Overall our work illustrates the attractiveness of combining a top-down parametrisation approach supported by experimental data, with bottom-up approaches for certain aspects of the molecular architecture such as bond lengths. However, one point of difficulty is that systematic experimental data sets are available for only a few chemical families (even for basic properties such as density) and so we quickly run into chemical groups where the data is sparse or non-existent which makes it difficult to apply our approach either for parametrization or validation. In such cases cheminformatics approaches may be required to fill in the gaps.

\section{Acknowledgments}

This work was supported by the Science and Technology Facilities Council (STFC) Hartree Centre's Innovation: Return on Research programme, funded by the Department for Business, Energy $\&$ Industrial Strategy, in addition to the STFC's Bridging for Innovators initiative and CLASP programme (grant number ST-S00646X-1). The first of these funding sources enabled the software development required to complete the work, the second funded the parametrization and testing of n-alkanes. The remaining work was conducted under the final listed funding source.

The authors would like to thank Pete Dowding for many interesting discussions and his insights in the very early parts of this work.

PBW declares a substantive ( $>$ \$10k) stock holding in Unilever PLC. All other authors declare no competing financial interests.

\section{Supporting Information}

This information is available free of charge via the Internet at http://pubs.acs.org.

- Supporting Information giving (in Sections A-E) further details on how the DPD models were fitted and validated, (in Section F) the raw statistics produced from simulation and 
their comparison to experiment, and (in Section G) behaviour of n-alkanes with temperature. (PDF).

\section{Appendix}

\section{Parametrization strategy for $A_{i j}$}

Potentially, fifteen different $A_{i j}$ parameters need to be specified to model all the possible linear and branched alkanes using our coarse-graining strategy. However we assume as a first pass that for the bead types used here to represent alkanes, the off-diagonal repulsion amplitudes $A_{i \neq j}$ can be calculated from the diagonal entries $\left(A_{i i}\right.$ and $\left.A_{j j}\right)$ by a mixing rule which weights in favour of larger beads:

$$
A_{i j}=\frac{R_{i i} A_{i i}+R_{j j} A_{j j}}{R_{i i}+R_{j j}} .
$$

With this in hand, the repulsion amplitudes for $\mathrm{CH}_{3}, \mathrm{CH}_{2}, \mathrm{CH}_{2} \mathrm{CH}_{2}$ were calculated first, as these form the core of all the molecules. The self-repulsion for $\mathrm{CH}_{2} \mathrm{CH}_{2}$ was set using the longer $\mathrm{n}$ alkanes, with chain length above n-octadecane $\left(n-C_{18}\right)$, keeping interactions involving with $\mathrm{CH}_{3}$ fixed at $A_{i j}=25$. Here we attempted to ensure that the gradient in liquid phase density, with respect to carbon chain length, was consistent between model and experiment. Next the short n-alkanes (n-hexane and n-octane) were used to determine the $\mathrm{CH}_{3}$ interaction.

These parameters were finally optimized by fitting the whole family of n-alkanes from $\mathrm{C}_{6}-\mathrm{C}_{20}$ to match the trend gradient in the liquid phase density, as well as actual values. No attempt was made to match $\mathrm{C}_{2}-\mathrm{C}_{4}$ (ethane-butane) as these are not liquid at $298 \mathrm{~K} / 25^{\circ} \mathrm{C}$ and atmospheric pressure. Once these are set, the odd n-alkanes, containing an additional $\mathrm{CH}_{2}$ bead, were parameterised. For n-alkanes the above $A_{i j}$ mixing rule worked well and no further adjustment was required.

With n-alkanes parameterised, branched alkanes were next fitted to obtain interactions for C and $\mathrm{CH}$ bead. We found that to avoid inducing artifacts in the liquid phase density behaviour, 
caused by the difference in degree of freedom of different chains close to the branch point, the fragmentation strategy needs to be such that the branch point is modelled as either iso-butyl-type (where a $\mathrm{CH}$ bead is bonded to three single carbon beads of either $\mathrm{CH}_{2}$ or $\mathrm{CH}_{3}$ ) or neopentyl-type (where a $\mathrm{C}$ bead is bonded to four single carbon beads of either $\mathrm{CH}_{2}$ or $\mathrm{CH}_{3}$ ). To fit the $\mathrm{CH}$ bead, the $m$-methyl n-alkane (where $m=1,2, \ldots)$ and $2,(n-1)$-dimethyl n-alkane families (where $n$ is the length of the n-alkane) were studied. In the case of isobutyl-type branched alkanes it was found that using the $A_{i j}$ mixing rule (Eq. (2)) under-predicted the liquid phase density, but this could be repaired by setting $A_{i j}=5$ for the $\mathrm{CH}_{2} \mathrm{CH}_{2}-\mathrm{CH}$ interaction.

To fit the $\mathrm{C}$ bead the $m, m$-dimethyl n-alkane (where $m=2,3, \ldots$ ) family was used. In the case of neopentyl-type branched alkanes, the liquid phase density was always underpredicted, and this could not be remedied by softening the interactions involving $\mathrm{C}$ bead. This suggest the problem lies with the methyl bead itself. In these structures there is significant overlap between neighbouring $\mathrm{CH}_{3}$ beads which gives the methyl beads a much larger apparent repulsion than in the n-alkane configuration. Tests suggest that the methyl self-repulsion amplitude needs to be reduced to around $A_{i i}=20$ to correctly reproduce the density. Such corrections have been addressed in united-atom (UA) force-fields in molecular dynamics, such as UA-OPLS, where unique unitedatom types are given for the n-alkane, isobutyl-type and neopentyl-type terminal methyl group. Thus it seems likely that to increase the accuracy of DPD models with this high degree of chemical specificity, bespoke bead types will be needed to reflect the surrounding molecular environment, or one turns to many-body DPD as mentioned in the main text conclusions.

\section{References}

(1) European Wax Federation. 2018; https : / /www . wax. org, (accessed June 11, 2020).

(2) Dreisbach, R. R. Physical Properties of Chemical Compounds-II; Adv. Chem. Ser.; American Chemical Society: Washington D.C., USA, Vol. 22; Chapter 1, pp 3-486.

(3) Aucejo, A.; Burguet, M. C.; Munoz, R.; Marques, J. L. Densities, Viscosities, and Refractive 
Indices of Some n-Alkane Binary Liquid Systems at 298.15 K. J. Chem. Eng. Data 1995, 40, 141-147.

(4) Kelland, M. Production Chemicals for the Oil and Gas Industry; CRC Press: Boca Raton, FL, USA, 2014.

(5) Sanjay, M.; Simanta, B.; Kulwant, S. Paraffin Problems in Crude Oil Production And Transportation: A Review. SPE Prod. Facil. 1995, 10, 50-54.

(6) Erastova, V. Molecular Simulation Studies of Diesel and Diesel Additives. Ph.D. thesis, Department of Chemistry, Durham University, 2012.

(7) Yang, F.; Zhao, Y.; Sjöblom, J.; Li, C.; Paso, K. G. Polymeric Wax Inhibitors and Pour Point Depressants for Waxy Crude Oils: A Critical Review. J. Disper. Sci. Technol. 2015, 36, 213225.

(8) San-miguel, M. A.; Rodger, P. M. Simulation of Deposition of Wax to Iron Oxide Surfaces. Mol. Simulat. 2001, 26, 193-216.

(9) Duffy, D. M.; Moon, C.; Rodger, P. M. Computer-assisted design of oil additives: hydrate and wax inhibitors. Mol. Phys. 2004, 102, 203-210.

(10) Dorset, D. L. Crystallography of the Polymethylene Chain: An Inquiry into the Structure of Waxes; Oxford University Press: Oxford, UK, 2004.

(11) Provost, E.; Chevallier, V.; Bouroukba, M.; Petitjean, D.; Dirand, M. Solubility of Some nAlkanes (C23, C25, C26, C28) in Heptane, Methylcyclohexane, and Toluene. J. Chem. Eng. Data 1998, 43, 745-749.

(12) Chang, S. S.; Maurey, J. R.; Pummer, W. J. Solubilities of two n-alkanes in various solvents. J. Chem. Eng. Data 1983, 28, 187-189. 
(13) Dirand, M.; Bouroukba, M.; Chevallier, V.; Petitjean, D.; Behar, E.; Ruffier-Meray, V. Normal Alkanes, Multialkane Synthetic Model Mixtures, and Real Petroleum Waxes: Crystallographic Structures, Thermodynamic Properties, and Crystallization. J. Chem. Eng. Data 2002, 47, 115-143.

(14) Mullin, J. W. Crystallization, 4th ed.; Butterworth-Heinemann: Oxford, UK, 2001.

(15) Lewtas, K. Improved fuel additives. Eur. Pat. EP0261959A2, March 30, 1988.

(16) Clydesdale, G.; Roberts, K. In Science and Technology of Crystal Growth: Lectures given at the Ninth International Summer School on Crystal Growth, 1st ed.; van der Eerden, J. P., Bruinsma, O. S. L., Eds.; Springer: Dordrecht, Netherlands, 1995; pp 179-192.

(17) Brooks, L.; Brunelli, M.; Pattison, P.; Jones, G.; Fitch, A. Crystal structures of eight monomethyl alkanes (C26-C32) via single-crystal and powder diffraction and DFT-D optimization. IUCrJ 2015, 2, 490-497.

(18) Ikedou, K.; Yamamoto, H.; Nagashima, H.; Nemoto, N.; Tashiro, K. Crystal Structures of nAlkanes with Branches of Different Size in the Middle. J. Phys. Chem. B 2005, 109, 1066810675.

(19) Singh, P.; Fogler, H. S.; Nagarajan, N. Prediction of the wax content of the incipient waxoil gel in a pipeline: An application of the controlled-stress rheometer. J. Rheol. 1999, 43, $1437-1459$.

(20) Neto, A.; Gomes, E. A.; Neto, E. L. B.; Dantas, T. N. C.; Moura, M. C. P. Determination of Wax Appearance Temperature (WAT) in Paraffin/Solvent Systems by Photoelectric Signal and Viscosimetry. Braz. J. Petro. Gas 2009, 3, 149-157.

(21) Zhang, J.; Yu, B.; Li, H.; Huang, Q. Advances in rheology and flow assurance studies of waxy crude. Petrol. Sci. 2013, 10, 538-547. 
(22) Roehner, R. M.; Hanson, F. V. Determination of Wax Precipitation Temperature and Amount of Precipitated Solid Wax versus Temperature for Crude Oils Using FT-IR Spectroscopy. Energy \& Fuels 2001, 15, 756-763.

(23) Coutinho, J. A. P.; Daridon, J.-L. The Limitations of the Cloud Point Measurement Techniques and the Influence of the Oil Composition on Its Detection. Petrol. Sci. Technol. 2005, 23, 1113-1128.

(24) Japper-Jaafar, A.; Bhaskoro, P.; Mior, Z. A new perspective on the measurements of wax appearance temperature: Comparison between DSC, thermomicroscopy and rheometry and the cooling rate effects. J. Petrol. Sci. Eng. 2016, 147, $672-681$.

(25) Meighani, H. M.; Ghotbi, C.; Behbahani, T. J.; Sharifi, K. A new investigation of wax precipitation in Iranian crude oils: Experimental method based on FTIR spectroscopy and theoretical predictions using PC-SAFT model. J. Mol. Liq. 2018, 249, 970 - 979.

(26) Coto, B.; Martos, C.; Espada, J. J.; Robustillo, M. D.; na, J. L. P. Analysis of paraffin precipitation from petroleum mixtures by means of DSC: Iterative procedure considering solid-liquid equilibrium equations. Fuel 2010, 89, 1087 - 1094.

(27) Alcazar-Vara, L. A.; Buenrostro-Gonzalez, E. Characterization of the wax precipitation in Mexican crude oils. Fuel Process. Technol. 2011, 92, 2366 - 2374.

(28) Fleming, F. P.; Daridon, J.-L.; Azevedo, L. F. A.; Pauly, J. Direct adjustment of wax thermodynamic model parameter to micro Differential Scanning Calorimetry thermograms. Fluid Phase Equilibr. 2017, 436, 20 - 29.

(29) ASTM D2500-17a, Standard Test Method for Cloud Point of Petroleum Products and Liquid Fuels; Standard, 2017; Vol. 05.01.

(30) Reddy, S. R. A thermodynamic model for predicting n-paraffin crystallization in diesel fuels. Fuel 1986, 65, 1647-1652. 
(31) Coutinho, J. A. P.; Andersen, S. I.; Stenby, E. H. Evaluation of activity coefficient models in prediction of alkane solid-liquid equilibria. Fluid Phase Equilibr. 1995, 103, 23-39.

(32) Coutinho, J. A. P.; Stenby, E. H. Predictive Local Composition Models for Solid/Liquid Equilibrium in n-Alkane Systems: Wilson Equation for Multicomponent Systems. Ind. Eng. Chem. Res. 1996, 35, 918-925.

(33) Coutinho, J. A. P. Predictive UNIQUAC: A New Model for the Description of Multiphase Solid-Liquid Equilibria in Complex Hydrocarbon Mixtures. Ind. Eng. Chem. Res. 1998, 37, $4870-4875$.

(34) Jorgensen, W. L.; Maxwell, D. S.; Tirado-Rives, J. Development and Testing of the OPLS All-Atom Force Field on Conformational Energetics and Properties of Organic Liquids. $J$. Am. Chem. Soc. 1996, 118, 11225-11236.

(35) Siu, S. W. I.; Pluhackova, K.; Böckmann, R. A. Optimization of the OPLS-AA Force Field for Long Hydrocarbons. J. Chem. Theory Comput. 2012, 8, 1459-1470.

(36) Sun, H. COMPASS: An ab Initio Force-Field Optimized for Condensed-Phase ApplicationsOverview with Details on Alkane and Benzene Compounds. J. Phys. Chem. B 1998, $102,7338-7364$.

(37) van Duin, A. C. T.; Dasgupta, S.; Lorant, F.; Goddard, W. A. ReaxFF: A Reactive Force Field for Hydrocarbons. J. Phys. Chem. A 2001, 105, 9396-9409.

(38) Martin, M. G.; Siepmann, J. I. Novel Configurational-Bias Monte Carlo Method for Branched Molecules. Transferable Potentials for Phase Equilibria. 2. United-Atom Description of Branched Alkanes. J. Phys. Chem. B 1999, 103, 4508-4517.

(39) Chen, B.; Siepmann, J. I. Transferable Potentials for Phase Equilibria. 3. Explicit-Hydrogen Description of Normal Alkanes. J. Phys. Chem. B 1999, 103, 5370-5379. 
(40) Wick, C. D.; Martin, M. G.; Siepmann, J. I. Transferable Potentials for Phase Equilibria. 4. United-Atom Description of Linear and Branched Alkenes and Alkylbenzenes. J. Phys. Chem. B 2000, 104, 8008-8016.

(41) Maerzke, K. A.; Siepmann, J. I. Transferable Potentials for Phase Equilibria: Coarse-Grain Description for Linear Alkanes. J. Phys. Chem. B 2011, 115, 3452-3465.

(42) Müller, E. A.; Jackson, G. Force-Field Parameters from the SAFT-y Equation of State for Use in Coarse-Grained Molecular Simulations. Annu. Rev. Chem. Biomol. 2014, 5, 405-427.

(43) Shahruddin, S.; Jiménez-Serratos, G.; Britovsek, G. J. P.; Matar, O. K.; Müller, E. A. Fluidsolid phase transition of n-alkane mixtures: Coarse-grained molecular dynamics simulations and diffusion-ordered spectroscopy nuclear magnetic resonance. Sci. Rep.-UK 2019, 9, 1002.

(44) Español, P.; Warren, P. B. Perspective: Dissipative particle dynamics. J. Chem. Phys. 2017, $146,150901$.

(45) Hoogerbrugge, P. J.; Koelman, J. M. V. A. Simulating Microscopic Hydrodynamic Phenomena with Dissipative Particle Dynamics. Europhys. Lett. 1992, 19, 155.

(46) Groot, R. D.; Warren, P. B. Dissipative particle dynamics: Bridging the gap between atomistic and mesoscopic simulation. J. Chem. Phys. 1997, 107, 4423-4435.

(47) Groot, R.; Rabone, K. Mesoscopic Simulation of Cell Membrane Damage, Morphology Change and Rupture by Nonionic Surfactants. Biophys. J. 2001, 81, 725-736.

(48) Español, P.; Warren, P. B. Statistical mechanics of dissipative particle dynamics. Europhys. Lett. 1995, 30, 191.

(49) Vishnyakov, A.; Lee, M.-T.; Neimark, A. V. Prediction of the Critical Micelle Concentration of Nonionic Surfactants by Dissipative Particle Dynamics Simulations. J. Phys. Chem. Lett. 2013, 4, 797-802. 
(50) Lee, M.-T.; Vishnyakov, A.; Neimark, A. V. Calculations of Critical Micelle Concentration by Dissipative Particle Dynamics Simulations: The Role of Chain Rigidity. J. Phys. Chem. B 2013, 117, 10304-10310.

(51) Mai, Z.; Couallier, E.; Rakib, M.; Rousseau, B. Parameterization of a mesoscopic model for the self-assembly of linear sodium alkyl sulfates. J. Chem. Phys. 2014, 140, 204902.

(52) Mao, R.; Lee, M.-T.; Vishnyakov, A.; Neimark, A. V. Modeling Aggregation of Ionic Surfactants Using a Smeared Charge Approximation in Dissipative Particle Dynamics Simulations. J. Phys. Chem. B 2015, 119, 11673-11683.

(53) Johnston, M. A.; Swope, W. C.; Jordan, K. E.; Warren, P. B.; Noro, M. G.; Bray, D. J.; Anderson, R. L. Toward a Standard Protocol for Micelle Simulation. J. Phys. Chem. B 2016, $120,6337-6351$.

(54) Lee, M.-T.; Mao, R.; Vishnyakov, A.; Neimark, A. V. Parametrization of Chain Molecules in Dissipative Particle Dynamics. J. Phys. Chem. B 2016, 120, 4980-4991.

(55) Anderson, R. L.; Bray, D. J.; Ferrante, A. S.; Noro, M. G.; Stott, I. P.; Warren, P. B. Dissipative particle dynamics: Systematic parametrization using water-octanol partition coefficients. J. Chem. Phys. 2017, 147, 094503.

(56) Tang, X.; Zou, W.; Koenig, P. H.; McConaughy, S. D.; Weaver, M. R.; Eike, D. M.; Schmidt, M. J.; Larson, R. G. Multiscale Modeling of the Effects of Salt and Perfume Raw Materials on the Rheological Properties of Commercial Threadlike Micellar Solutions. J. Phys. Chem. B 2017, 121, 2468-2485.

(57) Anderson, R. L.; Bray, D. J.; Del Regno, A.; Seaton, M. A.; Ferrante, A. S.; Warren, P. B. Micelle Formation in Alkyl Sulfate Surfactants Using Dissipative Particle Dynamics. J. Chem. Theory Comput. 2018, 14, 2633-2643. 
(58) Panoukidou, M.; Wand, C. R.; Del Regno, A.; Anderson, R. L.; Carbone, P. Constructing the phase diagram of sodium laurylethoxysulfate using dissipative particle dynamics. J. Colloid Interf. Sci. 2019, 557, $34-44$.

(59) Taddese, T.; Anderson, R. L.; Bray, D. J.; Warren, P. B. Recent advances in particle-based simulation of surfactants. Curr. Opin. Colloid Interface Sci. 2020, 48, 137-148.

(60) Zheng, R.; Liu, G.; Devlin, M.; Hux, K.; chi Jao, T. Friction Reduction of Lubricant Base Oil by Micelles and Crosslinked Micelles of Block Copolymers. Tribol. Trans. 2009, 53, 97-107.

(61) Zhang, S.-F.; Sun, L.; Xu, J.-B.; Wu, H.; Wen, H. Aggregate Structure in Heavy Crude Oil: Using a Dissipative Particle Dynamics Based Mesoscale Platform. Energy \& Fuels 2010, 24, $4312-4326$.

(62) Song, X.; Shi, P.; Zhao, S.; Duan, M.; Wang, C.; Ma, Y. Dissipative Particle Dynamics Study on the Aggregation Behavior of Asphaltenes under Shear Fields. Ind. Eng. Chem. Res. 2016, 55, 9077-9086.

(63) Skartlien, R.; Simon, S.; Sjöblom, J. A DPD study of asphaltene aggregation: The role of inhibitor and asphaltene structure in diffusion-limited aggregation. J. Disper. Sci. Technol. 2017, 38, 440-450.

(64) Guan, D.; Feng, S.; Zhang, L.; Shi, Q.; Zhao, S.; Xu, C. Mesoscale Simulation for Heavy Petroleum System Using Structural Unit and Dissipative Particle Dynamics (SU-DPD) Frameworks. Energy \& Fuels 2019, 33, 1049-1060.

(65) Deichmann, G.; Marcon, V.; van der Vegt, N. F. A. Bottom-up derivation of conservative and dissipative interactions for coarse-grained molecular liquids with the conditional reversible work method. J. Chem. Phys. 2014, 141, 224109.

(66) Trément, S.; Schnell, B.; Petitjean, L.; Couty, M.; Rousseau, B. Conservative and dissipa- 
tive force field for simulation of coarse-grained alkane molecules: A bottom-up approach. $J$. Chem. Phys. 2014, 140, 134113.

(67) Frenkel, D.; Smit, B. Understanding Molecular Simulation, 2nd ed.; Academic Press, Inc.: Orlando, FL, USA, 2001.

(68) Likos, C. N.; Löwen, H.; Watzlawek, M.; Abbas, B.; Jucknischke, O.; Allgaier, J.; Richter, D. Star polymers viewed as ultrasoft colloidal particles. Phys. Rev. Lett. 1998, 80, 4450-4453.

(69) Lang, A.; Likos, C. N.; Watzlawek, M.; Löwen, H. Fluid and solid phases of the Gaussian core model. J. Phys.: Condens. Mat. 2000, 12, 5087-5108.

(70) Zhao, T.; Wang, X. Solvent effect on phase transition of lyotropic rigid-chain liquid crystal polymer studied by dissipative particle dynamics. J. Chem. Phys. 2013, 138, 024910.

(71) Durchschlag, H.; Zipper, P. Calculation of the partial volume of organic compounds and polymers. Prog. Colloid. Polym. Sci. 1994, 94, 20-39.

(72) Venturoli, M.; Smit, B. Simulating the self-assembly of model membranes. Phys. Chem. Comm. 1999, 2, 45-49.

(73) Venturoli, M.; Sperotto, M. M.; Kranenburg, M.; Smit, B. Mesoscopic models of biological membranes. Phys. Rep. 2006, 437, 1-54.

(74) Tough, R. J. A.; Bradshaw, M. J. The determination of the order parameters of nematic liquid crystals by mean field extrapolation. J. Phys. France 1983, 44, 447-454.

(75) Seaton, M. A.; Anderson, R. L.; Metz, S.; Smith, W. DLMESO: highly scalable mesoscale simulations. Mol. Simulat. 2013, 39, 796-821.

(76) Jakobsen, A. F. Constant-pressure and constant-surface tension simulations in dissipative particle dynamics. J. Chem. Phys. 2005, 122, 124901. 
(77) Bray, D. J.; Del Regno, A.; Anderson, R. L. UMMAP: a statistical analysis software package for molecular modeling. Mol. Simulat. 2019, 46, 308-322.

(78) Fermeglia, M.; Torriano, G. Density, Viscosity, and Refractive Index for Binary Systems of n-C16 and Four Nonlinear Alkanes at 298.15 K. J. Chem. Eng. Data 1999, 44, 965-969.

(79) Jorgensen, W. L.; Madura, J. D.; Swenson, C. J. Optimized intermolecular potential functions for liquid hydrocarbons. J. Am. Chem. Soc. 1984, 106, 6638-6646.

(80) Aucejo, A.; Cruz Burguet, M.; Munoz, R.; Marques, J. L. Densities, Viscosities, and Refractive Indices of the Binary Liquid Systems n-Alkanes + Isomers of Hexane at 298.15 K. J. Chem.Eng. Data 1995, 40, 871-874.

(81) Ewen, J. P.; Gattinoni, C.; Thakkar, F. M.; Morgan, N.; Spikes, H. A.; Dini, D. A Comparison of Classical Force-Fields for Molecular Dynamics Simulations of Lubricants. Materials 2016, 9, 651 .

(82) McDonagh, J. L.; Shkurti, A.; Bray, D. J.; Anderson, R. L.; Pyzer-Knapp, E. O. Utilizing Machine Learning for Efficient Parameterization of Coarse Grained Molecular Force Fields. J. Chem. Inf. Model. 2019, 59, 4278-4288. 


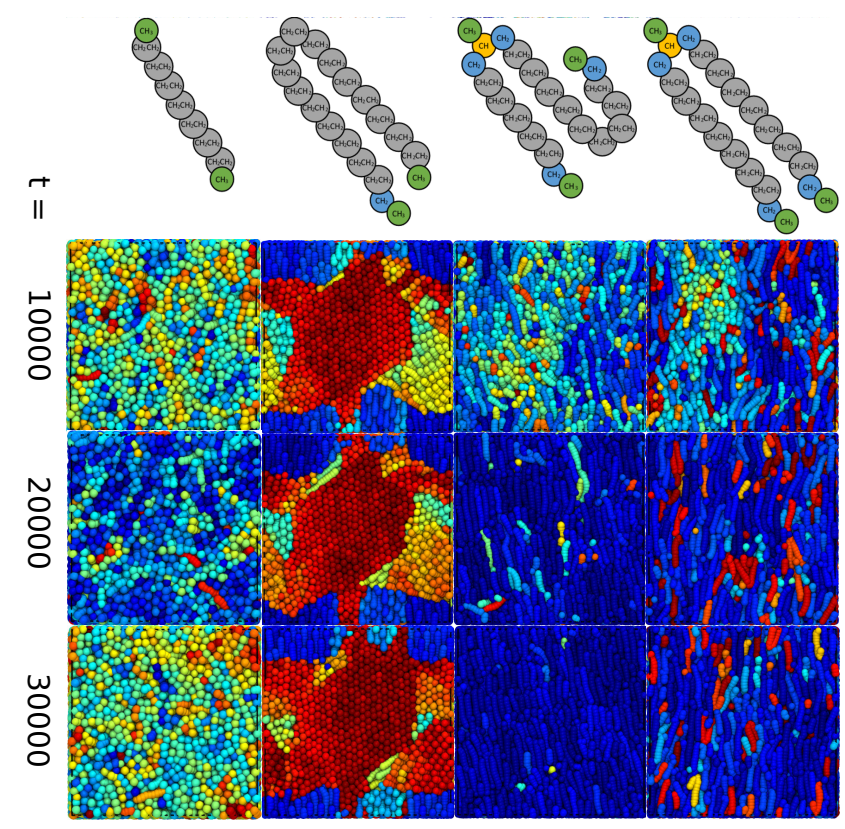




\section{Supporting Information: Wax Formation in}

Linear and Branched Alkanes with Dissipative Particle Dynamics

David J. Bray ${ }^{*, \dagger}{ }^{\dagger}$ Richard L. Anderson,${ }^{\dagger}$ Patrick B. Warren, ${ }^{\dagger, \dagger}$ and Kenneth Lewtas ${ }^{\mathbb{I I}, \S}$

$\dagger$ The Hartree Centre, STFC Daresbury Laboratory, Warrington, WA4 4AD, United Kingdom $\ddagger$ Unilever R\&D Port Sunlight, Quarry Road East, Bebington, Wirral, CH63 3JW, United

Kingdom.

ILLewtas Science \& Technologies Ltd., 246 Banbury Road, Oxford, OX2 7DY, United Kingdom $\S$ School of Chemistry, The University of Edinburgh, Joseph Black Building, David Brewster Road, Edinburgh, EH9 3FJ, United Kingdom.

E-mail: david.bray@stfc.ac.uk

\section{A Distance conversion from DPD to real units}

While a model for water is not strictly needed for alkanes we provide it as a reference point to facilitate future extension to wider set of chemistries, such as oil + water + surfactant mixtures, and to keep our models consistent with our previous efforts. ${ }^{1,2}$ We represent water by a single bead type with self-interaction parameters $R_{i i}=r_{c}=1$ (defines $r_{c}$ ) and $A_{i i}=25$ in DPD units. In our standard approach, after Groot and Rabone, ${ }^{3}$ each water bead corresponds to two water molecules (mapping number $N_{m}=2$ ). Then, using the molecular volume of water $\left(V_{m}=30 \AA^{3}\right)$, 
the distance unit conversion is $r_{c}=5.65 \AA$ when $\rho=3$ is used for the standard density of water in reduced units. We verified by simulating a box of 24,000 water beads that under NPT conditions with $P=23.7$, the density does indeed take this value in reduced units, corresponding to the actual density of water $1.0 \mathrm{~g} \mathrm{~cm}^{-3}$ at $298.15 \mathrm{~K} / 25^{\circ} \mathrm{C}$ and $1 \mathrm{~atm}$.

\section{B Generating reference structures of n-alkanes}

Atomistic-resolution model structures of ethane, propane, n-butane and n-hexane were created using the Molefacture Plugin in VMD. ${ }^{4,5}$ The experimental bond lengths were taken to be $\mathrm{C}\left(\mathrm{sp}^{3}\right)-\mathrm{C}\left(\mathrm{sp}^{3}\right)=1.54 \AA$ and $\mathrm{C}\left(\mathrm{sp}^{3}\right)-\mathrm{H}=1.10 \AA$. Corresponding bond angles were assigned to be $X-\mathrm{C}-X=109^{\circ}$, where $X$ is either $\mathrm{C}$ or $\mathrm{H}$ atom. All n-alkanes were assumed to be in trans conformation (i.e. a dihedral angle of $\mathrm{C}-\mathrm{C}-\mathrm{C}-\mathrm{C}=180^{\circ}$ ). From these structures the centre of mass of each DPD bead was calculated.

\section{Determining the equilibrium bond length $r_{0}^{i j}$}

The measured bond length between DPD beads was converted into DPD units and then rationalized into a limited set of values $l_{0}$. As the non-bonded interactions between bonded neighbouring beads act to lengthen the bond, it is not automatic that $l_{0}$ should be used as the bond equilibrium distance between beads (i.e. $r_{0}^{i j}$ ). Instead a correction should be made using the equation

$$
r_{0}^{i j}=\left(1+\left(A_{i j} / K_{B}^{i j}\right)\right) l_{0}-\left(A_{i j} / K_{B}^{i j}\right) R_{i j}
$$

which assumes the major contribution to the increase in separation distance is only due to the nearest-neighbour interaction of the bead pair. Note that this correction is unique to the $A_{i j}, R_{i j}$ and $K_{B}^{i j}$ combination used. For high values of $K_{B}^{i j}$ equation (1) effectively becomes $r_{0}^{i j} \approx l_{0}$, which is the case for the present work, and lead to the corresponding values shown in table 2 of main article. 


\section{Determining the equilibrium bond angle $\theta_{0}^{i j k}$}

The calculated angle for connected bead triplets are obtained from the structures. When used in the DPD model as the equilibrium angle $\left(\theta_{0}^{i j k}\right)$ these angles are sanitized into classes (as shown in table 2 of main article).

\section{E Validating Bond and Angle constraints}

\section{E.1 Atomistic simulations performed}

Atomistic molecular dynamic simulations of n-tetradecane, and n-decane were run (using Gromacs $2018.4^{6}$ ) to provide reference bond and angle distributions with which to build the DPD model. The OPLS force-field ${ }^{7}$ was chosen as it is well parameterized for alkanes molecules. Each simulation contained 1000 molecules run under NPT conditions of $298.15 \mathrm{~K}$ and $1 \mathrm{~atm}$, until the simulation reached equilibration (defined as stable density).

\section{E.2 Measuring angle and bond distribution}

From atomistic simulations of $n$-decane and n-hexadecane we calculated the bond and angle distribution for key bonded coarse-grained bead combinations. At each sampled time frame, the centre of mass of each virtual coarse-grained bead is obtained, derived from the atomistic coordinates represented by the bead, and the appropriate bond length or bond angle measured. These angles and bond lengths are then used to calculate the time-averaged distribution (probability density function - p.d.f). In the reference DPD simulation we modeled n-hexadecane and calculated the angle and bond length directly from the bead coordinates of each molecule. To make the comparison, all DPD distances have been converted to real units using the distance conversion as defined in Section A. 


\section{F Raw Statistics produced from simulation}

For densities, where possible we use available literature data on liquid phase densities for alkanes of short-medium carbon chain length. Where the alkane is solid (i.e. long alkanes) we adopt the measured value for the undercooled liquid. For each molecule the experimental melting point is used to determine whether the physical state at $298 \mathrm{~K}$ and $1 \mathrm{~atm}$ should be (crystalline) solid or liquid.

\section{F.1 Pure n-alkanes}

Table 1 gives the raw statistics obtained from the simulations of pure n-alkanes using the methods outlined in the main text. Measurements reported were taken between $10 \times 10^{3}$ and $20 \times 10^{3} \mathrm{DPD}$ time units.

Figures 1, 2 and 3 demonstrate the degree of stability of the result with respect to time and/or system size for the order parameter $S$, MSD and structure factor $S(q)$. Both isotropic liquids (n$\left.\mathrm{C}_{9}, \mathrm{n}-\mathrm{C}_{14}, \mathrm{n}-\mathrm{C}_{15}\right)$ and the solid $\mathrm{n}-\mathrm{C}_{18}$ have a single steady state behaviour reached by $2.5 \times 10^{3}$ time units. The $\mathrm{n}$-alkanes at lengths close to the solid transition $\left(\mathrm{n}-\mathrm{C}_{16}\right.$ and $\left.\mathrm{n}-\mathrm{C}_{17}\right)$ have a single steady temporal behaviour (MSD) of a liquid but show variability in the structural characteristics (differences in $S$ and $S(q)$ ). This is not a finite size effect as we ran multiple runs of the same box size and found different final states could be achieved (to demonstrate we have added additional trend lines for $\mathrm{n}^{-} \mathrm{C}_{17}$ given by runs started with a different value for the random seed). Instead, it suggests that the $n-C_{16}$ and $n-C_{17}$ models are in a liquid crystal arrangement (where nematic has $S>0.6$ and smetic has $S>0.8$ ). Thus it highlights the limitations of the $S$ measure which is affected by the size and number of sub-regions (where molecules are similarly orientated) initially

formed in the system that later become difficult to reorient out of. This is similarly true in the solid systems but the effects are generally much less noticeable and restricted to values $S>0.8$. 
Table 1 Comparison between experiment and model densities and state for pure n-alkanes.

\begin{tabular}{|c|c|c|c|c|c|c|c|c|c|}
\hline \multirow{2}{*}{$\begin{array}{l}\text { Molecule } \\
\text { Water }\end{array}$} & \multicolumn{3}{|c|}{$\begin{array}{c}\text { Formula Number of Exp. density } \\
\text { molecules }\left(\mathrm{g} / \mathrm{cm}^{3}\right)\end{array}$} & \multicolumn{2}{|c|}{$\begin{array}{l}\text { Sim. density rel. error } \\
\left(\mathrm{g} / \mathrm{cm}^{3}\right)\end{array}$} & \multirow{2}{*}{$\begin{array}{c}\text { Exp. } T_{m} \\
0^{\circ} \mathrm{C}\end{array}$} & \multirow{2}{*}{$\begin{array}{c}\begin{array}{l}\text { MSD } \\
@ 500\end{array} \\
\text { N/A }\end{array}$} & \multirow{2}{*}{$\begin{array}{c}S \pm 2 \sigma \\
\text { N/A }\end{array}$} & \multirow{2}{*}{$\begin{array}{c}\text { Sim. state } \\
\text { liquid }\end{array}$} \\
\hline & $\mathrm{H}_{2} \mathrm{O}$ & 12000 & $0.997048^{8}$ & $0.997048^{*}$ & N/A & & & & \\
\hline n-pentane & $\mathrm{C}_{5} \mathrm{H}_{12}$ & 7000 & $0.621(39)^{9}$ & $0.637(23)$ & $-2.55 \%$ & $-130^{\circ} \mathrm{C}^{9}$ & 121.581 & $0.046 \pm 0.012$ & liquid \\
\hline n-hexane & $\mathrm{C}_{6} \mathrm{H}_{14}$ & 6000 & $0.655(07)^{10}$ & $0.661(37)$ & $-0.96 \%$ & $-95^{\circ} \mathrm{C}^{9}$ & 108.588 & $0.057 \pm 0.013$ & liquid \\
\hline n-heptane & $\mathrm{C}_{7} \mathrm{H}_{16}$ & 3000 & $0.679(51)^{9}$ & $0.685(09)$ & $-0.82 \%$ & $-91{ }^{\circ} \mathrm{C}^{9}$ & 92.089 & $0.071 \pm 0.020$ & liquid \\
\hline n-octane & $\mathrm{C}_{8} \mathrm{H}_{18}$ & 4800 & $0.698(42)^{10}$ & $0.698(67)$ & $-0.04 \%$ & $-57^{\circ} \mathrm{C}^{9}$ & 77.812 & $0.086 \pm 0.016$ & liquid \\
\hline \multirow[t]{3}{*}{ n-nonane } & $\mathrm{C}_{9} \mathrm{H}_{20}$ & 3000 & $0.713(81)^{9}$ & $0.715(22)$ & $-0.20 \%$ & $-54^{\circ} \mathrm{C}^{9}$ & 67.901 & $0.097 \pm 0.021$ & liquid \\
\hline & & 6000 & & 0.715 (19) & $-0.19 \%$ & & 68.761 & $0.098 \pm 0.015$ & liquid \\
\hline & & 8000 & & $0.715(15)$ & $-0.19 \%$ & & 68.912 & $0.096 \pm 0.013$ & liquid \\
\hline n-decane & $\mathrm{C}_{10} \mathrm{H}_{22}$ & 4000 & $0.726(30)^{10}$ & $0.723(76)$ & $0.35 \%$ & $-30^{\circ} \mathrm{C}^{9}$ & 54.690 & $0.120 \pm 0.020$ & liquid \\
\hline n-undecane & $\mathrm{C}_{11} \mathrm{H}_{24}$ & 3000 & $0.736(55)^{9}$ & $0.736(01)$ & $0.07 \%$ & $-26^{\circ} \mathrm{C}^{9}$ & 50.088 & $0.132 \pm 0.024$ & liquid \\
\hline n-dodecane & $\mathrm{C}_{12} \mathrm{H}_{26}$ & 4000 & $0.745(03)^{10}$ & $0.741(65)$ & $0.45 \%$ & $-10^{\circ} \mathrm{C}^{9}$ & 38.979 & $0.185 \pm 0.025$ & liquid \\
\hline n-tridecane & $\mathrm{C}_{13} \mathrm{H}_{24}$ & 3000 & $0.752(8)^{9}$ & $0.751(08)$ & $0.23 \%$ & $5^{\circ} \mathrm{C}^{9}$ & 36.786 & $0.198 \pm 0.030$ & liquid \\
\hline \multirow[t]{3}{*}{ n-tetradecane } & $\mathrm{C}_{14} \mathrm{H}_{30}$ & 4000 & $0.759(3)^{9}$ & $0.754(98)$ & $0.57 \%$ & $6^{\circ} \mathrm{C}^{9}$ & 28.863 & $0.304 \pm 0.031$ & liquid \\
\hline & & 6000 & & 0.754 (99) & $0.57 \%$ & & 28.910 & $0.300 \pm 0.030$ & liquid \\
\hline & & 8000 & & $0.755(04)$ & $0.56 \%$ & & 28.9637 & $0.302 \pm 0.023$ & liquid \\
\hline \multirow[t]{3}{*}{ n-pentadecane } & $\mathrm{C}_{15} \mathrm{H}_{32}$ & 3000 & $0.765(0)^{9}$ & $0.762(63)$ & $0.31 \%$ & $10^{\circ} \mathrm{C}^{9}$ & 27.992 & $0.324 \pm 0.036$ & liquid \\
\hline & & 6000 & & $0.762(61)$ & $0.31 \%$ & & 28.267 & $0.326 \pm 0.027$ & liquid \\
\hline & & 8000 & & $0.762(69)$ & $0.30 \%$ & & 28.410 & $0.324 \pm 0.028$ & liquid \\
\hline \multirow[t]{3}{*}{ n-hexadecane } & $\mathrm{C}_{16} \mathrm{H}_{34}$ & 4000 & $0.769(82)^{10}$ & $0.765(94)$ & $0.50 \%$ & $18^{\circ} \mathrm{C}^{9}$ & 30.409 & $0.735 \pm 0.077$ & liquid \\
\hline & & 6000 & & $0.765(91)$ & $0.51 \%$ & & 30.414 & $0.849 \pm 0.012$ & liquid \\
\hline & & 8000 & & $0.765(87)$ & $0.51 \%$ & & 31.029 & $0.852 \pm 0.008$ & liquid \\
\hline \multirow[t]{3}{*}{ n-heptadecane } & $\mathrm{C}_{17} \mathrm{H}_{36}$ & 3000 & $0.774(5)^{10}$ & $0.772(16)$ & $0.30 \%$ & $22^{\circ} \mathrm{C}^{9}$ & 30.270 & $0.609 \pm 0.085$ & liquid \\
\hline & & 6000 & & $0.772(22)$ & $0.29 \%$ & & 30.556 & $0.848 \pm 0.009$ & liquid \\
\hline & & 8000 & & $0.772(20)$ & $0.30 \%$ & & 30.552 & $0.598 \pm 0.052$ & liquid \\
\hline \multirow[t]{3}{*}{ n-octadecane } & $\mathrm{C}_{18} \mathrm{H}_{38}$ & 3000 & $0.778(5)^{9 \dagger}$ & $0.773(27)$ & $0.67 \%$ & $28^{\circ} \mathrm{C}^{9}$ & 0.497 & $0.936 \pm 0.005$ & solid \\
\hline & & 6000 & & $0.773(23)$ & $0.68 \%$ & & 0.509 & $0.949 \pm 0.004$ & solid \\
\hline & & 8000 & & $0.773(24)$ & $0.68 \%$ & & 0.751 & $0.870 \pm 0.014$ & solid \\
\hline n-nonadecane & $\mathrm{C}_{19} \mathrm{H}_{40}$ & 3000 & $0.782(1)^{9 \dagger}$ & $0.777(32)$ & $0.61 \%$ & $32^{\circ} \mathrm{C}^{9}$ & 0.554 & $0.954 \pm 0.005$ & solid \\
\hline n-eicosane & $\mathrm{C}_{20} \mathrm{H}_{42}$ & 3000 & $0.785(3)^{9 \dagger}$ & $0.779(38)$ & $0.75 \%$ & $37^{\circ} \mathrm{C}^{9}$ & 0.425 & $0.944 \pm 0.005$ & solid \\
\hline n-heneicosane & $\mathrm{C}_{21} \mathrm{H}_{44}$ & 3000 & $0.788(3)^{9 \dagger}$ & $0.783(53)$ & $0.60 \%$ & $41^{\circ} \mathrm{C}^{9}$ & 0.674 & $0.962 \pm 0.005$ & solid \\
\hline n-docosane & $\mathrm{C}_{22} \mathrm{H}_{46}$ & 3000 & $0.791(0)^{9 \dagger}$ & $0.785(05)$ & $0.75 \%$ & $44^{\circ} \mathrm{C}^{9}$ & 0.582 & $0.918 \pm 0.010$ & solid \\
\hline n-tricosane & $\mathrm{C}_{23} \mathrm{H}_{48}$ & 3000 & $0.793(5)^{9 \dagger}$ & $0.788(26)$ & $0.66 \%$ & $48^{\circ} \mathrm{C}^{9}$ & 0.324 & $0.945 \pm 0.005$ & solid \\
\hline n-tetracosane & $\mathrm{C}_{24} \mathrm{H}_{50}$ & 3000 & $0.795(8)^{9 \dagger}$ & $0.789(54)$ & $0.79 \%$ & $51^{\circ} \mathrm{C}^{9}$ & 0.429 & $0.929 \pm 0.008$ & solid \\
\hline n-pentacosane & $\mathrm{C}_{25} \mathrm{H}_{52}$ & 3000 & $0.797(9)^{9 \dagger}$ & $0.792(78)$ & $0.64 \%$ & $54^{\circ} \mathrm{C}^{9}$ & 0.646 & $0.940 \pm 0.016$ & solid \\
\hline n-hexacosane & $\mathrm{C}_{26} \mathrm{H}_{54}$ & 4000 & $0.799(8)^{9 \dagger}$ & $0.793(50)$ & $0.79 \%$ & $56^{\circ} \mathrm{C}^{9}$ & 0.349 & $0.951 \pm 0.004$ & solid \\
\hline n-octacosane & $\mathrm{C}_{28} \mathrm{H}_{58}$ & 4000 & $0.803(3)^{9 \dagger}$ & $0.797(11)$ & $0.77 \%$ & $62^{\circ} \mathrm{C}^{9}$ & 0.417 & $0.949 \pm 0.004$ & solid \\
\hline n-triacontane & $\mathrm{C}_{30} \mathrm{H}_{62}$ & 4000 & $0.806(4)^{9 \dagger}$ & $0.799(76)$ & $0.82 \%$ & $66^{\circ} \mathrm{C}^{9}$ & 0.379 & $0.964 \pm 0.004$ & solid \\
\hline n-pentatriacontane & $\mathrm{C}_{35} \mathrm{H}_{72}$ & 3000 & $0.812(4)^{9 \dagger}$ & $0.806(97)$ & $0.67 \%$ & $75^{\circ} \mathrm{C}^{9}$ & 0.592 & $0.960 \pm 0.005$ & solid \\
\hline n-tetracontane & $\mathrm{C}_{40} \mathrm{H}_{82}$ & 3000 & $0.817(2)^{9 \dagger}$ & $0.819(81)$ & $-0.32 \%$ & $82^{\circ} \mathrm{C}^{9}$ & 0.545 & $0.956 \pm 0.009$ & solid \\
\hline
\end{tabular}

\footnotetext{
* water is used for the scale conversion between DPD and real units so has no error.
}

$\dagger$ density value is for undercooled liquid. 

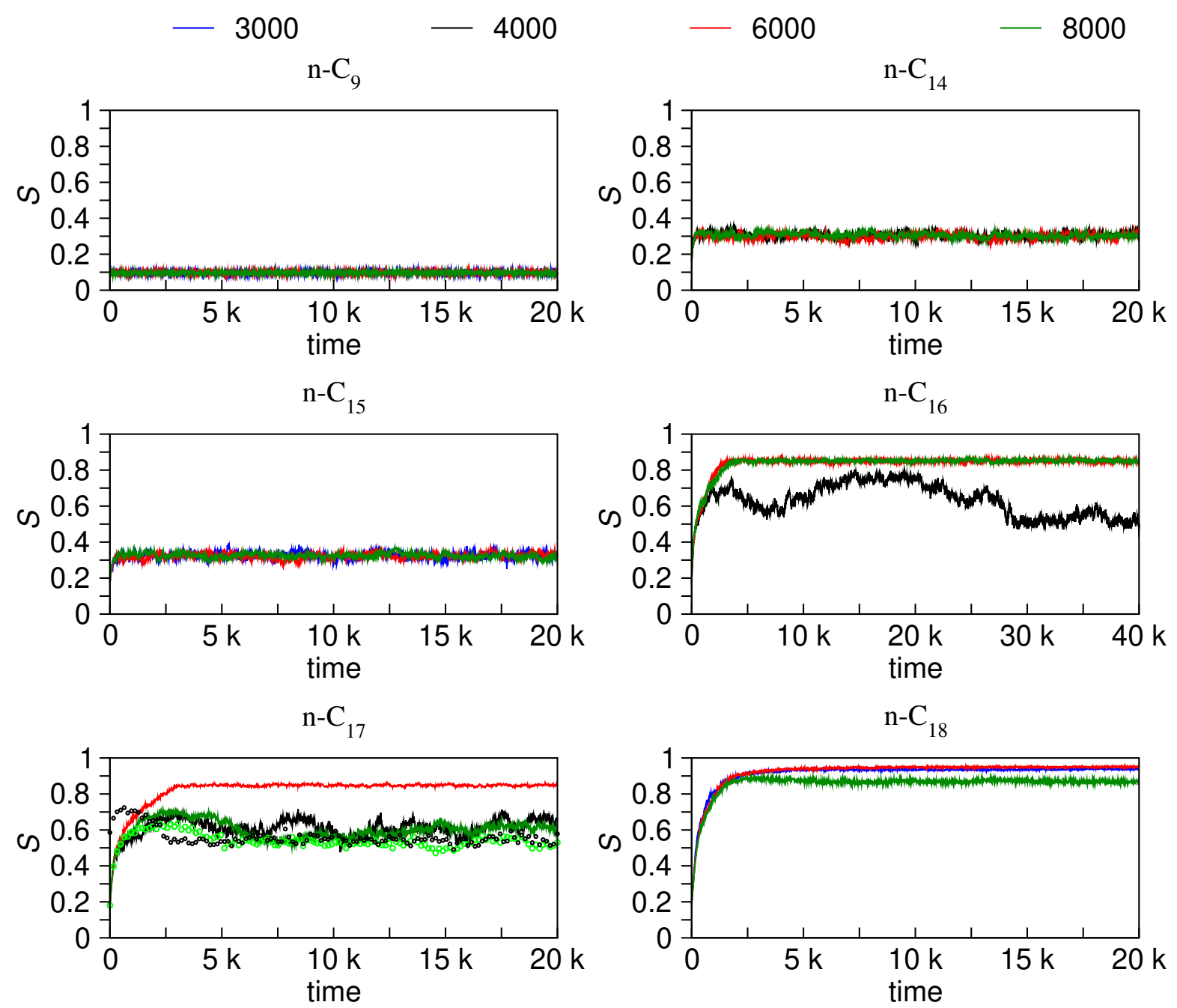

Figure 1 Behaviour of $S$ order parameter with time for pure n-alkanes for different system sizes of 3000, 4000, 6000 and 8000 molecules. 

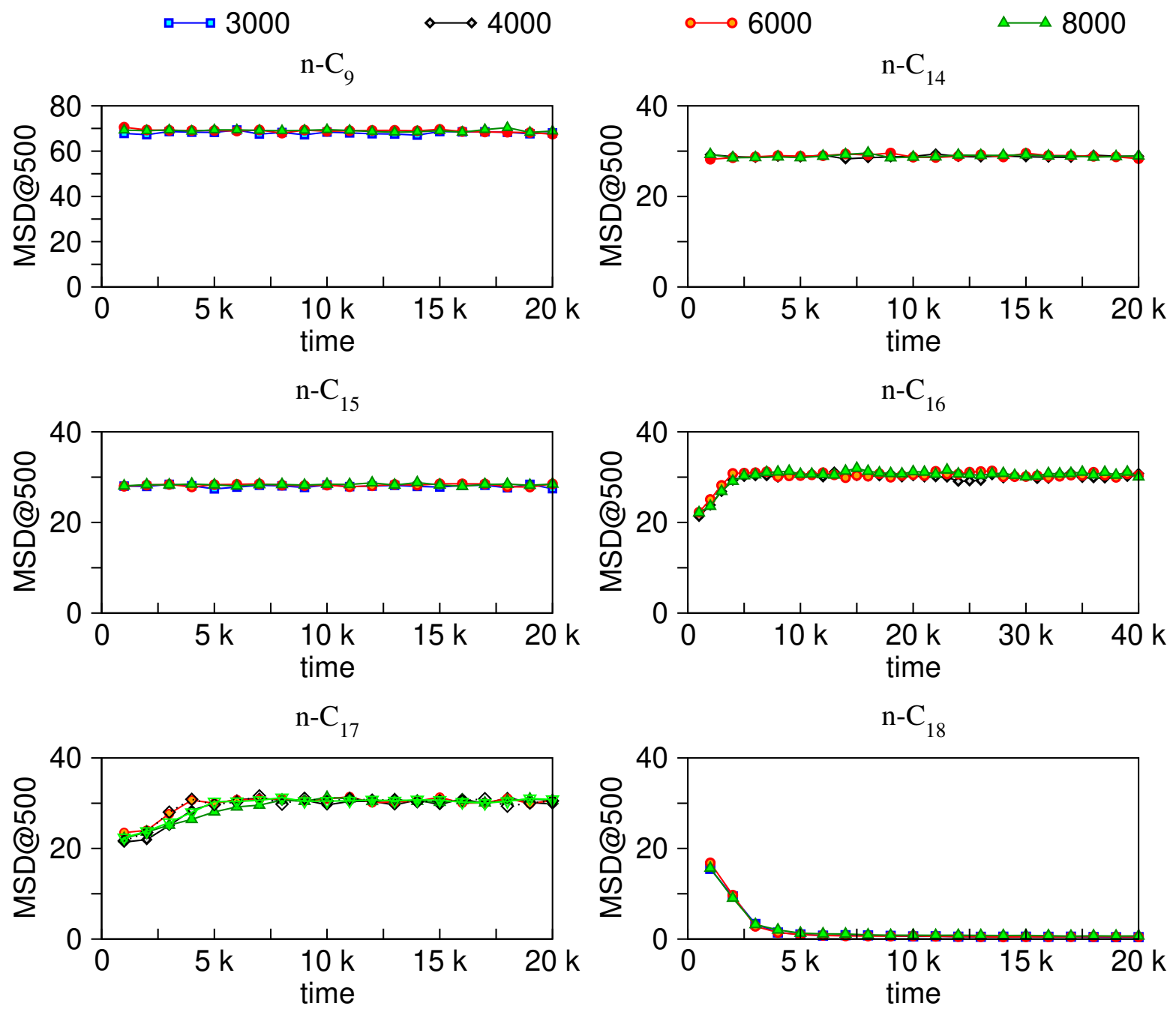

Figure 2 Behaviour of the MSD with time for pure n-alkanes for different system sizes of 3000, 4000, 6000 and 8000 molecules. 

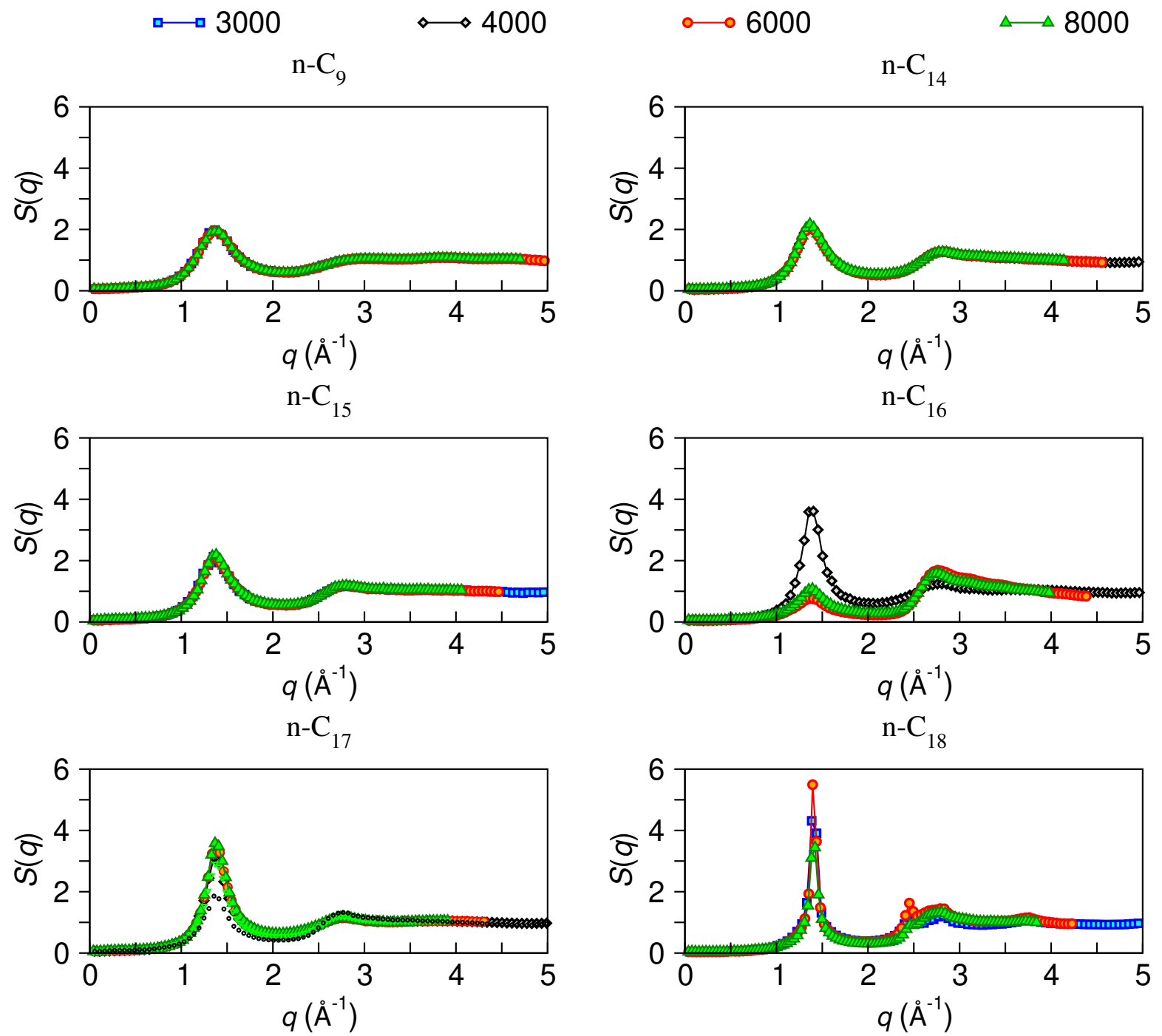

Figure 3 Behaviour of structure factor $S(q)$ for pure n-alkanes for different system sizes of 3000, 4000, 6000 and 8000 molecules. 


\section{F.2 Pure isobutyl-type branched alkanes}

Table 2 gives the raw statistics obtained from the simulations of pure isobutyl-type branched alkane using the methods outlined in the main text. Measurements reported were taken between $10 \times 10^{3}$ and $20 \times 10^{3}$ DPD time units.

Table 2 Comparison between experiment and model densities and state for pure isobutyl-type iso-alkanes. Validation of $\mathrm{CH}$ bead.

\begin{tabular}{|c|c|c|c|c|c|c|c|c|c|}
\hline Molecule & Formula & $\begin{array}{l}\text { Number of } \\
\text { molecules }\end{array}$ & $\begin{array}{l}\text { Exp. density } \\
\left(\mathrm{g} / \mathrm{cm}^{3}\right)\end{array}$ & $\begin{array}{l}\text { Sim. density } \\
\left(\mathrm{g} / \mathrm{cm}^{3}\right)\end{array}$ & rel. error & Exp. $T_{m}$ & $\begin{array}{l}\text { MSD } \\
@ 500\end{array}$ & $S \pm 2 \sigma$ & Sim. state \\
\hline 2-methyl butane & $\mathrm{C}_{5} \mathrm{H}_{12}$ & 7000 & $0.614(62)^{9}$ & $0.618(70)$ & $-0.66 \%$ & $-160^{\circ} \mathrm{C}^{9}$ & 83.118 & $0.043 \pm 0.012$ & liquid \\
\hline 2-methyl pentane & $\mathrm{C}_{6} \mathrm{H}_{14}$ & 7000 & $0.648(52)^{9}$ & 0.651 (99) & $-0.53 \%$ & $-154^{\circ} \mathrm{C}^{9}$ & 78.471 & $0.054 \pm 0.012$ & liquid \\
\hline 2-methyl hexane & $\mathrm{C}_{7} \mathrm{H}_{16}$ & 7000 & $0.674(39)^{9}$ & $0.671(69)$ & $0.40 \%$ & $-118^{\circ} \mathrm{C}^{9}$ & 72.047 & $0.063 \pm 0.012$ & liquid \\
\hline 2-methyl heptane & $\mathrm{C}_{8} \mathrm{H}_{18}$ & 7000 & $0.693(92)^{9}$ & $0.692(52)$ & $0.20 \%$ & $-109^{\circ} \mathrm{C}^{9}$ & 62.243 & $0.072 \pm 0.011$ & liquid \\
\hline 2-methyl octane & $\mathrm{C}_{9} \mathrm{H}_{20}$ & 7000 & $0.709(5)^{9}$ & $0.706(27)$ & $0.46 \%$ & $-80^{\circ} \mathrm{C}^{9}$ & 57.099 & $0.084 \pm 0.012$ & liquid \\
\hline 2-methyl nonane & $\mathrm{C}_{10} \mathrm{H}_{22}$ & 7000 & $0.724(2)^{9}$ & $0.720(94)$ & $0.45 \%$ & $-75^{\circ} \mathrm{C}^{9}$ & 50.660 & $0.090 \pm 0.013$ & liquid \\
\hline 2,3-dimethyl butane & $\mathrm{C}_{6} \mathrm{H}_{14}$ & 7000 & $0.657(02)^{9}$ & $0.629(17)$ & $4.24 \%$ & $-129^{\circ} \mathrm{C}^{9}$ & 60.256 & $0.054 \pm 0.011$ & liquid \\
\hline 2,4-dimethyl pentane & $\mathrm{C}_{7} \mathrm{H}_{16}$ & 7000 & $0.668(32)^{9}$ & $0.648(10)$ & $3.02 \%$ & $-119^{\circ} \mathrm{C}^{9}$ & 57.960 & $0.059 \pm 0.011$ & liquid \\
\hline 2,5-dimethyl hexane & $\mathrm{C}_{8} \mathrm{H}_{18}$ & 7000 & $0.689(34)^{9}$ & $0.673(50)$ & $2.30 \%$ & $-91^{\circ} \mathrm{C}^{9}$ & 54.706 & $0.070 \pm 0.011$ & liquid \\
\hline 2,6-dimethyl heptane & $\mathrm{C}_{9} \mathrm{H}_{20}$ & 7000 & $0.704(9)^{9}$ & $0.697(56)$ & $1.04 \%$ & $-103^{\circ} \mathrm{C}^{9}$ & 47.949 & $0.079 \pm 0.011$ & liquid \\
\hline 2,7-dimethyl octane & $\mathrm{C}_{10} \mathrm{H}_{22}$ & 7000 & $0.720(2)^{9}$ & $0.706(30)$ & $1.93 \%$ & $-54{ }^{\circ} \mathrm{C}^{9}$ & 43.200 & $0.088 \pm 0.012$ & liquid \\
\hline 3-methyl pentane & $\mathrm{C}_{6} \mathrm{H}_{14}$ & 7000 & $0.659(76)^{9}$ & $0.655(36)$ & $0.67 \%$ & $-163^{\circ} \mathrm{C}$ & 79.799 & $0.053 \pm 0.011$ & liquid \\
\hline 3-methyl hexane & $\mathrm{C}_{7} \mathrm{H}_{16}$ & 7000 & $0.682(95)^{9}$ & $0.683(04)$ & $-0.01 \%$ & $-119^{\circ} \mathrm{C}$ & 74.427 & $0.060 \pm 0.011$ & liquid \\
\hline 3-methyl heptane & $\mathrm{C}_{8} \mathrm{H}_{18}$ & 7000 & $0.701(75)^{9}$ & $0.695(42)$ & $0.90 \%$ & $-120^{\circ} \mathrm{C}^{9}$ & 68.255 & $0.069 \pm 0.011$ & liquid \\
\hline 4-methyl heptane & $\mathrm{C}_{8} \mathrm{H}_{18}$ & 7000 & $0.700(55)^{9}$ & $0.706(60)$ & $-0.86 \%$ & $-121^{\circ} \mathrm{C}^{9}$ & 68.711 & $0.065 \pm 0.012$ & liquid \\
\hline 3-methyl octane & $\mathrm{C}_{9} \mathrm{H}_{20}$ & 7000 & $0.716(8)^{9}$ & $0.713(33)$ & $0.48 \%$ & $-108^{\circ} \mathrm{C}^{9}$ & 60.561 & $0.077 \pm 0.012$ & liquid \\
\hline 4-methyl octane & $\mathrm{C}_{9} \mathrm{H}_{20}$ & 7000 & $0.716(0)^{9}$ & $0.714(89)$ & $0.16 \%$ & $-113^{\circ} \mathrm{C}^{9}$ & 62.854 & $0.074 \pm 0.011$ & liquid \\
\hline 3-methyl nonane & $\mathrm{C}_{10} \mathrm{H}_{22}$ & 7000 & $0.729(6)^{9}$ & $0.723(40)$ & $0.85 \%$ & $-85^{\circ} \mathrm{C}^{9}$ & 54.610 & $0.087 \pm 0.012$ & liquid \\
\hline 4-methyl nonane & $\mathrm{C}_{10} \mathrm{H}_{22}$ & 7000 & $0.728(4)^{9}$ & $0.730(59)$ & $-0.30 \%$ & $-99^{\circ} \mathrm{C}^{9}$ & 56.409 & $0.080 \pm 0.012$ & liquid \\
\hline 5-methyl nonane & $\mathrm{C}_{10} \mathrm{H}_{22}$ & 7000 & $0.728(8)^{9}$ & $0.722(16)$ & $0.91 \%$ & $-88^{\circ} \mathrm{C}^{9}$ & 58.064 & $0.081 \pm 0.012$ & liquid \\
\hline $\begin{array}{l}\text { 2,6,10,14-tetramethyl } \\
\text {-pentadecane }\end{array}$ & $\mathrm{C}_{19} \mathrm{H}_{40}$ & 7000 & $0.779(11)^{11}$ & $0.780(99)$ & $-0.24 \%$ & $-100^{\circ} \mathrm{C}$ & 22.071 & $0.122 \pm 0.012$ & liquid \\
\hline $\begin{array}{l}\text { 2,6,10,15,19,23-hexa } \\
\text {-methyltetracosane }\end{array}$ & $\mathrm{C}_{30} \mathrm{H}_{62}$ & 7000 & $0.805(13)^{11}$ & $0.808(89)$ & $-0.47 \%$ & $-38^{\circ} \mathrm{C}$ & 14.604 & $0.189 \pm 0.012$ & liquid \\
\hline 2-methyl eicosane & $\mathrm{C}_{21} \mathrm{H}_{44}$ & 3000 & N/A & $0.778(49)$ & N/A & N/A & 1.297 & $0.949 \pm 0.011$ & solid \\
\hline 3-methyl eicosane & $\mathrm{C}_{21} \mathrm{H}_{44}$ & 3000 & N/A & $0.786(28)$ & N/A & N/A & 15.286 & $0.432 \pm 0.041$ & liquid \\
\hline 10-methyl eicosane & $\mathrm{C}_{21} \mathrm{H}_{44}$ & 3000 & N/A & $0.786(48)$ & N/A & N/A & 19.543 & $0.167 \pm 0.019$ & liquid \\
\hline $\begin{array}{l}\text { 2-methyl } \\
\text { pentatriacontane }\end{array}$ & $\mathrm{C}_{36} \mathrm{H}_{72}$ & 3000 & N/A & $0.806(05)$ & N/A & N/A & 0.848 & $0.952 \pm 0.009$ & solid \\
\hline $\begin{array}{l}\text { 4-methyl } \\
\text { pentatriacontane }\end{array}$ & $\mathrm{C}_{36} \mathrm{H}_{72}$ & 3000 & N/A & $0.810(57)$ & N/A & N/A & 1.248 & $0.941 \pm 0.012$ & solid \\
\hline $\begin{array}{l}\text { 10-methyl } \\
\text { pentatriacontane }\end{array}$ & $\mathrm{C}_{36} \mathrm{H}_{72}$ & 3000 & N/A & $0.788(965)$ & N/A & N/A & 2.327 & $0.906 \pm 0.012$ & liquid \\
\hline $\begin{array}{l}\text { 14-methyl } \\
\text { pentatriacontane }\end{array}$ & $\mathrm{C}_{36} \mathrm{H}_{72}$ & 3000 & N/A & $0.813(39)$ & N/A & N/A & 10.288 & $0.901 \pm 0.0064$ & liquid \\
\hline $\begin{array}{l}\text { 16-methyl } \\
\text { pentatriacontane }\end{array}$ & $\mathrm{C}_{36} \mathrm{H}_{72}$ & 3000 & N/A & $0.813(81)$ & N/A & N/A & 10.982 & $0.708 \pm 0.023$ & liquid \\
\hline $\begin{array}{l}\text { 17-methyl } \\
\text { pentatriacontane }\end{array}$ & $\mathrm{C}_{36} \mathrm{H}_{72}$ & 3000 & N/A & $0.814(05)$ & N/A & N/A & 11.674 & $0.897 \pm 0.017$ & liquid \\
\hline
\end{tabular}




\section{F.3 Pure neopentyl-type branched alkanes}

Table 3 gives the raw statistics obtained from the simulations of pure neopentyl-type branched alkane using the methods outlined in the main text. Measurements reported were taken between $10 \times 10^{3}$ and $20 \times 10^{3}$ DPD time units.

Table 3 Comparison between experiment and model densities and state for pure neopentyl-type iso-alkanes. Validation of $\mathrm{C}$ bead.

\begin{tabular}{|c|c|c|c|c|c|c|c|c|c|}
\hline Molecule & Formula & $\begin{array}{l}\text { Number of } \\
\text { molecules }\end{array}$ & $\begin{array}{l}\text { Exp. density } \\
\left(\mathrm{g} / \mathrm{cm}^{3}\right)\end{array}$ & $\begin{array}{l}\text { Sim. density } \\
\left(\mathrm{g} / \mathrm{cm}^{3}\right)\end{array}$ & rel. error & Exp. $T_{m}$ & $\begin{array}{l}\text { MSD } \\
@ 500\end{array}$ & $S \pm 2 \sigma$ & Sim. state \\
\hline 2,2-dimethyl butane & $\mathrm{C}_{6} \mathrm{H}_{14}$ & 7000 & $0.644(46)^{9}$ & $0.620(31)$ & $3.75 \%$ & $-100^{\circ} \mathrm{C}^{9}$ & 65.286 & $0.053 \pm 0.011$ & liquid \\
\hline 2,2-dimethyl pentane & $\mathrm{C}_{7} \mathrm{H}_{16}$ & 7000 & $0.669(53)^{9}$ & $0.659(76)$ & $1.46 \%$ & $-124^{\circ} \mathrm{C}^{9}$ & 57.960 & $0.059 \pm 0.011$ & liquid \\
\hline 3,3-dimethyl pentane & $\mathrm{C}_{7} \mathrm{H}_{16}$ & 7000 & $0.689(09)^{9}$ & $0.670(56)$ & $2.69 \%$ & $-134{ }^{\circ} \mathrm{C}^{9}$ & 51.759 & $0.058 \pm 0.011$ & liquid \\
\hline 2,2-dimethyl hexane & $\mathrm{C}_{8} \mathrm{H}_{18}$ & 7000 & $0.691(12)^{9}$ & $0.672(43)$ & $2.70 \%$ & $-121^{\circ} \mathrm{C}^{9}$ & 54.706 & $0.070 \pm 0.011$ & liquid \\
\hline 3,3-dimethyl hexane & $\mathrm{C}_{8} \mathrm{H}_{18}$ & 7000 & $0.705(96)^{9}$ & $0.689(15)$ & $2.38 \%$ & $-126^{\circ} \mathrm{C}^{9}$ & 54.188 & $0.065 \pm 0.011$ & liquid \\
\hline 2,2-dimethyl heptane & $\mathrm{C}_{9} \mathrm{H}_{20}$ & 7000 & $0.706(6)^{9}$ & $0.689(31)$ & $2.45 \%$ & $-113^{\circ} \mathrm{C}^{9}$ & 47.949 & $0.079 \pm 0.011$ & liquid \\
\hline 3,3-dimethyl heptane & $\mathrm{C}_{9} \mathrm{H}_{18}$ & 7000 & $0.721^{9}$ & $0.697(39)$ & $3.28 \%$ & $-126^{\circ} \mathrm{C}^{9}$ & 51.612 & $0.075 \pm 0.012$ & liquid \\
\hline 4,4-dimethyl heptane & $\mathrm{C}_{9} \mathrm{H}_{18}$ & 7000 & $0.721^{9}$ & $0.705(26)$ & $2.18 \%$ & N/A & 54.026 & $0.070 \pm 0.012$ & liquid \\
\hline 2,2-dimethyl octane & $\mathrm{C}_{10} \mathrm{H}_{22}$ & 7000 & $0.72(08)^{9}$ & $0.700(97)$ & $2.75 \%$ & N/A & 43.200 & $0.088 \pm 0.012$ & liquid \\
\hline 3,3-dimethyl octane & $\mathrm{C}_{10} \mathrm{H}_{22}$ & 7000 & $0.735(1)^{9}$ & $0.712(06)$ & $3.13 \%$ & N/A & 45.592 & $0.082 \pm 0.012$ & liquid \\
\hline 4,4-dimethyl octane & $\mathrm{C}_{10} \mathrm{H}_{22}$ & 7000 & $0.733^{9}$ & $0.710(61)$ & $3.05 \%$ & N/A & 50.464 & $0.078 \pm 0.011$ & liquid \\
\hline $\begin{array}{l}\text { 2,2,4-trimethyl } \\
\text {-pentane }\end{array}$ & $\mathrm{C}_{8} \mathrm{H}_{18}$ & 7000 & $0.687(78)^{11}$ & $0.659(71)$ & $4.08 \%$ & N/A & 41.844 & $0.067 \pm 0.011$ & liquid \\
\hline $\begin{array}{r}2,2,4,4,6,8,8 \text {-hepta } \\
\text {-methylnonane }\end{array}$ & $\mathrm{C}_{16} \mathrm{H}_{34}$ & 7000 & $0.781(23)^{11}$ & $0.729(89)$ & $6.57 \%$ & N/A & 16.107 & $0.113 \pm 0.011$ & liquid \\
\hline
\end{tabular}




\section{F.4 Miscible Liquids}

Tables 4, 5 and 6 give the raw statistics obtained from the simulations of binary mixtures of alkanes that form miscible liquids using the methods outlined in the main text. Measurements reported were taken between $10 \times 10^{3}$ and $20 \times 10^{3}$ DPD time units. 
Table 4 Comparison between experimental and model densities of miscible mixtures.

Experimental data from Aucejo et al. ${ }^{10}$ All simulations contain 4000 molecules.

\begin{tabular}{|c|c|c|c|}
\hline$x_{1}$ & $\begin{array}{l}\text { Exp. Density } \\
\left(\mathrm{g} / \mathrm{cm}^{3}\right)\end{array}$ & $\begin{array}{l}\text { Sim. density } \\
\left(\mathrm{g} / \mathrm{cm}^{3}\right)\end{array}$ & rel. error \\
\hline \multicolumn{4}{|c|}{$n$-heptane (1) $+n$-undecane (2) } \\
\hline 0.0000 & $0.736(30)$ & 0.735 (92) & $0.05 \%$ \\
\hline 0.1084 & $0.732(06)$ & $0.732(00)$ & $0.01 \%$ \\
\hline 0.2093 & $0.727(80)$ & $0.728(09)$ & $-0.04 \%$ \\
\hline 0.3019 & $0.723(60)$ & $0.724(30)$ & $-0.10 \%$ \\
\hline 0.4051 & $0.718(57)$ & $0.719(68)$ & $-0.15 \%$ \\
\hline 0.5067 & $0.713(21)$ & $0.714(86)$ & $-0.23 \%$ \\
\hline 0.6076 & 0.707 (43) & 0.709 (70) & $-0.32 \%$ \\
\hline 0.7041 & $0.701(44)$ & $0.704(40)$ & $-0.42 \%$ \\
\hline 0.8052 & $0.694(61)$ & $0.698(36)$ & $-0.54 \%$ \\
\hline 0.8998 & 0.687 (63) & $0.692(09)$ & $-0.65 \%$ \\
\hline 1.0000 & $0.679(54)$ & 0.685 (11) & $-0.82 \%$ \\
\hline \multicolumn{4}{|c|}{$n$-hexane $(1)+n$-hexadecane $(2)$} \\
\hline 0.0000 & $0.769(81)$ & 0.765 (94) & $0.50 \%$ \\
\hline 0.1046 & $0.764(83)$ & $0.760(53)$ & $0.56 \%$ \\
\hline 0.1966 & $0.759(51)$ & $0.755(20)$ & $0.57 \%$ \\
\hline 0.3000 & $0.752(67)$ & $0.748(72)$ & $0.53 \%$ \\
\hline 0.4037 & $0.744(87)$ & $0.741(26)$ & $0.48 \%$ \\
\hline 0.5142 & $0.735(22)$ & $0.732(12)$ & $0.42 \%$ \\
\hline 0.6072 & $0.725(62)$ & $0.723(06)$ & $0.35 \%$ \\
\hline 0.7062 & $0.713(30)$ & $0.711(66)$ & $0.23 \%$ \\
\hline 0.8048 & 0.698 (10) & 0.698 (11) & $0.00 \%$ \\
\hline 0.9026 & 0.679 (18) & $0.681(74)$ & $-0.38 \%$ \\
\hline 1.0000 & $0.655(07)$ & $0.661(36)$ & $-0.96 \%$ \\
\hline \multicolumn{4}{|c|}{$n$-dodecane (1) $+n$-hexadecane (2) } \\
\hline 0.0000 & $0.769(81)$ & $0.765(94)$ & $0.50 \%$ \\
\hline 0.1077 & $0.767(72)$ & $0.763(72)$ & $0.52 \%$ \\
\hline 0.2213 & $0.765(59)$ & $0.761(36)$ & $0.55 \%$ \\
\hline 0.3061 & $0.763(59)$ & $0.759(35)$ & $0.55 \%$ \\
\hline 0.4097 & $0.761(22)$ & $0.757(06)$ & $0.55 \%$ \\
\hline 0.5073 & $0.758(89)$ & $0.754(80)$ & $0.54 \%$ \\
\hline 0.6082 & $0.756(37)$ & $0.752(38)$ & $0.53 \%$ \\
\hline 0.7053 & $0.753(80)$ & $0.749(94)$ & $0.51 \%$ \\
\hline 0.8045 & $0.751(02)$ & $0.747(24)$ & $0.50 \%$ \\
\hline 0.9050 & $0.748(03)$ & $0.744(45)$ & $0.48 \%$ \\
\hline 1.0000 & $0.745(03)$ & $0.741(65)$ & $0.45 \%$ \\
\hline
\end{tabular}


Table 5 Comparison between experimental and model densities of miscible mixtures.

Experimental data from Aucejo et al. ${ }^{12}$ All simulations contain 4000 molecules.

\begin{tabular}{llll}
$x_{1}$ & $\begin{array}{l}\text { Exp. Density } \\
\left(\mathrm{g} / \mathrm{cm}^{3}\right)\end{array}$ & $\begin{array}{l}\text { Sim. density } \\
\left(\mathrm{g} / \mathrm{cm}^{3}\right)\end{array}$ & rel. error \\
\hline \multicolumn{4}{c}{$n$-dodecane $(1)+2$-methyl pentane $(2)$} \\
0.0000 & $0.648(54)$ & $0.651(97)$ & $-0.53 \%$ \\
0.0997 & $0.665(51)$ & $0.667(74)$ & $-0.33 \%$ \\
0.1998 & $0.680(02)$ & $0.681(19)$ & $-0.17 \%$ \\
0.3004 & $0.692(26)$ & $0.692(84)$ & $-0.08 \%$ \\
0.3998 & $0.702(80)$ & $0.702(58)$ & $0.03 \%$ \\
0.4992 & $0.712(00)$ & $0.711(19)$ & $0.11 \%$ \\
0.5973 & $0.720(12)$ & $0.718(66)$ & $0.20 \%$ \\
0.6982 & $0.727(52)$ & $0.725(40)$ & $0.29 \%$ \\
0.7993 & $0.734(18)$ & $0.731(41)$ & $0.38 \%$ \\
0.8996 & $0.740(10)$ & $0.736(76)$ & $0.45 \%$ \\
1.0000 & $0.745(03)$ & $0.741(65)$ & $0.45 \%$ \\
\hline$n-h e x a d e c a n e(1)+2,2-$ dimethyl butane $(2)$ \\
0.0000 & $0.644(65)$ & $0.620(33)$ & $3.77 \%$ \\
0.0986 & $0.671(53)$ & $0.647(49)$ & $3.58 \%$ \\
0.1978 & $0.692(54)$ & $0.669(89)$ & $3.27 \%$ \\
0.2952 & $0.708(85)$ & $0.688(28)$ & $2.90 \%$ \\
0.3943 & $0.722(21)$ & $0.704(15)$ & $2.50 \%$ \\
0.4987 & $0.733(79)$ & $0.718(45)$ & $2.09 \%$ \\
0.5986 & $0.743(20)$ & $0.730(02)$ & $1.75 \%$ \\
0.6892 & $0.750(70)$ & $0.739(69)$ & $1.47 \%$ \\
0.7902 & $0.758(10)$ & $0.749(07)$ & $1.19 \%$ \\
0.8893 & $0.764(34)$ & $0.757(56)$ & $0.89 \%$ \\
1.0000 & $0.769(81)$ & $0.765(91)$ & $0.51 \%$ \\
\hline
\end{tabular}


Table 6 Comparison between experimental and model densities of miscible mixtures.

Experimental data from Fermeglia and Torriano ${ }^{11}$ All simulations contain 4000 molecules.

\begin{tabular}{cllr}
\hline$x_{1}$ & $\begin{array}{l}\text { Exp. Density } \\
\left(\mathrm{g} / \mathrm{cm}^{3}\right)\end{array}$ & $\begin{array}{l}\text { Sim. density } \\
\left(\mathrm{g} / \mathrm{cm}^{3}\right)\end{array}$ & rel. error \\
\hline n-hexadecane $(1)+$ & $2,6,10,15,19,23$-hexamethyl tetracosane $(2)$ \\
0.0000 & $0.805(13)$ & $0.808(59)$ & $-0.43 \%$ \\
0.0869 & $0.803(34)$ & $0.806(96)$ & $-0.45 \%$ \\
0.1871 & $0.801(09)$ & $0.804(83)$ & $-0.47 \%$ \\
0.2723 & $0.798(99)$ & $0.802(71)$ & $-0.47 \%$ \\
0.3912 & $0.795(75)$ & $0.799(28)$ & $-0.44 \%$ \\
0.4905 & $0.792(73)$ & $0.795(77)$ & $-0.38 \%$ \\
0.5924 & $0.789(26)$ & $0.791(59)$ & $-0.30 \%$ \\
0.6885 & $0.785(59)$ & $0.786(96)$ & $-0.17 \%$ \\
0.7942 & $0.781(02)$ & $0.780(83)$ & $0.02 \%$ \\
0.8969 & $0.775(93)$ & $0.773(78)$ & $0.28 \%$ \\
1.0000 & $0.770(08)$ & $0.765(91)$ & $0.54 \%$ \\
\hline$n$-hexadecane $(1)+$ & $2,2,4,4,6,8,8-h e p t a m e t h y l$ nonane & $(2)$ \\
0.0000 & $0.781(23)$ & $0.730(00)$ & $6.56 \%$ \\
0.0810 & $0.780(20)$ & $0.732(76)$ & $6.08 \%$ \\
0.2005 & $0.778(75)$ & $0.736(83)$ & $5.38 \%$ \\
0.2928 & $0.777(66)$ & $0.739(99)$ & $4.84 \%$ \\
0.3879 & $0.776(55)$ & $0.743(28)$ & $4.28 \%$ \\
0.4892 & $0.775(40)$ & $0.746(82)$ & $3.69 \%$ \\
0.6130 & $0.774(04)$ & $0.751(22)$ & $2.95 \%$ \\
0.7028 & $0.773(07)$ & $0.754(45)$ & $2.41 \%$ \\
0.8099 & $0.771(95)$ & $0.758(31)$ & $1.77 \%$ \\
0.9145 & $0.770(89)$ & $0.762(41)$ & $1.10 \%$ \\
1.0000 & $0.770(08)$ & $0.765(91)$ & $0.54 \%$ \\
\hline & & &
\end{tabular}




\section{F.5 Solubility of long alkanes in solvent alkane n-heptane}

Table 7 Computed solubility data for mixtures of the solvent and paraffin n-alkane $n$-heptane $(1)+$ n-tricosane (2).

The left-hand of the table gives the data for systems which were initially arranged randomly with $4000,8000(*)$ or 12000 molecules $(* *)$. The right-hand of the table gives the data for systems of $\sim 72000$ beads where n-heptane and n-tricosane were initially arranged fully segregated. See

\begin{tabular}{|c|c|c|c|c|c|c|c|c|}
\hline \multirow[b]{2}{*}{$x_{2}$} & \multicolumn{4}{|c|}{ Random } & \multicolumn{4}{|c|}{ Fully segregated } \\
\hline & $\begin{array}{l}\text { Sim. density } \\
\left(\mathrm{g} / \mathrm{cm}^{3}\right)\end{array}$ & $\begin{array}{l}\operatorname{MSD}_{(2)} \\
@ 500\end{array}$ & $S_{(2)} \pm 2 \sigma$ & $\begin{array}{l}\text { Sim. state } \\
\text { of (2) }\end{array}$ & $\begin{array}{l}\text { Sim. density } \\
\left(\mathrm{g} / \mathrm{cm}^{3}\right)\end{array}$ & $\begin{array}{l}\operatorname{MSD}_{(2)} \\
\text { @ } 500\end{array}$ & $S_{(2)} \pm 2 \sigma$ & $\begin{array}{l}\text { Sim. state } \\
\text { of (2) }\end{array}$ \\
\hline 0.0125 & $0.688(69)$ & 60.156 & $0.872 \pm 0.118$ & liquid & $0.688(69)$ & 61.963 & $0.869 \pm 0.056$ & liquid \\
\hline 0.025 & $0.692(12)$ & 55.960 & $0.772 \pm 0.099$ & liquid & $0.692(16)$ & 60.211 & $0.768 \pm 0.051$ & liquid \\
\hline 0.05 & $0.698(63)$ & 53.462 & $0.639 \pm 0.077$ & liquid & $0.698(63)$ & 56.986 & $0.638 \pm 0.022$ & liquid \\
\hline$*$ & $0.698(64)$ & 55.544 & $0.640 \pm 0.054$ & liquid & & & & \\
\hline$* *$ & $0.698(63)$ & 55.208 & $0.644 \pm 0.045$ & liquid & & & & \\
\hline 0.075 & $0.704(65)$ & 51.020 & $0.563 \pm 0.063$ & liquid & $0.704(59)$ & 53.275 & $0.563 \pm 0.018$ & liquid \\
\hline$*$ & $0.704(60)$ & 51.834 & $0.563 \pm 0.043$ & liquid & & & & \\
\hline$* *$ & $0.704(59)$ & 52.084 & $0.564 \pm 0.035$ & liquid & & & & \\
\hline 0.1 & $0.710(13)$ & 47.758 & $0.517 \pm 0.058$ & liquid & $0.710(09)$ & 49.928 & $0.513 \pm 0.032$ & liquid \\
\hline$*$ & $0.710(09)$ & 48.792 & $0.511 \pm 0.020$ & liquid & & & & \\
\hline$* *$ & $0.710(10)$ & 49.059 & $0.517 \pm 0.034$ & liquid & & & & \\
\hline 0.125 & $0.715(18)$ & 45.803 & $0.484 \pm 0.057$ & liquid & $0.715(18)$ & 47.324 & $0.484 \pm 0.030$ & liquid \\
\hline 0.15 & $0.719(92)$ & 43.134 & $0.472 \pm 0.053$ & liquid & $0.719(74)$ & 35.110 & $0.626 \pm 0.025$ & liquid+solid \\
\hline 0.175 & $0.724(28)$ & 40.848 & $0.469 \pm 0.048$ & liquid & $0.724(12)$ & 30.035 & $0.630 \pm 0.040$ & liquid+solid \\
\hline 0.1875 & $0.726(39)$ & 39.632 & $0.468 \pm 0.045$ & liquid & $0.726(17)$ & 27.223 & $0.702 \pm 0.021$ & liquid+solid \\
\hline 0.2 & $0.728(36)$ & 38.304 & $0.470 \pm 0.047$ & liquid & $0.728(17)$ & 27.237 & $0.646 \pm 0.014$ & liquid+solid \\
\hline 0.225 & $0.732(22)$ & 36.167 & $0.487 \pm 0.055$ & liquid & $0.731(88)$ & 22.696 & $0.736 \pm 0.019$ & liquid+solid \\
\hline$*$ & $0.732(30)$ & 36.570 & $0.485 \pm 0.036$ & liquid & & & & \\
\hline 0.25 & $0.735(46)$ & 20.032 & $0.746 \pm 0.034$ & liquid+platelet & $0.735(10)$ & 12.911 & $0.880 \pm 0.016$ & liquid+solid \\
\hline$*$ & $0.735(84)$ & 34.125 & $0.520 \pm 0.033$ & liquid & & & & \\
\hline 0.275 & $0.739(59)$ & 15.112 & $0.789 \pm 0.060$ & liquid+platelet & $0.738(73)$ & 16.259 & $0.816 \pm 0.017$ & liquid+solid \\
\hline$*$ & $0.738(66)$ & 17.117 & $0.779 \pm 0.017$ & liquid + platelet & & & & \\
\hline 0.3 & $0.741(80)$ & 13.249 & $0.827 \pm 0.021$ & liquid+platelet & $0.741(87)$ & 16.470 & $0.787 \pm 0.016$ & liquid+solid \\
\hline$*$ & $0.741(76)$ & 13.399 & $0.834 \pm 0.017$ & liquid+platelet & & & & \\
\hline 0.325 & $0.744(61)$ & 13.778 & $0.807 \pm 0.021$ & liquid+platelet & $0.744(83)$ & 14.064 & $0.820 \pm 0.014$ & liquid+solid \\
\hline$*$ & $0.744(58)$ & 10.478 & $0.869 \pm 0.015$ & liquid+platelet & & & & \\
\hline 0.375 & $0.750(12)$ & 5.648 & $0.937 \pm 0.019$ & liquid+solid & $0.750(20)$ & 9.443 & $0.875 \pm 0.015$ & liquid+solid \\
\hline 0.45 & $0.756(98)$ & 5.645 & $0.920 \pm 0.017$ & liquid+solid & $0.757(28)$ & 6.809 & $0.911 \pm 0.009$ & liquid+solid \\
\hline 0.5 & $0.761(45)$ & 4.457 & $0.932 \pm 0.011$ & liquid+solid & $0.761(38)$ & 5.068 & $0.924 \pm 0.010$ & liquid+solid \\
\hline 0.625 & $0.769(91)$ & 1.600 & $0.984 \pm 0.003$ & liquid+solid & $0.770(30)$ & 2.519 & $0.950 \pm 0.007$ & liquid+solid \\
\hline 0.75 & $0.777(53)$ & 1.485 & $0.960 \pm 0.004$ & liquid+solid & 0.777 (77) & 1.849 & $0.953 \pm 0.008$ & liquid+solid \\
\hline 0.833 & $0.781(79)$ & 0.928 & $0.970 \pm 0.006$ & liquid+solid & & & & \\
\hline 0.875 & $0.783(48)$ & 0.933 & $0.975 \pm 0.003$ & liquid+solid & $0.783(32)$ & 0.913 & $0.959 \pm 0.009$ & liquid+solid \\
\hline 1 & $0.788(23)$ & 0.272 & $0.947 \pm 0.004$ & liquid+solid & & & & \\
\hline
\end{tabular}

Tables 7 and 8 give the raw statistics obtained from the simulations of long alkane $\left(n-C_{23}\right.$ and $\mathrm{n}-\mathrm{C}_{28}$ ) in solvent $\mathrm{n}$-heptane using the methods outlined in the main text. Measurements reported were taken between $50 \times 10^{3}$ and $60 \times 10^{3}$ DPD time units.

Figure 4 demonstrates the degree of stability of the result with respect to time and system size (of the random start models) for the order parameter $S_{(2)}$ and $\operatorname{MSD}_{(2)}$ of the mixture of n-heptane and n-tricosane at three mole concentrations $x_{2}$ of $0.1,0.25$ and 0.275 . For $x_{2}=0.1$ all simulations converge to the same behaviour and the final state is liquid. When $x_{2}=0.275$ all simulations again converge to the same behaviour and the final state is liquid + solid. Note, as it is a mixture of liquid 
Table 8 Computed solubility data for mixtures of the solvent and paraffin n-alkane $n$-heptane $(1)+$ n-octacosane (2).

The left-hand of the table gives the data for systems which were initially arranged randomly with $4000,8000(*)$ or 12000 molecules $(* *)$. The right-hand of the table gives the data for systems of $\sim 72000$ beads where $n$-heptane and n-tricosane were initially arranged fully segregated. See

\begin{tabular}{|c|c|c|c|c|c|c|c|c|}
\hline \multirow[b]{2}{*}{$x_{2}$} & \multicolumn{4}{|c|}{ Random } & \multicolumn{4}{|c|}{ Fully segregated } \\
\hline & $\begin{array}{l}\text { Sim. density } \\
\left(\mathrm{g} / \mathrm{cm}^{3}\right)\end{array}$ & $\begin{array}{l}\operatorname{MSD}_{(2)} \\
@ 500\end{array}$ & $S_{(2)} \pm 2 \sigma$ & $\begin{array}{l}\text { Sim. state } \\
\text { of (2) }\end{array}$ & $\begin{array}{l}\text { Sim. density } \\
\left(\mathrm{g} / \mathrm{cm}^{3}\right)\end{array}$ & $\begin{array}{l}\operatorname{MSD}_{(2)} \\
@ 500\end{array}$ & $S_{(2)} \pm 2 \sigma$ & $\begin{array}{l}\text { Sim. state } \\
\text { of (2) }\end{array}$ \\
\hline 0.0125 & $0.680(79)$ & 57.186 & $0.874 \pm 0.054$ & liquid & $0.689(76)$ & 59.232 & $0.871 \pm 0.057$ & liquid \\
\hline 0.01875 & $0.691(98)$ & 54.910 & $0.825 \pm 0.095$ & liquid & $0.691(95)$ & 58.033 & $0.817 \pm 0.052$ & liquid \\
\hline 0.025 & $0.694(20)$ & 54.265 & $0.783 \pm 0.095$ & liquid & $0.694(12)$ & 57.658 & $0.783 \pm 0.051$ & liquid \\
\hline 0.03125 & $0.696(24)$ & 54.346 & $0.744 \pm 0.082$ & liquid & $0.696(63)$ & 55.192 & $0.740 \pm 0.046$ & liquid \\
\hline$*$ & $0.696(21)$ & 53.806 & $0.742 \pm 0.060$ & liquid & & & & \\
\hline$* *$ & $0.696(28)$ & 54.396 & $0.746 \pm 0.050$ & liquid & & & & \\
\hline 0.0375 & $0.698(34)$ & 51.523 & $0.707 \pm 0.079$ & liquid & $0.698(17)$ & 30.093 & $0.868 \pm 0.065$ & liquid+solid \\
\hline$*$ & $0.698(26)$ & 51.849 & $0.710 \pm 0.056$ & liquid & & & & \\
\hline$* *$ & $0.698(29)$ & 52.968 & $0.713 \pm 0.048$ & liquid & & & & \\
\hline 0.05 & $0.702(31)$ & 50.170 & $0.667 \pm 0.079$ & liquid & $0.701(94)$ & 18.741 & $0.874 \pm 0.055$ & liquid+solid \\
\hline$*$ & $0.702(20)$ & 49.570 & $0.663 \pm 0.025$ & liquid & & & & \\
\hline$* *$ & $0.702(26)$ & 49.785 & $0.667 \pm 0.044$ & liquid & & & & \\
\hline 0.0625 & $0.706(00)$ & 47.433 & $0.630 \pm 0.079$ & liquid & $0.705(68)$ & 22.065 & $0.914 \pm 0.027$ & liquid+solid \\
\hline * & $0.705(92)$ & 47.499 & $0.631 \pm 0.049$ & liquid & & & & \\
\hline$* *$ & $0.705(96)$ & 47.233 & $0.633 \pm 0.039$ & liquid & & & & \\
\hline 0.075 & $0.709(46)$ & 44.073 & $0.612 \pm 0.068$ & liquid & $0.709(32)$ & 27.264 & $0.816 \pm 0.051$ & liquid+solid \\
\hline 0.0875 & $0.712(91)$ & 41.741 & $0.604 \pm 0.072$ & liquid & $0.712(47)$ & 19.613 & $0.904 \pm 0.019$ & liquid+solid \\
\hline 0.1 & $0.715(50)$ & 11.146 & $0.867 \pm 0.083$ & liquid+platelet & $0.715(71)$ & 14.305 & $0.941 \pm 0.014$ & liquid+solid \\
\hline 0.125 & $0.721(30)$ & 6.000 & $0.981 \pm 0.012$ & liquid+platelet & $0.721(37)$ & 8.546 & $0.971 \pm 0.008$ & liquid+solid \\
\hline 0.15 & $0.726(74)$ & 9.069 & $0.934 \pm 0.027$ & liquid+platelet & $0.726(74)$ & 9.211 & $0.957 \pm 0.009$ & liquid+solid \\
\hline 0.25 & $0.743(94)$ & 5.700 & $0.961 \pm 0.013$ & liquid+solid & $0.744(15)$ & 5.256 & $0.957 \pm 0.008$ & liquid+solid \\
\hline 0.375 & $0.759(49)$ & 2.764 & $0.979 \pm 0.007$ & liquid+solid & $0.759(65)$ & 3.227 & $0.930 \pm 0.022$ & liquid+solid \\
\hline 0.5 & $0.771(15)$ & 1.544 & $0.973 \pm 0.008$ & liquid+solid & $0.770(98)$ & 1.819 & $0.957 \pm 0.011$ & liquid+solid \\
\hline 0.625 & $0.779(78)$ & 1.132 & $0.971 \pm 0.007$ & liquid+solid & $0.778(88)$ & 10.139 & $0.960 \pm 0.007$ & liquid+solid \\
\hline 0.75 & $0.786(43)$ & 0.782 & $0.971 \pm 0.002$ & liquid+solid & $0.786(60)$ & 0.792 & $0.960 \pm 0.002$ & liquid+solid \\
\hline 0.875 & $0.792(25)$ & 0.564 & $0.972 \pm 0.003$ & liquid+solid & $0.791(36)$ & 9.450 & $0.952 \pm 0.012$ & liquid+solid \\
\hline 1 & 0.797 (18) & 0.364 & $0.944 \pm 0.006$ & liquid+solid & & & & \\
\hline
\end{tabular}


and solid we do not expect the MSD to be as small as would be expected for a full solid due to the contribution of the liquid component. At the intermediate concentration, $x_{2}=0.25$, we find that the steady state solution varies from solid + liquid (when started as fully segregated) to liquid (when started as random and 8000 molecules). This is within the region of hysteresis (discussed in main text) where several metastable states may form depending on initial starting conditions.

$$
\multimap 4000 \quad \square 8000 \quad \backsim 12000 \quad \backsim \text { F Fully Segregated }
$$

(a) $x_{2}=0.1$
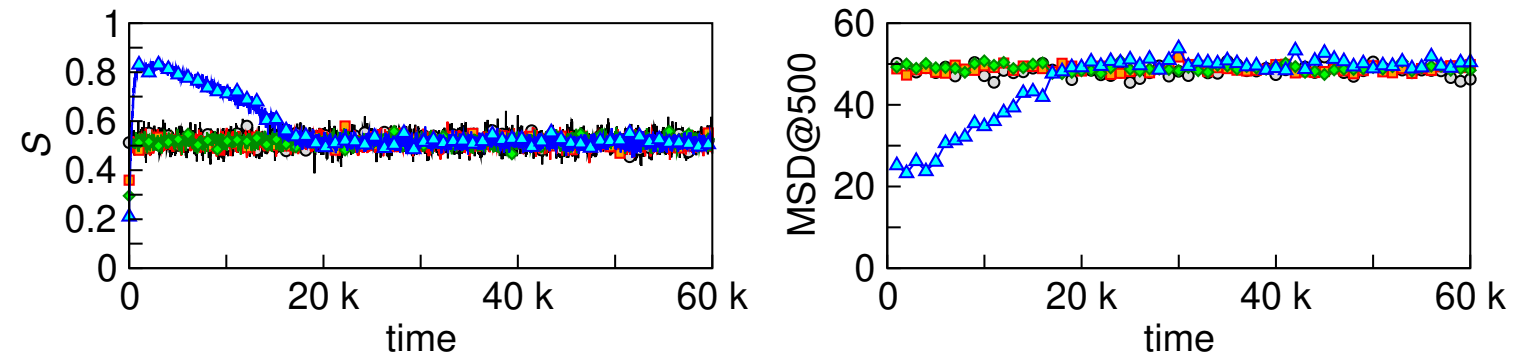

(b) $x_{2}=0.25$
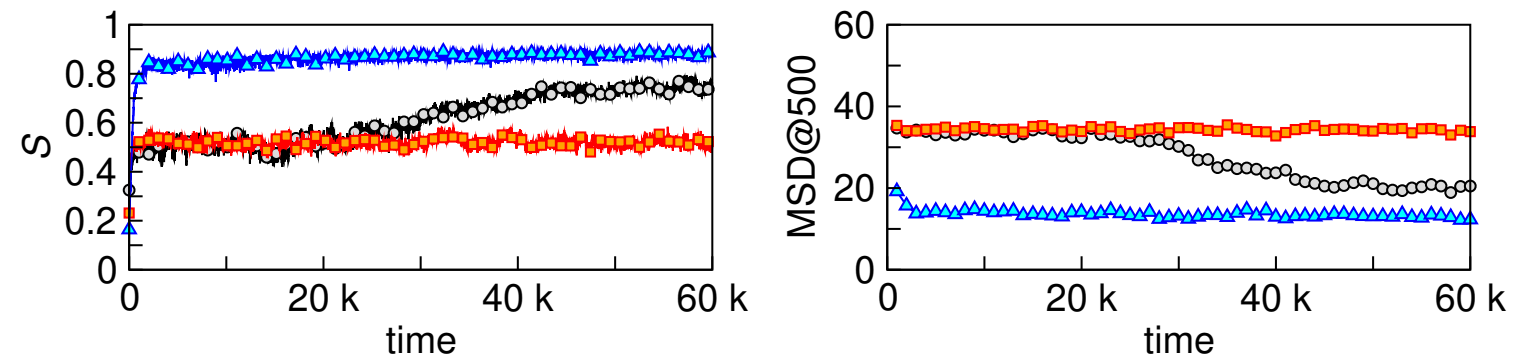

(c) $x_{2}=0.275$
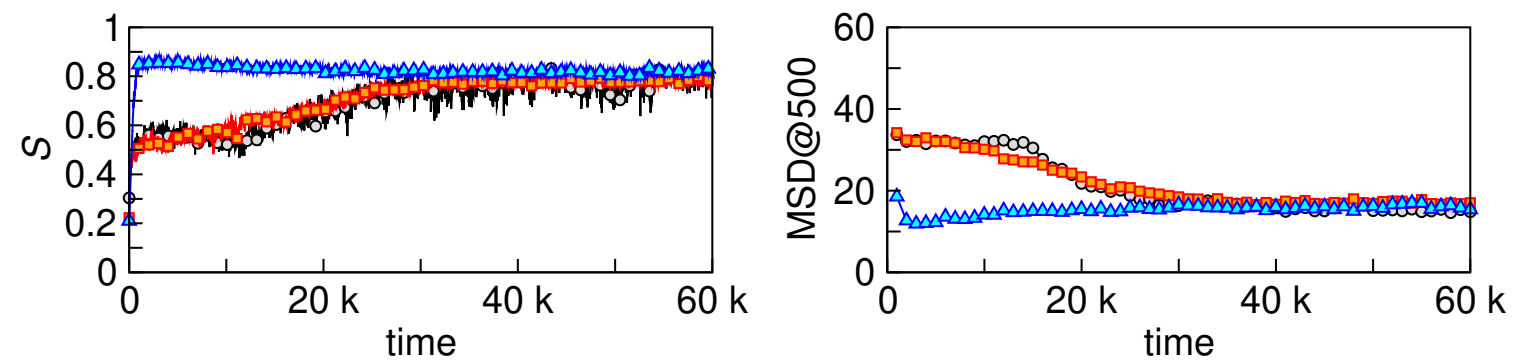

Figure 4 Behaviour of $S_{(2)}$ order parameter and $\mathrm{MSD}_{(2)}$ with time for mixtures of n-heptane and $\mathrm{n}$-tricosane at three mole concentrations when either using a random initiation and box sizes of 4000, 8000 or 12000 molecules or 72000 beads in fully segregated arrangement. 


\section{F.6 Behaviour of long methyl-alkane}

For examples of raw statistics see end of Table 2. Figure 5 extends the time given in Figure 9 (c) of the main text out to $500 \times 10^{3}$ DPD time units. At much longer times (i.e. $10 \times$ longer than for 14-methyl pentatriacontane at around $200 \times 10^{3}$ DPD time units) the pure solution of 16-methyl pentatriacontane crystallizes as indicated by the sharp drop in MSD towards zero. By contrast, even at $500 \times 10^{3}$ DPD time units 17 - methyl pentatriacontane has not crystallise and we speculate that much longer times would be required for it to solidify (if indeed it is possible). These simulations illustrates that the nematic/smetic liquid state can appear stable for a long duration before crystallisation occurs as freezing is essentially a nucleation/packing problem.

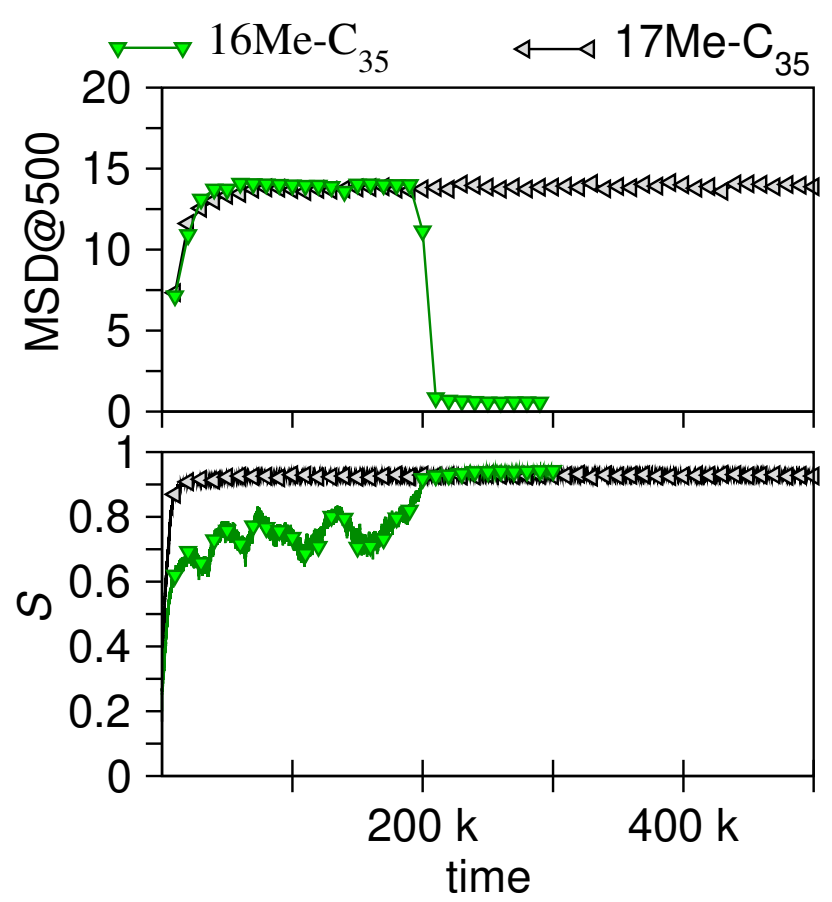

Figure 5 Behaviour of order parameter $S$ and MSD for methyl-alkanes: an extended time version of main text Figure 9(c) demonstrating that steady state behaviour has been reached by $500 \times 10^{3}$ time units for the simulations of $16 \mathrm{Me}-\mathrm{C}_{35}$ and $17 \mathrm{Me}-\mathrm{C}_{35}$. 


\section{G Behaviour of n-alkanes with temperature}

Here we provide a brief study of our model's behaviour as the thermostat temperature $(T)$ is changed away from $298.15 \mathrm{~K} / 25^{\circ} \mathrm{C}$ using the linear temperature scaling rule $T=T_{\text {real }} / 298.15 \mathrm{~K}$, where $T_{\text {real }}$ is the real world temperature in Kelvin. Note, we do not change any other model parameter and use the standard DPD definition of assigning $T=1$ to be equivalent to $298.15 \mathrm{~K}$. Additionally, we note that the model was not parameterized for temperatures other than $25^{\circ} \mathrm{C}$ and hence the study is only used to get a sense of the range of temperatures that the model is applicable to.

Table 9 Comparison between experiment and model densities and state for pure n-alkanes.

\begin{tabular}{|c|c|c|c|c|c|c|c|c|c|c|}
\hline $\begin{array}{l}\text { Model } \\
\text { Temperature }\end{array}$ & Molecule & $\begin{array}{l}\text { Formula } \\
\text { molecule }\end{array}$ & $\begin{array}{l}\text { Number of } \\
\left(\mathrm{g} / \mathrm{cm}^{3}\right)\end{array}$ & $\begin{array}{l}\text { Exp. density } \\
\left(\mathrm{g} / \mathrm{cm}^{3}\right)\end{array}$ & Sim. density & el. error 1 & $\begin{array}{r}\text { Exp. } T_{m} \\
@ 500\end{array}$ & MSD & $S \pm 2 \sigma$ & Sim. state \\
\hline $0^{\circ} \mathrm{C} / 0.92$ & n-pentadecane & $\mathrm{C}_{15} \mathrm{H}_{32}$ & 3000 & & $0.763(62)$ & & $10^{\circ} \mathrm{C}^{9}$ & 21.720 & $0.388 \pm 0.045$ & liquid \\
\hline $5^{\circ} \mathrm{C} / 0.93$ & & & & & 0.763 (47) & & & 22.591 & $0.363 \pm 0.047$ & liquid \\
\hline $10^{\circ} \mathrm{C} / 0.95$ & & & & & $0.763(27)$ & & & 24.990 & $0.363 \pm 0.047$ & liquid \\
\hline $15^{\circ} \mathrm{C} / 0.97$ & n-hexadecane & $\mathrm{C}_{16} \mathrm{H}_{34}$ & 4000 & & $0.765(03)$ & & $18^{\circ} \mathrm{C}^{9}$ & 0.667 & $0.835 \pm 0.030$ & solid \\
\hline $20^{\circ} \mathrm{C} / 0.98$ & & & & $0.773(44)^{9}$ & 0.764 (10) & $1.21 \%$ & & 0.396 & $0.977 \pm 0.002$ & solid \\
\hline $25^{\circ} \mathrm{C} / 1.00$ & & & & $0.769(82)^{9}$ & $0.765(94)$ & $0.50 \%$ & & 30.409 & $0.735 \pm 0.077$ & liquid \\
\hline $15^{\circ} \mathrm{C} / 0.97$ & n-heptadecane & $\mathrm{C}_{17} \mathrm{H}_{36}$ & 3000 & & $0.770(08)$ & & $22^{\circ} \mathrm{C}^{9}$ & 0.717 & $0.966 \pm 0.004$ & solid \\
\hline $20^{\circ} \mathrm{C} / 0.98$ & & & & $0.778^{9 \dagger}$ & $0.772(45)$ & $0.71 \%$ & & 28.210 & $0.711 \pm 0.012$ & liquid \\
\hline $25^{\circ} \mathrm{C} / 1.00$ & & & & $0.774(5)^{9}$ & $0.772(16)$ & $0.30 \%$ & & 30.270 & $0.609 \pm 0.085$ & liquid \\
\hline $25^{\circ} \mathrm{C} / 1.00$ & n-octadecane & $\mathrm{C}_{18} \mathrm{H}_{38}$ & 3000 & $0.778(5)^{9 \dagger}$ & $0.773(27)$ & $0.67 \%$ & $28^{\circ} \mathrm{C}^{9}$ & 0.497 & $0.936 \pm 0.005$ & solid \\
\hline $30^{\circ} \mathrm{C} / 1.02$ & & & & $0.775(1)^{9}$ & 0.773 (15) & $0.25 \%$ & & 0.643 & $0.958 \pm 0.004$ & solid \\
\hline $35^{\circ} \mathrm{C} / 1.03$ & & & & & $0.772(79)$ & & & 0.521 & $0.981 \pm 0.003$ & solid \\
\hline $40^{\circ} \mathrm{C} / 1.05$ & & & & & $0.771(81)$ & & & 0.266 & $0.976 \pm 0.004$ & solid \\
\hline $30^{\circ} \mathrm{C} / 1.02$ & n-nonadecane & $\mathrm{C}_{19} \mathrm{H}_{40}$ & 3000 & $0.778(7)^{9}$ & $0.776(91)$ & $0.23 \%$ & $32^{\circ} \mathrm{C}^{9}$ & 0.763 & $0.967 \pm 0.003$ & solid \\
\hline $35^{\circ} \mathrm{C} / 1.03$ & & & & & $0.777(68)$ & & & 1.249 & $0.954 \pm 0.002$ & solid \\
\hline $40^{\circ} \mathrm{C} / 1.05$ & & & & & $0.776(80)$ & & & 0.459 & $0.983 \pm 0.002$ & solid \\
\hline
\end{tabular}

$\bar{\dagger}$ density value is for undercooled liquid.

Table 9 gives the model behavior of alkanes $n-C_{15}$ to $n-C_{19}$ in the temperature range $0-40^{\circ} \mathrm{C}$ (273.15-313.15 K). We find that the model works well ( i.e. has a physical state consistent with experiment) in the range $15-30^{\circ} \mathrm{C}$ : that is $\mathrm{n}-\mathrm{C}_{16}$ and $\mathrm{n}-\mathrm{C}_{17}$ have the correct melting points. In contrast, we find that the remaining models $n-C_{15}, n-C_{18}$ and $n-C_{19}$ do not transition between liquid and solid within the temperature range studied. For $n-\mathrm{C}_{15}$ the angular constant $\left(K_{A}^{i j k}\right)$ of $\mathrm{CH}_{2} \mathrm{CH}_{2}-\mathrm{CH}_{2} \mathrm{CH}_{2}-\mathrm{CH}_{2} \mathrm{CH}_{2}$ appears insufficient to cause solidification even at $0^{\circ} \mathrm{C}$. Whereas, for n- $\mathrm{C}_{18}$ and $\mathrm{n}-\mathrm{C}_{19} K_{A}^{i j k}$ appears to be too strong and these alkanes remain solid even at $40^{\circ} \mathrm{C}$. 
Hence the data supports the idea that $K_{A}^{i j k}$ may either be temperature dependent or chain-length dependent. In either case this work suggests that fitting a DPD model to other temperatures requires more than just changing the thermostat temperature. Thus further work is required to enable this model to operate under a wider range of temperatures away from $298.15 \mathrm{~K}$.

\section{References}

(1) Anderson, R. L.; Bray, D. J.; Ferrante, A. S.; Noro, M. G.; Stott, I. P.; Warren, P. B. Dissipative particle dynamics: Systematic parametrization using water-octanol partition coefficients. J. Chem. Phys. 2017, 147, 094503.

(2) Anderson, R. L.; Bray, D. J.; Del Regno, A.; Seaton, M. A.; Ferrante, A. S.; Warren, P. B. Micelle Formation in Alkyl Sulfate Surfactants Using Dissipative Particle Dynamics. J. Chem. Theory Comput. 2018, 14, 2633-2643.

(3) Groot, R.; Rabone, K. Mesoscopic Simulation of Cell Membrane Damage, Morphology Change and Rupture by Nonionic Surfactants. Biophys. J. 2001, 81, 725-736.

(4) Humphrey, W.; Dalke, A.; Schulten, K. VMD: Visual molecular dynamics. J. Mol. Graphics 1996, $14,33-38$.

(5) LLC, M. Molefacture Plugin, Version 1.3. 2012; www.ks . uiuc.edu/Research/vmd/ plugins/molefacture/.

(6) Spoel, D. V. D.; Lindahl, E.; Hess, B.; Groenhof, G.; Mark, A. E.; Berendsen, H. J. C. GROMACS: Fast, flexible, and free. J. Comput. Chem. 2005, 26, 1701-1718.

(7) Jorgensen, W. L.; Maxwell, D. S.; Tirado-Rives, J. Development and Testing of the OPLS All-Atom Force Field on Conformational Energetics and Properties of Organic Liquids. $J$. Am. Chem. Soc. 1996, 118, 11225-11236. 
(8) CRC Handbook, CRC Handbook of Chemistry and Physics, 88th Edition, 88th ed.; CRC Press: Boca Raton, FL, USA, 2007.

(9) Dreisbach, R. R. Physical Properties of Chemical Compounds-II; Adv. Chem. Ser.; American Chemical Society: Washington D.C., USA, Vol. 22; Chapter 1, pp 3-486.

(10) Aucejo, A.; Burguet, M. C.; Munoz, R.; Marques, J. L. Densities, Viscosities, and Refractive Indices of Some n-Alkane Binary Liquid Systems at 298.15 K. J. Chem. Eng. Data 1995, 40, 141-147.

(11) Fermeglia, M.; Torriano, G. Density, Viscosity, and Refractive Index for Binary Systems of n-C16 and Four Nonlinear Alkanes at 298.15 K. J. Chem. Eng. Data 1999, 44, 965-969.

(12) Aucejo, A.; Cruz Burguet, M.; Munoz, R.; Marques, J. L. Densities, Viscosities, and Refractive Indices of the Binary Liquid Systems n-Alkanes + Isomers of Hexane at 298.15 K. J. Chem.Eng. Data 1995, 40, 871-874.

(13) Provost, E.; Chevallier, V.; Bouroukba, M.; Petitjean, D.; Dirand, M. Solubility of Some nAlkanes (C23, C25, C26, C28) in Heptane, Methylcyclohexane, and Toluene. J. Chem. Eng. Data 1998, 43, 745-749. 